\title{
WestVirginiaUniversity
}

THE RESEARCH REPOSITORY @ WVU

Graduate Theses, Dissertations, and Problem Reports

2014

\section{A Pedagogical Approach to Technique in Chopin's Preludes Op. 28}

Sheila Kay Barnhart

West Virginia University

Follow this and additional works at: https://researchrepository.wvu.edu/etd

\section{Recommended Citation}

Barnhart, Sheila Kay, "A Pedagogical Approach to Technique in Chopin's Preludes Op. 28" (2014).

Graduate Theses, Dissertations, and Problem Reports. 663.

https://researchrepository.wvu.edu/etd/663

This Dissertation is protected by copyright and/or related rights. It has been brought to you by the The Research Repository @ WVU with permission from the rights-holder(s). You are free to use this Dissertation in any way that is permitted by the copyright and related rights legislation that applies to your use. For other uses you must obtain permission from the rights-holder(s) directly, unless additional rights are indicated by a Creative Commons license in the record and/ or on the work itself. This Dissertation has been accepted for inclusion in WVU Graduate Theses, Dissertations, and Problem Reports collection by an authorized administrator of The Research Repository @ WVU.

For more information, please contact researchrepository@mail.wvu.edu. 
A Pedagogical Approach to Technique in Chopin's Preludes Op. 28

Sheila Kay Barnhart

Research Project submitted to the College of Creative Arts at West Virginia University

in partial fulfillment of the requirements for the degree of

Doctor of Musical Arts in Piano Performance

\author{
Mary Ferer, Ph.D., Research Advisor \\ William Haller, D.M.A. \\ Christine Kefferstan, D.M.A., Committee Chair \\ James Miltenberger, D.M.A. \\ Janet Snyder, Ph.D. \\ Virginia Thompson, D.M.A.
}

School of Music

Morgantown, West Virginia

2014

Keywords: Frederic Chopin, preludes, Preludes Opus 28, Technique, Piano, Pedagogy Copyright 2014 Sheila Kay Barnhart 


\author{
Abstract \\ A Pedagogical Approach to \\ Technique in Chopin's Preludes Op. 28
}

Sheila Kay Barnhart

The current project is a reference guide for using Chopin's Preludes in the applied studio to teach technique, and consists of three main components: determining the technical challenges of each prelude; categorizing each prelude by level of technical difficulty; compiling practice suggestions for successful navigation of each technique. The following technical challenges are represented throughout the set: voicing, passagework, cross-rhythms and tuplet rhythms, stretches, leaps, fingering, double notes, octaves, repeated notes, pedaling, hand coordination, hand independence. Each of these challenges is manifested in a multiple ways. While a variety of techniques are required to perform any given work, in the Preludes often one or two technical skills are most prominently on display, making for a suitable technical study. This project indicates the main technical challenges presented by each prelude, as well as those which are more subtly employed. With the classification provided in this document it is possible to choose a prelude to focus on and reinforce a particular skill.

The grading scale, based on level of technical difficulty, consists of four categories: easy, intermediate, advanced, and very advanced. This system used is based on, though not identical to, that found in Eleanor Bailie's Chopin, A Graded Practical Guide (London: Kahn \& Averill, 1998). The grading scale is not intended to compare the Preludes with other repertoire; it categorizes the preludes in relation to others in the set only. Many of the techniques listed above are represented, to greater and lesser degrees of prominence, in three of the four grading categories, making it possible to find an appropriate prelude for both a specific technique and difficulty level.

The compilation of practice suggestions includes those that have been presented by other scholars, as well as tips gleaned from performance experience of the set by the author. In addition, Chopin's approach to the piano and technique is explored and compared to our modern conception of technique. Incorporating writings by Chopin, interviews of his students, and other contemporary accounts with current ideas on technique creates a unique amalgamation of suggestions and considerations for students and teachers alike. 


\section{Acknowledgments}

I would like to thank several people who have helped me complete this document as well as this degree. First, I would like to thank Dr. Mary Ferer, my research advisor, for her help and guidance through the writing process. Many thanks to my committee, Dr. Bill Haller, Dr. Janet Snyder and Dr. Virginia Thompson for the time and support you've given throughout these past four years. A special thank you to Dr. James Miltenberger for "taking me in" during my final semester - I truly appreciate the efforts expended to help me graduate and the faith you have had in me. To Dr. Christine Kefferstan - thank you is not enough, but will have to suffice. For six years you have guided me and helped me achieve things I never would have otherwise. To my fiancé, Jacob Womack, thank you for supporting me and putting up with me during this stressful time! Finally, thank you to my family, especially Mom and Dad, who have always believed that I can achieve whatever I put my mind to. 
Contents

List of Musical Examples...................................................

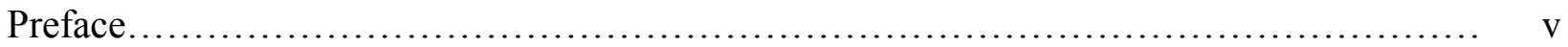

Chapter 1 - Introduction.................................................. 1

Discussion of the Preludes by Level of Technical Difficulty

Chapter 2 - Intermediate Preludes....................................... 12

Chapter 3 - Advanced Preludes............................................ 26

Chapter 4 - Very Advanced Preludes..................................... 40

Chapter 5 - Comparison of the Preludes Op. 28 with other Chopin Works................. 58

Chapter 6 - Conclusion.................................................. 73

Bibliography............................................................ 75

Appendix A: Technical Difficulty Levels of Chopin's 24 Preludes Op. 28................ 78

Appendix B: Primary Technical Challenges of Chopin's 24 Preludes Op. 28............. 79

Appendix C: Preludes Requiring Specific Skills at Various Technique Levels............ 80

Appendix D: Preludes which can Introduce or Substitute for Etudes $\ldots \ldots \ldots \ldots \ldots \ldots \ldots \ldots \ldots \ldots$. 81 


\section{List of Musical Examples}

Example 2.1: Prelude No. 9, E major, mm. 1, three voice layers......................... 13

Example 2.2: Practicing each quarter note as a block chord ........................... 15

Example 2.3: Practice melody note first, followed by the rest of the chord.................. 15

Example 2.4: Prelude No. 9, E major, mm. 3 and 4, measured trills 4:1 ratio................. 16

Example 2.5: Prelude No. 9, E major, mm. 3 and 4, measure trills 3:1 ratio.................. 16

Example 2.6: Prelude No. 14, E-flat minor, mm. 1-3, group in half-bar gestures............. 18

Example 2.7: Jerky back and forth motion........................................... 19

Example 2.8: Smooth directional motion found in Chopin's Sonata Op. 35, Finale............... 19

Example 2.9: Down-up hand/wrist motion for the half-bar gesture........................ 19

Example 2.10: Practice in block chords to study hand/wrist position in relation to white and black keys.................................................. 20

Example 2.11: Holding the common tones.......................................... 20

Example 2.12: Rhythmic patterns to practice for stability and evenness.................... 21

Example 2.13: Prelude No. 21, B-flat major, mm. 1-4................................. 22

Example 2.14: Left hand pattern direction beginning on the second eighth note of the bar and proceeding to the downbeat of the following bar....................... 23

Example 2.15: Prelude No. 21, B-flat major, mm. 33-36................................. 24

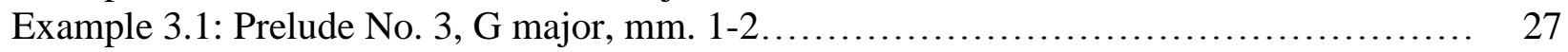

Example 3.2: Rhythms for practicing left hand of $\mathrm{G}$ major prelude.......................... 28

Example 3.3: Division of left hand pattern into gestures................................ 29

Example 3.4: Left-right wrist motion of left hand pattern.............................. 30

Example 3.5: Combination left-right, up-down wrist motion to turn around and repeat left hand pattern ........................................................ 31

Example 3.6: Prelude No. 3, G major, mm. 3-4, right hand entrance ........................ 31

Example 3.7: Isolation of right hand sixteenth note gesture............................ 32

Example 3.8: To practice coordination, add one note at a time working backwards......... 33

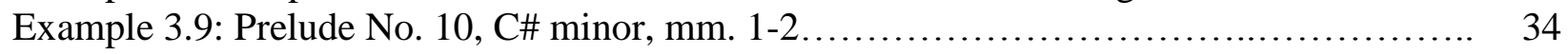

Example 3.10: Practice the bottom notes only .......................................... 34

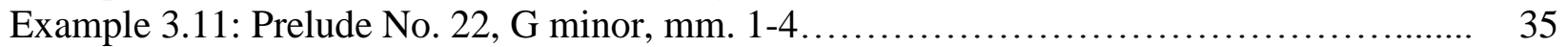

Example 3.12: Left hand phrase markings...................................... 36

Example 3.13: Prelude No. 22, G minor, mm. 17-18, left hand descending octaves.......... 37

Example 3.14: Right hand down-up motion........................................ 38

Example 3.15: Prelude No. 22, G minor, m. 13, right hand finishing a gesture while the left hand continues........................................................................................... 41

Example 4.1: Prelude No. 8, F\# minor, m. 1...................................... 42

Example 4.2: Combination down-up and left write wrist motion ....................... 42

Example 4.3: Right hand pattern in block chords..................................... 43

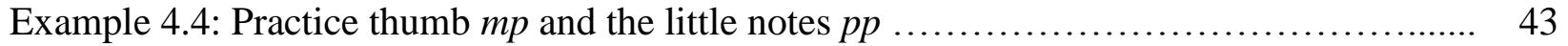

Example 4.5: Rhythmic patterns for practicing .................................... 43

Example 4.6: Pause on the sixteenth note of the melodic line............................. 44

Example 4.7: How to practice right hand thumb and left hand together in strict time......... 45

Example 4.8: Notes which are played together between the right and left hands............... 46

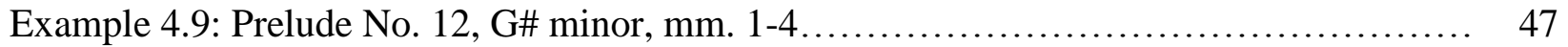


Example 4.10: Group left hand from beat two to following downbeat; perform with a single gesture.......................................................

47

Example 4.11: Grouping by the measure resulting in two separate motions

Example 4.12: Chopin Prelude No. 12, G\# minor, mm. 5-6 left hand, use the middle of the hand as a pivot, in this instance on D.

Example 4.13: Treatment of eighth notes as two-note slurs............................ 49

Example 4.14: Group repeated eighth notes together across the beat..................... 49

Example 4.15: Rhythmic pattern for practice of eighth notes............................. 44

Example 4.16: Prelude No. 19, E-flat Major, mm. 1-2............................ 50

Example 4.17: Group eighth note triplets across the beat........................... 51

Example 4.18: Rhythmic practice for eighth note triplet groups........................ 51

Example 4.19: Eleanor Bailie's suggestion for note grouping........................... 52

Example 4.20: Prelude No. 24, D minor, mm. 1-2 .................................... 53

Example 4.21: Outline of left hand gesture, emphasizes beats one and three, then four and

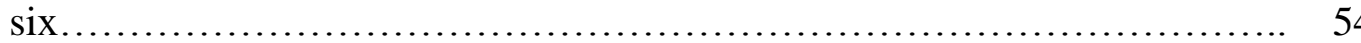

Example 4.22: Prelude No. 24, D minor, m. 14 tuplet rhythm........................... 55

Example 4.23: Prelude No. 24, D minor, mm. 55-56.............................. 56

Example 5.1: Prelude No. 13, F\# major, mm. 1-2, left hand ............................. 59

Example 5.2: Nocturne Op. 9 No. 1, B-flat minor, mm. 1-2, left hand ........................ 59

Example 5.3: Nocturne Op. 27 No. 1, D-flat major, mm. 1-2, left hand .................... 60

Example 5.4: Prelude No. 13, F\# major, chordal voicing of opening ...................... 60

Example 5.5: Nocturne Op. 15 No. 3, G minor, mm. 89-92, chordal voicing mm. 89-92..... 60

Example 5.6: Nocturne Op. 48 No. 1, C minor, mm. 30-31, chordal voicing ................ 61

Example 5.7: Prelude No. 13, F\# major, mm. 21-22, melodic lines embedded within

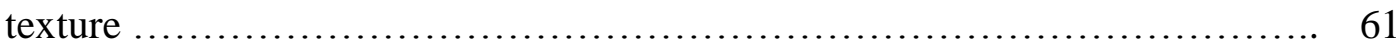

Example 5.8: Nocturne Op. 27 No. 1, D-flat major, m.15, melodic line embedded within

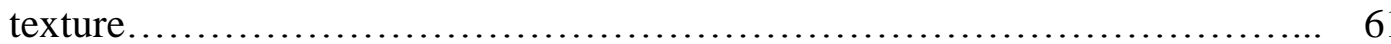

Example 5.9: Prelude No. 7, A major, mm. 1-4, left hand dance pattern..................... 63

Example 5.10: Mazurka Op. 7 No. 1, B-flat major, mm. 4-7, left hand pattern................ 63

Example 5.11: Mazurka Op. 59 No. 2, A-flat major, mm. 1-4, left hand pattern.............. 64

Example 5.12: Prelude No. 7, A major, mm. 1-4, dotted rhythm characteristic of

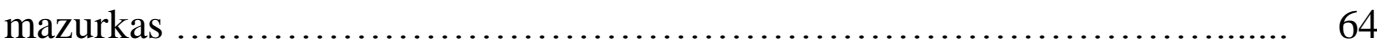

Example 5.13: Mazurka Op. 7 No. 5, C major, mm. 5-8................................. 64

Example 5.14: Mazurka Op. 67 No. 1, G major, mm. 15-16.......................... 65

Example 5.15: Prelude No. 3, G major, mm. 1-4..................................... 66

Example 5.16: Etude Op. 10 No. 12, C minor, mm. 9-10.......................... 66

Example 5.17: Etude Op. 10 No. 12, C minor, mm. 5-6............................... 67

Example 5.18: Prelude No. 14, E-flat minor, mm. 1-2 ................................ 68

Example 5.19: Etude Op. 10 No. 12, C minor, mm. 1-2.............................. 68

Example 5.20: Prelude No. 12, G\# minor, mm. 1-4....................................... 69

Example 5.21: Etude Op. 10 No. 2, A minor, mm. 1-2................................. 69

Example 5.22: Prelude No. 24, D minor, mm. 1-3............................... 70

Example 5.23: Etude Op. 10 No. 9, F minor, mm. 1-2.............................. 71 


\section{Preface}

\section{Document Intention}

While many aspects of the Preludes have been studied, pedagogical studies are decidedly lacking scholarship. Two sources are cited here which address pedagogy: the notes on Nelita True's session about teaching the easier preludes, and Eleanor Bailie's graded guide to all of Chopin's literature. The former source discusses only three preludes, numbers 4, 7 and $20-$ those found most often in method books and collections of "Easy Classics." Among the most well-known preludes, these preludes are not the focus of this research project. The latter source discusses each prelude briefly, addressing both musical and technical problems, but neither in very great detail. This project delves more specifically into the technical aspects of the more demanding preludes.

The current study focuses on using the more technically advanced preludes as teaching pieces, filling a gap in the literature concerning Chopin's Preludes in several ways. First, it addresses the more advanced preludes. These preludes are used less frequently in the teaching studio; however, they have much to offer to students in the area of technical study. Second, it provides more in depth information about the technical aspects of the Preludes, a subject which has been only mentioned in passing in the literature. Finally, by drawing connections between the Preludes and other works by Chopin, this study provides teachers with a useful reference tool for using the Preludes in the studio as stepping-stones for or substitution for other Chopin repertoire which is routinely assigned to students.

Chapter 1, an introduction to the Preludes, examines the circumstances surrounding their composition, their unique place in piano literature, and their reception by Chopin's contemporaries and later critics. A brief overview of Chopin as a teacher is also presented. 
Chapters 2, 3, and 4 discuss selected preludes from each technical level in order of increasing difficulty. Drawing on experience in performing the set, an account of the technical benefits to be found in the Preludes will be detailed. Technique can be defined in many ways.

For this study, Chopin's definition will be used:

I am not, let it be understood, dealing here with musical feeling or style, but purely with the technical aspect of playing, what I call the mechanism. I divide the study of piano mechanism into three parts. [First,] teaching both hands to play adjacent notes (notes a tone apart), that is, scales - chromatic and diatonic - and trills... [Second,] notes farther than a tone or semitone apart, that is, intervals of a tone and a half upwards... (disjunct notes)... [Third,] double notes (in two parts): thirds, sixths, octaves... and there is nothing more to be invented for the study as far as mechanism of piano playing is concerned. ${ }^{1}$

While this is an extreme simplification of piano technique, it is the mechanism of playing which will be explored here. Included will be a discussion of ways to teach and practice each technical challenge. For the purposes of this document pedaling is not addressed in detail since many external factors must be taken into account when making decisions on pedal usage. The focus is on the physical approach of the fingers, hands, and arms to the piano.

It is interesting to note that Chopin himself did not hold with studying technique in the

abstract. In his Sketch of a Method he states:

People have tried out all kinds of methods of learning to play the piano, methods that are tedious and useless and have nothing to do with the study of this instrument. It's like learning, for example, to walk on one's hands in order to go for a stroll. Eventually one is no longer able to walk properly on one's feet, and not very well on one's hands either. It doesn't teach us how to play the music itself - and the kind of difficulty we are practicing is not the difficulty encountered in good music, the music of the great masters. It's an abstract difficulty, a new genre of acrobatics. ${ }^{2}$

\footnotetext{
${ }^{1}$ Frederic Chopin, "Sketch for a Method" (Project de Méthode), in Chopin, Pianist and Teacher: As Seen by his Pupils, Jean-Jacques Eigeldinger (New York: Cambridge University Press, 1986), 192-193.

${ }^{2}$ Chopin, "Sketch for a Method," in Eigeldinger, 193.
} 
This is not to say that his students never practiced scales and technique, but that he had little patience for mindless virtuosic exercises. Chopin felt that "piano technique should be no more than a means; and so it should come directly out of an imperative for musical self-expression.”3

Chapter 5 compares the technical elements found in Chopin's Preludes Op. 28 to those of other works by Chopin, making a case for using some preludes as introductory pieces to others in his oeuvre. Other preludes may be used as substitutes for works in these genres which are assigned to students with regularity. This comparison focuses on issues of technique and pedagogical concerns, drawing connections between works with similar challenges. Only technical elements which occur consistently throughout a piece are considered.

This study is limited in that the approaches to technique discussed are considered only in relation to the modern grand piano. Technique on an instrument of Chopin's era was undoubtedly different than that of a modern piano. Future study in this area should include an exploration of the differences in piano construction from Chopin's time to the present and how these differences affect piano technique and the decision-making, problem-solving process of teaching and performing Chopin's works.

The following table will be referenced throughout the document:

\footnotetext{
${ }^{3}$ Eigeldinger, 15 .
} 
Table 1: Technical Difficulty of Chopin's Preludes Op. 28

\begin{tabular}{|c|l|}
\hline Difficulty & \\
\hline Easy** & $\# 4-$ E minor \\
& $\# 6-$ B minor \\
& $\# 7-$ A major* \\
& $\# 20-$ C minor* \\
\hline \multirow{3}{*}{ Intermediate** } & $\# 2-$ A minor* \\
& $\# 9-$ E major* \\
& $\# 13-$ F\# major \\
& $\# 14-$ Eb minor \\
& $\# 15-$ Db major \\
& $\# 21-$ Bb major \\
\hline \multirow{3}{*}{ Advanced** } & $\# 1-$ C major \\
& $\# 3-$ G major \\
& $\# 10-$ C\# minor \\
& $\# 11-$ B major \\
& $\# 17-$ Ab major \\
& $\# 22-$ G minor \\
& $\# 23-$ F major \\
\hline \multirow{3}{*}{ Very Advanced** } & $\# 5-$ D major \\
& $\# 8-$ F\# minor \\
& $\# 12-$ G\# minor \\
& $\# 16-$ Bb minor \\
& $\# 18-$ F minor \\
& $\# 19-$ Eb major \\
& $\# 24-$ D minor \\
\hline
\end{tabular}

* Represents a piece most suitable for students wit fully grown hands, or those with larger hands, as the prelude contains stretches not easily executed by smaller hands. This also includes all of the Advanced and Very Advanced preludes.

** These categories are representative of the Preludes in relation to each other, not as compared with other repertoire. It is advisable that none of the Preludes be attempted until a later intermediate level (Grade 4-5) has been achieved.

This table is a representation of technical difficulty only without consideration of the challenges of musical expression. Each prelude presents significant musical challenges, and they are all appropriate for the most advanced students. Discussed in this document are selected preludes from the intermediate, advanced, and very advanced categories. In selecting which preludes to address, consideration has been given to the specific technical elements present in each prelude, 
with an attempt to represent as many different skills as possible. This table, along with others which highlight various aspects of the Preludes, can also be found in the Appendices.

Scores and recordings of Chopin's Preludes Op. 28 are readily available. It is suggested that the reader have a complete score of the Preludes on hand as reference for the following discussion. Urtext editions are recommended, and the Henle edition is referenced by the author. 


\section{Chapter One}

\section{Review of the Literature and Introduction}

Frédéric François Chopin's Op. 28 is one of the great masterpieces to be found in his oeuvre. "Nearly a century and a half after they were first published the Twenty-four Preludes still give off a sparkle and exercise a fascination unique in the literature of the piano."4 There is a sizeable amount of literature pertaining to Chopin's Preludes Op. 28, not all of which is relevant to this document. The bibliography provided is divided into two categories: works cited and additional resources.

Eleanor Bailie's Chopin: A Graded Practical Guide provides grading levels according to difficulty for Chopin's entire oeuvre. ${ }^{5}$ Based on a grading scale ranging from Grade 1 through $8+$ with an additional VA (Very Advanced) level to indicate the most difficult pieces, Bailie's grading is accompanied by descriptions and performance analyses for each piece, as well as suggestions for practice. Suggestions address both musical and technical challenges. Bailie's text was a highly useful resource in the completion of this document and is referenced frequently.

Maurice Brown, a prominent scholar of Schubert, has also published research on Chopin by compiling the standard thematic index of Chopin's works and clarifying their publishing history. His article "The Chronology of Chopin's Preludes" in The Musical Times examines the circumstances surrounding the composition of the Preludes. In spite of a lack of manuscripts to date each prelude, Brown brings together evidence to create a comprehensive picture of their

\footnotetext{
${ }^{4}$ Jean-Jaques Eigeldinger, "Twenty-Four Preludes Op. 28: Genre, Structure, Significance,” in Chopin Studies, ed. Jim Samson (New York: Cambridge, 1988), 167.

${ }^{5}$ Bailie's grading of Chopin's Preludes provided the basis for the levels of difficulty referenced in this document. While Bailie's grading of Chopin's works is in relation to all music, the grading of the preludes used here compares the difficulty of the preludes only in relation to others in the set. Also, in some instances the author, through opinion gained by performance experience of the set, assigned different difficulty levels to certain preludes than Bailie.
} 
composition. While some of the conclusions are speculative, they are presented clearly and thoroughly.

A compilation of historical documents and analyses concerning the Preludes are included in the Authoritative Score, Historical Background, Analysis, Views and Comments edited by Thomas Higgins. In many cases scholars use this edition of the score as reference when writing about the Preludes. The volume provides insight into the contemporary perception and reception of the Preludes.

Jean-Jacques Eigeldinger's book Chopin, Pianist and Teacher : As seen by His Pupils is an interesting compilation of accounts from Chopin's pupils, acquaintances and contemporaries, along with Chopin's own writing. Eigeldinger's introduction includes information about how Chopin balanced teaching and composing throughout his career. A glimpse into Chopin's teaching methods, aesthetic beliefs, and pianistic and stylistic practices is provided in this text. Eigeldinger quotes both unpublished sources as well as sources that are not readily available. In these instances, references in footnotes here are made to the primary source as quoted in the Eigeldinger text.

Eigeldinger's text also contains a translation of Chopin's own Sketch of a Method. The method, a long-term project, was never completed; only sketches survive. It is doubtful that he would have ever finished:

[E]ven had he lived longer, he probably would have recoiled from the restraint of such a task. Besides, Chopin did not like to express himself on matters close to his heart except through music. He hardly ever spoke of his own aesthetic pianistic of pedagogical views outside the narrow circle of his pupils and a few close friends. ${ }^{6}$

However, the sketches that remain, in combination with interviews of pupils and colleagues, provide invaluable insight to Chopin's approach to the piano. To emphasize that certain material

\footnotetext{
${ }^{6}$ Jean-Jacques Eigeldinger, Chopin, Pianist and Teacher: As seen by His Pupils, ed. Roy Howat, trans. Naomi Shohet, Krysia Osostowicz and Roy Howat (New York: Cambridge University Press, 1986), 4.
} 
referenced throughout this document was the work of Chopin himself, the Sketch of a Method is cited as written by Chopin, translated by Eigeldinger.

A Reader's Guide to the Chopin Preludes by Jeffrey Kresky offers a detailed account of the Preludes, both individually and as a set. Kresky contends that Op. 28 is both a collection of discrete pieces as well as a "super-organism of many small parts."7 While each prelude can stand alone as a separate piece, each complete in itself, the collection also forms a compelling total entity with a precise balance of key and mood relationships as well as other interconnecting details. Kresky discusses each prelude in turn, presenting analysis, musical commentary, and opinion.

Jim Samson is generally regarded as one of the foremost Chopin scholars. His book The Music of Chopin is a "must-have" for anyone researching Chopin's music. Uniting recent Chopin scholarship with recent analytical techniques, Samson provides analysis of the style and structures of Chopin's music. Of particular relevance to this project is Chapter 9, “The Preludes Revisited," along with Chapter 1, “A Biographical Sketch.”

The Cambridge Companion to Chopin, a compilation of essays by various scholars, provides insight into Chopin’s musical style. Jeffrey Kalberg’s essay, “Small 'Forms': In Defense of the Prelude," discusses our modern conception of what the genre is and compares it with that of composers and critics of the $19^{\text {th }}$ century. He defends Chopin's use of the title Prelude, and discusses the resultant expansion of the form. Even though it was expanded the prelude is still a small form, and it is generally acknowledged that Chopin was a "master of the miniature." Kallberg goes to some lengths to defend the small form, which is often given a backseat to large forms. As evidence, Kallberg points to the fact that it has become popular to perform the entire Op. 28 as a large set, with many have argued that the 24 Preludes should be

\footnotetext{
${ }^{7}$ Jeffrey Kresky, A Reader's Guide to the Chopin Preludes (Westport, CN: Greenwood Press, 1994), xviii.
} 
considered as one entity. Kallberg, conversely, asserts that Chopin intended the preludes to stand as individual pieces.

Jean-Jacques Eigeldinger’s essay “Twenty-Four Preludes Op. 28: Genre, Structure and Significance" in Chopin Studies edited by Jim Samson, stresses that Chopin's Preludes charted new territory in character piece composition, Eigeldinger explores the history of the prelude, J.S. Bach's influence on Chopin, musical structure of the Preludes as a set, and their significance in piano repertoire.

In the June 1995 edition of IRMT Journal, Rosemary Miller Stott provides notes from a presentation given by Nelita True, currently a professor at Eastman School of Music. In a session titled “An Introduction to Chopin: Teaching the Easier Preludes," True discusses preludes 4, 7 and 20, providing suggestions for practicing, and highlighting technical and musical trouble spots within the selected preludes.

The Chopin Companion: Profiles of the Man and the Musician, edited by Alan Walker, another compilation of essays, address Chopin's life as well as historical background, and his works in each of the major genres. Of relevance to this study is the essay "Studies, Preludes and Impromptus" by Robert Collet.

Studies cited under "Additional Resources" discuss more specific aspects of the Preludes. Many are analyses of one or more preludes, such as Howard Cinnamon's "New Observations on Voice Leading, Hemiola, and their Roles in Tonal and Rhythmic Structures in Chopin's Prelude in B Minor, Op. 28, no. 6," Alison Hood's "Tonal and Rhythmic Hidden Repetition in Chopin's Prelude, Op. 28 no. 14,” and Marianne Kielian-Gilbert's “Motive Transfer in Chopin's A-minor Prelude." These, and others like them, explore the formal, harmonic, thematic, and rhythmic elements of certain preludes. 
Other studies compare the Preludes with works by other composers, or literary works. These include Benjamin Oren's "Connections between Bach and Chopin" and Anatole Leiken's “Chopin's Preludes Op. 28 and Lamartine's Les Préludes.” Some consider performance aspects of the Preludes, such as Martin Hansen's "The Pedal Indications in Chopin's Preludes: A Performer's Look at the Autograph" and William Rothstein's "Like Falling off a Log: Rubato in Chopin's Prelude in A-Flat Major (Op. 28, no. 17)."

Many studies consider various aspects of the set as a whole. Some deal with musical issues, such as V. Kofi Agawu's "Concepts of Closure and Chopin's Opus 28," Andreas Boelcke's dissertation “Chopin’s 24 Preludes, Opus 28: A Cycle Unified by Motion Between the Fifth and Sixth Scale Degrees," and Kenneth Patrick Kirk's dissertation "The Golden Ratio in Chopin's Preludes, Opus 28.” Others deal with external influences on the Preludes, such as Janet Marie Lopinski’s “The Preludes Opus 28 by Fryderyk Chopin with an Emphasis on Polish Sources.”

Chopin's Preludes Op. 28 contains a prelude in each of the 24 keys organized by major followed by relative minor, moving around the circle of fifths, beginning with $\mathrm{C}$ major. Most of the Preludes are short, requiring approximately two minutes or less to perform, the shortest lasting about 30 seconds. A few are more extended such as number 15 in D-flat major and number 17 in A-flat major, their performances lasting approximately six and three minutes respectively. Almost every aspect of Chopin's style can be found among the Preludes and a wide range of technical benefits can be gained from their study.

While the Preludes appear roughly in the middle of Chopin's compositional career, there is some ambiguity about the precise time period during which they were composed. There are no dated autographs of most of the set. Music historian Maurice Brown speculates that Chopin 
began composing the set around the end of 1835 or early in 1836, falling between the two nocturnes of Op. 27, completed in the autumn of 1835, and the A-flat Impromptu Op. 29, published in 1837. Brown suggests that Op. 28 was reserved for the Preludes. At the very least, he believes they were an idea begun after Op. 27 was complete. By the time the Preludes were published in 1839 Chopin's opus numbers had reached 34. Assuming the chronological assignment of opus numbers and that composition had begun on the Preludes in 1835-36, this suggests that Chopin worked on the Preludes at the same time he was completing other pieces. ${ }^{8}$

However, Brown's assumption that Chopin's opus numbers were assigned chronologically cannot be verified. Jim Samson, a prominent Chopin scholar, asserts that "the chronology of Chopin's music is anything but well established." ${ }^{, 9}$ His more recent scholarship lists the Preludes as being composed 1838-39, but without explanation. ${ }^{10}$ In his essay found in Chopin Studies, Jean-Jacques Eigeldinger declines to conjecture on the chronology of the Preludes stating that "it is in any case almost insoluble for lack of sound evidence." 11

The first prelude that can be dated with certainty is that in A major which Chopin gave to his friend and pupil Countess Delfine Potocka in $1836 .{ }^{12}$ Another, in A-flat major, can be dated with reasonable certainty to 1837 when Chopin asked his friend Julian Fontana to copy it for Count Perthuis. It is uncertain when most of the other preludes were composed; however, there is evidence that the set was completed in January of 1839 during Chopin's trip to Majorca with George Sand. ${ }^{13}$

\footnotetext{
${ }^{8}$ Maurice Brown, "The Chronology of Chopin's Preludes," The Musical Times 98, no. 1374 (August 1957): 423.

${ }^{9}$ Jim Samson, The Music of Chopin (New York: Oxford University Press, 1994), 235.

${ }^{10}$ Samson, 236.

${ }^{11}$ Eigeldinger, "Twenty-Four Preludes Op. 28," 168.

${ }^{12}$ Jean-Jacques Eigeldinger, Chopin, Pianist and Teacher: As seen by His Pupils, ed. Roy Howat, trans. Naomi Shohet, Krysia Osostowicz and Roy Howat (New York: Cambridge University Press, 1986), 143. Known for her beauty and vocal talent, Delfina Potocka was greatly admired by Chopin. He dedicated the Concerto Op. 21 and the Waltz Op. 64 No. 1 to her.

${ }^{13}$ Brown, 423.
} 
The trip to Majorca, taken in the winter of 1838-39, was financed by a partial advance payment for the Preludes by Camille Pleyel, a piano builder, pianist, and friend of Chopin. ${ }^{14}$ While "one cannot know how far along the Preludes were when Chopin arrived on the island... or how much new work had to be done," from an autograph sketch, dated "Palma 28 November," it is known that the preludes in A minor and E minor were composed in Majorca. ${ }^{15}$ These sketches also contain ideas for preludes in both B-flat major and C-sharp minor, neither of which resemble the preludes in those keys included in the finished set. Brown argues that these rejected sketches indicate that these two preludes were also composed while in Majorca. ${ }^{16}$ Chopin had some difficulty procuring a piano to suit him during this trip, and the set was not completed until he received a Pleyel upright piano in the middle of January. ${ }^{17} \mathrm{He}$ sent the final manuscript to Fontana to copy and send to publishers on January $22,1839 .^{18}$

When the manuscripts were finally given to publishers there was some confusion about their intended opus number. Chopin himself wrote to Pleyel confessing that he could not remember what opus number he had reserved. Consequently, the French edition for Pleyel was published in two parts (for commercial reasons) without opus number. The English publisher Wessel \& Co. also published the Preludes without opus number, having mistakenly called the Aflat Impromptu “Op. 28” and leaving Op. 29 blank in their record of Chopin's works. The German publishers Breitkopf \& Härtel alone were correct in titling the Preludes as Op. 28 when they were published in June 1839. ${ }^{19}$

\footnotetext{
${ }^{14}$ The French edition of the Preludes Op. 28 was dedicated to Pleyel.

15 Thomas Higgins, "Historical Background" in Preludes, Op. 28: An Authoritative Score, Historical Background,Analysis, Views and Comments by Frederic Chopin, ed. Thomas Higgins (New York: W.W. Norton, 1973), 4.

${ }^{16}$ Brown, 423.

${ }^{17}$ Higgins, "Historical Background, 3.

18 Brown, 423.

19 Brown, 424.
} 
At this point in his career Chopin sold "exclusive rights-in-perpetuity of his compositions in exchange for a lump sum." ${ }^{, 20}$ Consequently, teaching fees constituted a large part of his income, with his time being divided equally between teaching and composition for most of the latter part of his life, from 1832-1849. ${ }^{21}$ Indeed, teaching had "some bearing on the nature of his creative output in the 1830 s, encouraging the production of short, manageable pieces...,"22 and some of the Preludes stand as evidence to this fact. It is not clear to what extent Chopin used the Preludes in his teaching, but they are present on a list of repertoire which his student Jane Stirling studied with him. ${ }^{23}$

In titling these miniatures "prelude" Chopin ventured into new territory. The keyboard prelude, tracing its origins back to organ tablatures of the $15^{\text {th }}$ century, was traditionally defined by its improvisatory nature and by its function. "Testing the instrument and checking its tuning; establishing silence before a performance and putting the audience in the mood for the piece or pieces that are to follow; giving practice in the modes or keys to be used, and, if necessary, providing the opportunity for virtuosity" are among the common functions of preludes at this time. $^{24}$

In most cases the prelude was introductory to another piece, the most well-known examples being from Johann Sebastian Bach's Well-Tempered Clavier. Chopin's use of the term "prelude" without the customary succeeding piece confused not only his contemporaries, but scholars for many years. Nobel Prize winning French author André Gide, a century later, wrote

\footnotetext{
${ }^{20}$ Eigeldinger, Chopin, Pianist and Teacher, 7.

${ }^{21}$ Eigeldinger, Chopin, Pianist and Teacher., 6.

${ }^{22}$ Samson, 16.

${ }^{23}$ Eigeldinger, Chopin, Pianist and Teacher, 62. More information about Chopin's teaching will be discussed throughout this document.

${ }^{24}$ Eigeldinger, "Twenty-Four Preludes Op. 28," 170.
} 
"I admit that I do not understand well the title that Chopin liked to give to these short pieces:

Preludes. Preludes to what?" ${ }^{25}$ Modern scholar Jeffrey Kresky writes:

Chopin's twenty-four preludes for piano, taken either individually or as a group, are quite obviously preludes to nothing - unless each is a prelude to the next prelude. This may have been a historically pivotal situation - in the sense of its heralding a change in the application of this title, such pieces soon becoming 'character pieces' in their own right. ${ }^{26}$

While Chopin was by no means the first to write a set of preludes in all keys, ${ }^{27}$ his is the earliest set in the repertoire which is regularly performed, and the first preludes to be considered "character pieces." Although there is some evidence that Chopin may have performed his preludes as introductions to larger works, more often he performed them as separate pieces or in groups with other preludes. This practice would indicate "an expansion in the functional possibilities of the genre, such that preludes might also serve as separate concert pieces. Chopin appears largely responsible for this functional expansion." 28

The influence of Bach on the Preludes is quite evident. Chopin "was called by Liszt 'an enthusiastic student of Bach,' and he took the Wohltemperirtes Clavier for his gospel, whether as composer, pianist or teacher." ${ }^{29}$ He took a copy with him to Majorca while finishing Op. 28. There are several studies which analyze Chopin's preludes and compare them with those of Bach. ${ }^{30}$ One of the most important comparisons drawn is the similarity of texture. Even though Chopin's language was new and different, like Bach, "the harmony is often clearly the result of superimposed lines. Many of the pieces are built from a polymelodic texture of the most

\footnotetext{
${ }^{25}$ André Gide, Notes on Chopin, trans. Bernard Frechtman (New York, 1949), 32, quoted in Thomas Higgins, ed., "Views and Comments" in Preludes, Op. 28: An Authoritative score, Historical Background, Analysis, Views and Comments, by Frederic Chopin (New York: WW. Norton, 1973), 96.

${ }^{26}$ Jeffrey Kresky, A Reader's Guide to the Chopin Preludes (Westport, CN: Greenwood Press, 1994), xiii.

${ }^{27}$ Chopin's set of 24 preludes was pre-dated by those from the likes of Johann Nepomuk Hummel (1814-15) and Frédéric Kalkbrenner (1827).

${ }^{28}$ Jeffrey Kallberg, “'Small 'Forms': In Defense of the Prelude,” in The Cambridge Companion to Chopin, ed. Jim Samson (New York: Cambridge University Press, 1992), 137-138.

${ }^{29}$ Eigeldinger, "Twenty-Four Preludes Op. 28," 174.

${ }^{30}$ The author has not found any source material to suggest that Chopin ever thought or intended to compose corresponding fugues with his preludes.
} 
inventive kind, and a very long way from the neo-Baroque counterpoint practiced at this same period by [Felix] Mendelssohn or [Robert] Schumann."31

However, it was not Chopin's contrapuntal textures which struck his contemporaries about the Preludes; it was that there was no precedence for them to be found in the literature. They were a new and unique type of composition, and the reception of them was mixed. Many critics did not know what to make of them. Schumann wrote:

The preludes are strange pieces. I confess I imagined them differently, and designed in the grandest style, like his Etudes. But almost the opposite is true; they are sketches, beginnings of Etudes, or, so to speak, ruins, eagle wings, a wild motley of pieces. But each piece, written in fine, pearly hand, shows: "Frederick Chopin wrote it"... He is and remains the boldest and proudest poetic mind of the time. $^{32}$

Franz Liszt gave a similarly glowing review:

Chopin's Preludes are compositions of an order entirely apart: they are not merely, as the title would indicate, introductions to other morceaux - they are preludes instinct with poesy, analogous to those of another great contemporary poet... Admirable for their variety, the labour and learning with which they abound are appreciable only by the aid of a scrupulous examination: everything seems fresh, elastic, created at the impulse of the moment, abounding with that freedom of expression which is characteristic of works of genius. ${ }^{33}$

Gide, after expressing his confusion about their title, concludes that "each one of them is a prelude to a meditation... nowhere has Chopin revealed himself more intimately. Each of them... creates a particular atmosphere, establishes an emotional setting, then fades out as a bird alights. All is still.",34

The Preludes, which so enchanted Chopin's contemporaries, have stood the test of time and are performed by many artists today. In the teaching studio, a few of the easier preludes are

\footnotetext{
${ }^{31}$ Eigeldinger, "Twenty-Four Preludes Op. 28," 175.

${ }^{32}$ Robert Schumann, trans. Edward Lowinsky. Neue Zeitschrift für Musik 41 (November 19, 1839), 163, quoted in Thomas Higgins, ed., "Views and Comments," 91.

${ }^{33}$ Franz Liszt, "M. Chopin the Pianiste," The Musical World (June 10, 1841), quoted in Thomas Higgins, ed., "Views and Comments," 91-92.

${ }^{34}$ Gide, 32, quoted in Thomas Higgins, ed., "Views and Comments," 96.
} 
often found in method books or collections of "Easy Classics," and of course the ever-popular "Raindrop" prelude in D-flat major is a favorite among students and teachers alike. The following chapters can be used as a resource for teachers of high school and college level students in teaching the more difficult preludes. 


\section{Chapter Two}

\section{Intermediate Preludes ${ }^{35}$}

The Op. 28 preludes that require moderate technical skill and are thus appropriate for intermediate students meet the following criteria: 1) at most, only two major technical challenges are present at a time and 2) the tempo facilitates reasonable ease in negotiating the technical challenges. ${ }^{36}$ While some preludes cited as intermediate may appear daunting due to difficult keys (such as F-sharp major and E-flat minor), the repetitive nature of these pieces makes them quite manageable, and familiarity with notes and fingering can be achieved quickly.

A variety of technical challenges are found among this group. Prelude in A minor, No .2, requires stretches and inner voicing of the left hand. Prelude No. 9 in E major, presents trills in the left hand as well as three separate layers in a chorale-like setting which must be balanced and voiced appropriately. Prelude No. 13 in F-sharp major, poses a mixture of challenges including chordal voicing and left hand passagework. Prelude No. 14 in E-flat minor is a study for hand coordination. The famous Prelude No. 15 in D-flat major, requires extreme tone control of a pedal note, presents stretches and voicing challenges for the left hand, and includes some manageable tuplet rhythms. ${ }^{37}$ Finally, Prelude No. 21 in B-flat major is an exercise in double notes. The following discussion will focus on preludes 9, 14 and 21.

Prelude No. 9 in E major, marked Largo, contains long melodic lines in an essentially chordal setting. As stated above, the primary technical challenge encountered in this twelve bar piece is voicing. Three voices are presented with which to contend (see Example 2.1).

\footnotetext{
35 "Intermediate" is used here to indicated degree of technical difficulty among Chopin's Preludes Op. 28 only.

${ }^{36}$ Refer to Appendix, page 73, Table 1 for a list of Intermediate Preludes.

${ }^{37}$ Tuplet refers to a "temporary increase or decrease in the number of notes subdividing a beat from what is standard for a given time signature. Tuplets are usually notated with a numeral or ratio that indicates the number of notes to be performed within the beat." "Tuplet," Oxford Music Online, accessed February 4, 2014, http://www.oxfordmusiconline.com.www.libproxy.wvu.edu/subscriber/article/grove/music/ $2233258 ?$ q=tuplet $\&$ search=quick $\&$ pos $=1 \& \_$start=1\#firsthit.
} 


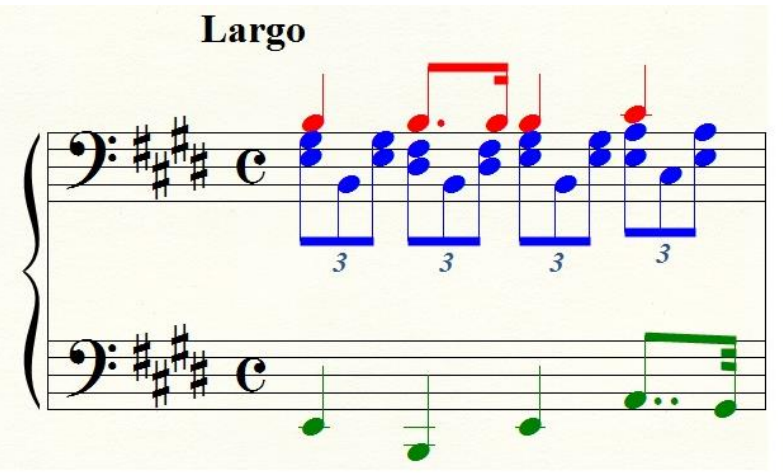

Example 2.1: Prelude No. 9, E major, mm. 1, three voice layers

Each voice has a different function: the top voice (red) is the melody; the bottom voice (green) is an equally important countermelody; the inner voice (blue) is accompanimental, filling out the harmonies. The harmonic rhythm is quite fast, a new harmony being presented on every beat and being driven by the movement of the bass line. These characteristics are consistent with the Baroque style and could be construed as evidence of Bach's influence on Chopin.

The melodic line is fairly static, encompassed within the range of a minor seventh, and, with only one exception, moves entirely in step-wise motion. ${ }^{38}$ It is also presented in long note values as compared with the inner accompanimental voice. The relative stasis of this melodic line in long notes, combined with the fact that it is executed with the weak fifth finger, make it very difficult to project.

It is beneficial to practice this line by itself, using whatever fingering is necessary to make the line as legato as possible. This is an important step in training the ear to listen for the smooth legato line. Listening in this manner also aids in maintaining the line even though the long note values are decaying. To this end, it helps to sing the line as it is played, sustaining the notes and giving direction that can be elusive in this context. Once a firm idea of the contour and

\footnotetext{
${ }^{38}$ Measure 8, beat 1, the melody skips from A-flat down to E-flat, the only instance of a skip in the melodic line of the E major prelude.
} 
direction of the melodic line has been determined, switch to practicing it with only the fifth finger, lifting the finger as little as possible to achieve a legato line, and getting used to balancing the weight of the arm on the outer portion of the hand. ${ }^{39}$ Learning to balance the weight of the arm on different parts of the hand is essential to developing the technical ability to voice properly, and as Chopin asserted, "the goal is not to learn to play everything with an equal sound, [but rather,] it seems to me, a well-formed technique that can control and vary [bien nuance] a beautiful sound quality., ${ }^{, 40}$ Indeed, Chopin placed greater importance on sound production and control than on finger velocity and disliked technical exercises, calling them "an abstract difficulty, a new genre of acrobatics." ${ }^{41}$

The next challenge is learning to control two voices within one hand. The right hand in this case is responsible for not only the projection of the melodic line, but for the lilting inner accompaniment of triplets. To achieve the control necessary to balance two lines within one hand properly, it is important to establish an aural expectation of what the balance should be. This is most readily achieved by playing the triplet figures with the left hand at a mezzo piano dynamic while playing the melody in the right hand at a forte dynamic. Once the proper balance has been established, attempt to imitate it by playing both lines with the right hand only. This control can be arduous to attain. Some suggestions for practicing include: playing all the notes in the span of a quarter note (melody note and all notes of the triplet figure) together in block chords (see Example 2.2); play the melody note first at $f$, then while holding the melody note play the rest of the chord at $m p$ (see Example 2.3).

\footnotetext{
${ }^{39}$ Eleanor Bailie, Chopin: A Graded Practical Guide, (London: Kahn and Averill, 1998), 85-86.

${ }^{40}$ Frederic Chopin, "Sketch for a Method" (Project de Méthode), in Chopin, Pianist and Teacher: As Seen by his Pupils, Jean-Jacques Eigeldinger (New York: Cambridge University Press, 1986), 195.

${ }^{41}$ Chopin, "Sketch for a Method," in Eigeldinger, 193.
} 


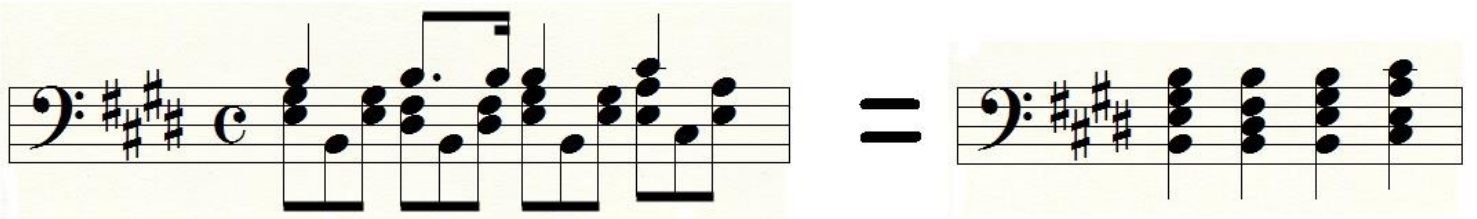

Example 2.2: Practicing each quarter note as a block chord

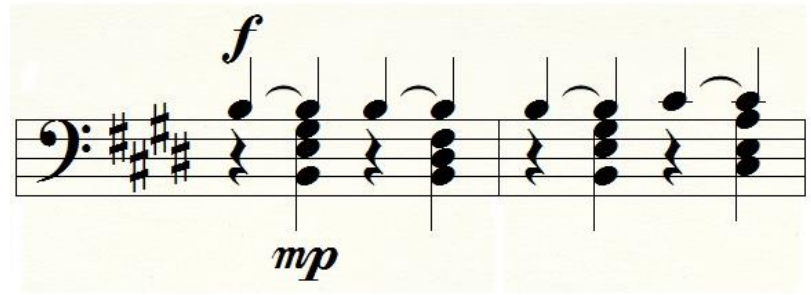

Example 2.3: Practice the melody note first, followed by the rest of the chord

The key to keeping the inner triplets soft and lilting is a loose and relaxed thumb, keeping all arm weight on the outer portion of the hand and the fifth finger.

Lastly, in terms of voicing and balance, one must achieve an appropriate balance between all three voices at the same time. At this point, it is necessary to make personal aesthetic decisions. The top line and bass line are equally important. Experiment with these two voices to find a balance that is pleasing - and it is entirely possible that the emphasis may switch between the two throughout the prelude. It is also very revealing and promotes clarity to practice with the hands in different octaves than those written, putting the hands further apart as the range in which it is written makes it easy for the sound to become jumbled.

When practicing, it is also beneficial to sing all of the three voice layers. It may be helpful to play and sing the line together, or it may be helpful to play two voices while singing the third (e.g. playing the top and bottom lines while singing the triplets). This exercise will help increase awareness of the independence of each line. 
A secondary technical challenge found in Prelude No. 9 in E major prelude is to trill with the left hand. Generally the weaker of the two, the left hand often lacks the dexterity to execute convincing free trills. ${ }^{42}$ For students it is easier, and in the case equally convincing, to play measured trills. The two left hand trills, found in measures 3 and 4, can be easily executed in the following manners:
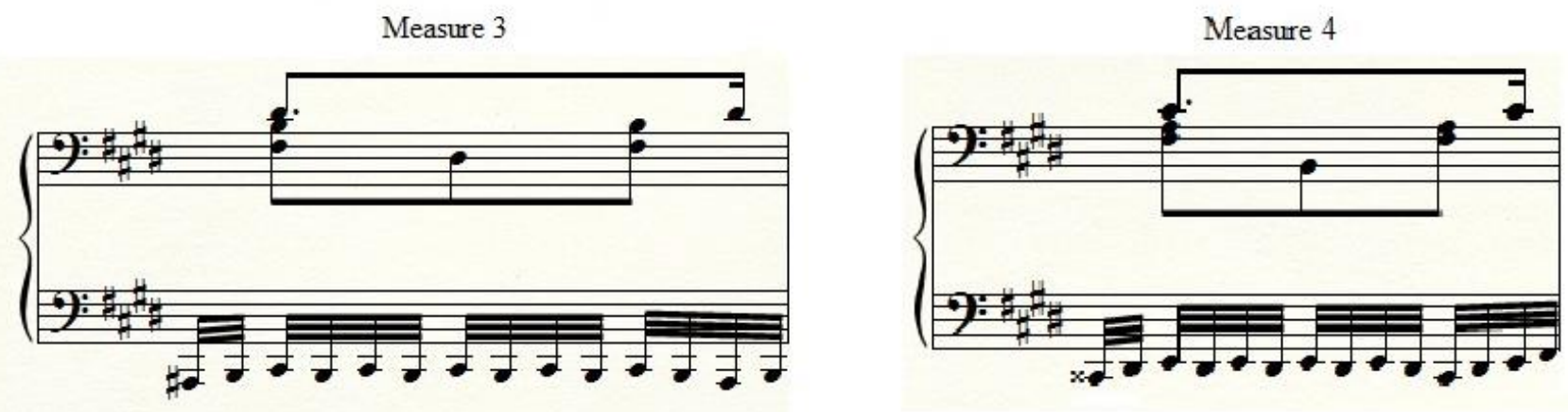

Example 2.4: Prelude No. 9, E major, mm. 3 and 4, measured trills 4:1 ratio ${ }^{43}$

If the 4:1 ratio is uncomfortable or uneven, it is possible to reduce the trill to a 3:1 ratio.
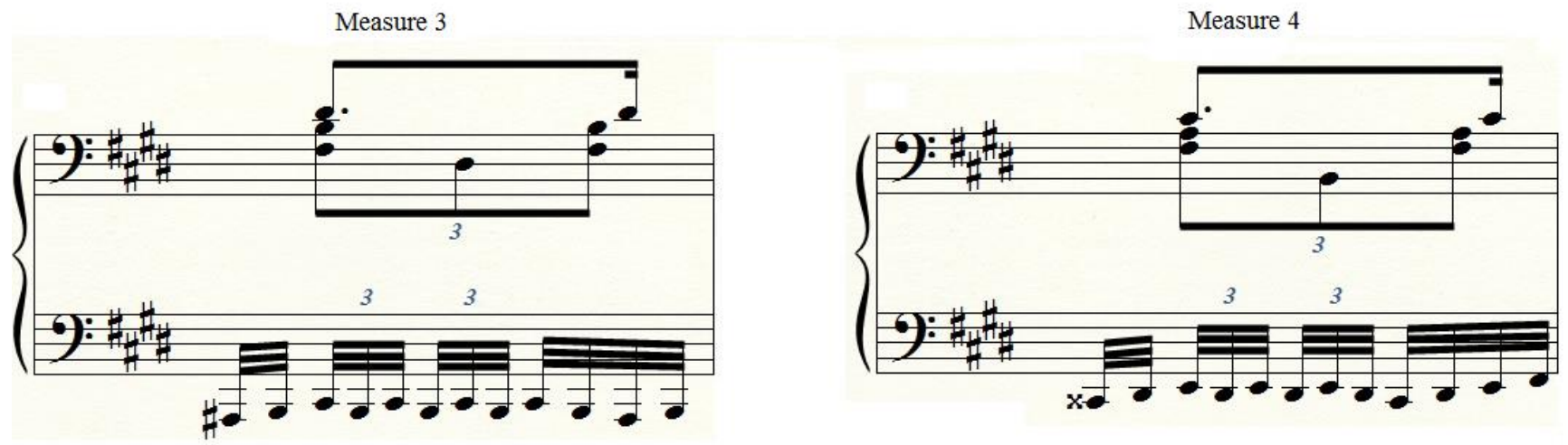

Example 2.5: Prelude No. 9, E major, mm. 3 and 4, measure trills 3:1 ratio ${ }^{44}$

\footnotetext{
42 "Free trills" are those which are executed in an unmeasured fashion, alternating notes as quickly as possible without regard to the metric beat. Generally, the left hand, especially for students, cannot alternate notes as quickly as the right hand. Thus, free trills in the left hand are harder to execute convincingly.

${ }^{43}$ Bailie, 86.

${ }^{44}$ Bailie, 86.
} 
When teaching Prelude No. 9 in E major, it is important to be aware of the questions and debates surrounding the execution of the notated rhythms. As seen in Example 2.1, the upper voice of the right hand is notated as a dotted eighth and sixteenth (duple notation) while the inner voice is notated as eighth note triplets (triplet notation). There is some debate about whether this rhythm should be performed strictly as notated, or if the upper voice should be executed as a triplet, lining up rhythmically with the inner voice. To further complicate the question, sometimes a double dotted eighth and thirty-second is notated (see left hand, beat 4 of Example 2.1). Again, should this be performed strictly as notated, or in a more relaxed manner as suggested by the underlying triplet motion? While no specific approach is explicitly endorsed here, an awareness of these rhythmic questions is necessary for both teacher and student when making decisions about the execution of the notated rhythms of this prelude.

Prelude No. 14 in E-flat minor is a study in perpetual parallel motion between the two hands. The constant allegro triplet motion creates swirls and swells of sound, unprecedented in the literature of earlier composers. The overall effectiveness of the performance of this prelude lies in appropriate use of the damper pedal and meticulous attention to the dynamic markings. Chopin was an innovator of pianistic technique, and this texture that is heavily dependent upon the pedal is an expansion of technique that is attributed to him. ${ }^{45}$

The primary technical challenge presented in this prelude is that of hand coordination. The hands play a single-note line in unison one octave apart. One hand is often weaker, less facile, than the other. This inequality of skill between the hands often makes perfect synchronization difficult. In this texture, if the hands are not exactly together it is strikingly apparent to the listener. The most common advice given to remedy this problem is to focus on

\footnotetext{
${ }^{45}$ Jean-Jacques Eigeldinger, Chopin, Pianist and Teacher: As seen by His Pupils, ed. Roy Howat, trans. Naomi Shohet, Krysia Osostowicz and Roy Howat (New York: Cambridge University Press, 1986), 20.
} 
the weaker hand, letting it lead. Sometimes this works, but for a student (or really anyone) who is put in a performance or high stress situation, that kind of focus may be hard to maintain, proving the method unreliable.

A more reliable technique is to organize and group the notes in such a way to create gestures in the music instead of individual notes; it is much easier to coordinate six gestures than 36 notes. For this particular prelude, it is helpful to group the notes in correspondence with the motion of the lowest pitches of the triplet patterns (see example 2.6).

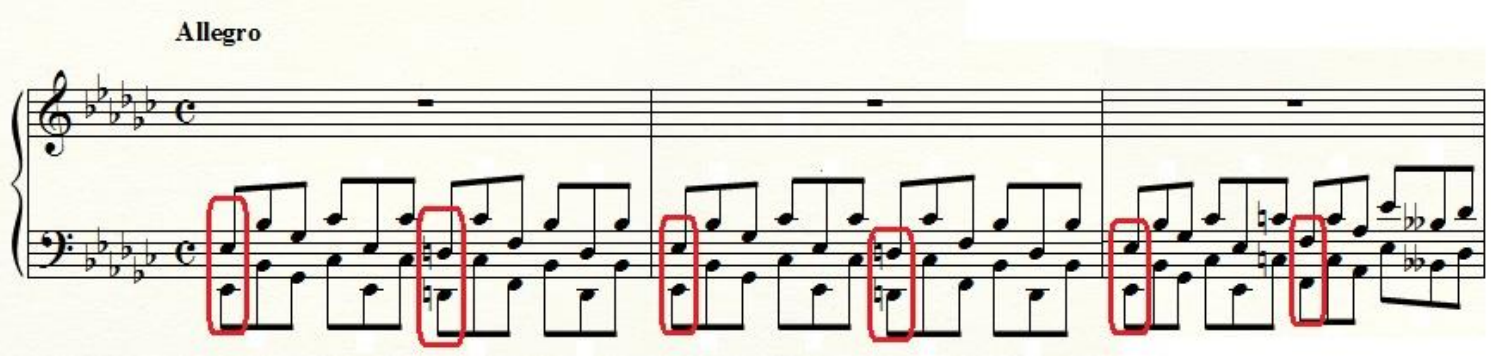

Example 2.6: Prelude No. 14, E-flat minor, mm. 1-3, group in half-bar gestures

These lowest notes form a sort of quasi bass line which the ear can follow, and since it moves at regular rhythmic intervals, it naturally divides the measures into recurrent gestures.

As important as it is for the hands to be exactly together in their execution of the triplets, it is equally important for the triplets to be absolutely even in duration. This is an issue of finger control and ease within the patterns. This prelude presents triplets in a rather disjointed, back and forth motion, as opposed to a rolling motion of directional sweeps (see example 2.7 and 2.8). Because the notes are constantly changing direction, it is necessary, and more difficult, to perform the aforementioned gestures in one hand/wrist motion. For instance, each half bar should be executed in a single down-up motion (see example 2.9). This will minimize tension which would otherwise lead to unevenness. 


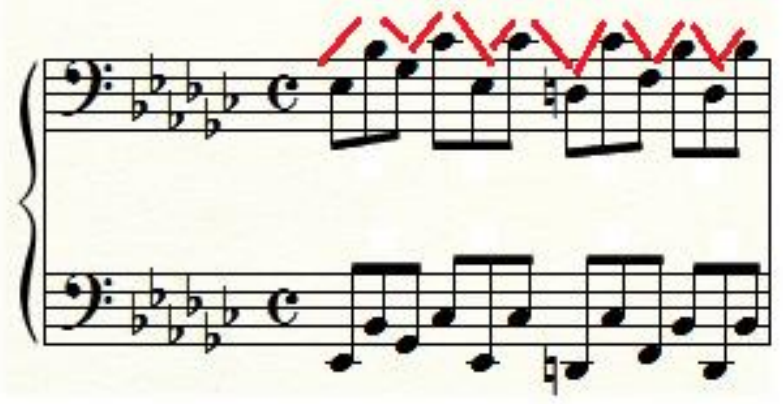

Example 2.7: Jerky back and forth motion

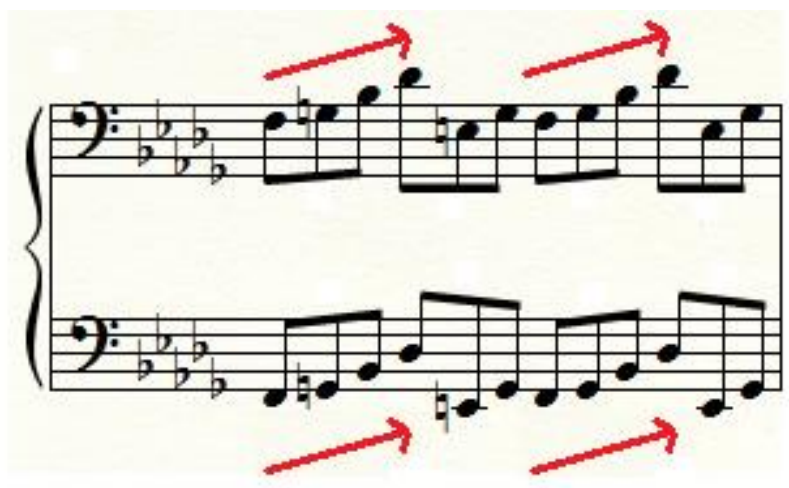

Example 2.8: Smooth directional motion found in Chopin's Sonata Op. 35, Finale

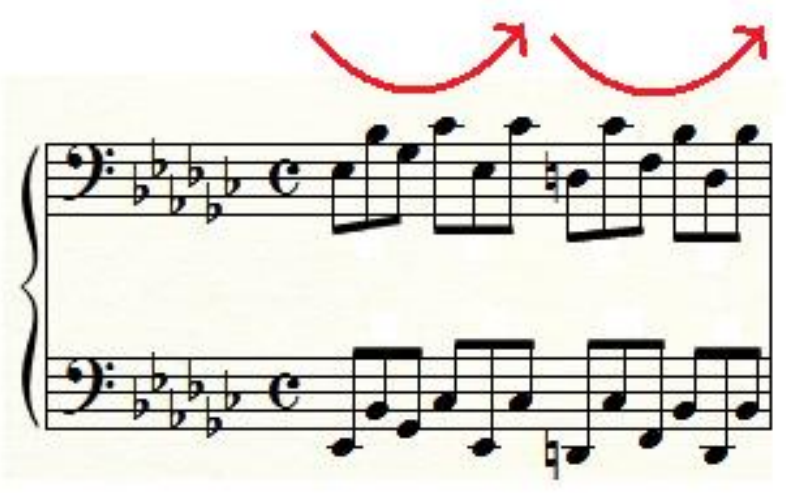

Example 2.9: Down-up hand/wrist motion for the half-bar gesture

It is also beneficial to be familiar and comfortable with the changes in the keyboard topography from one gesture to the next (i.e. knowing the changes in black keys and white keys) and how it affects the height and position of the wrist and hand. This comfort is best achieved by playing the 
chord changes in blocks, noticing how the hand changes position for each successive chord (see example 2.10). Since this prelude is in a key which employs all of the black keys, many of the chord positions fit naturally under the hand. ${ }^{46}$

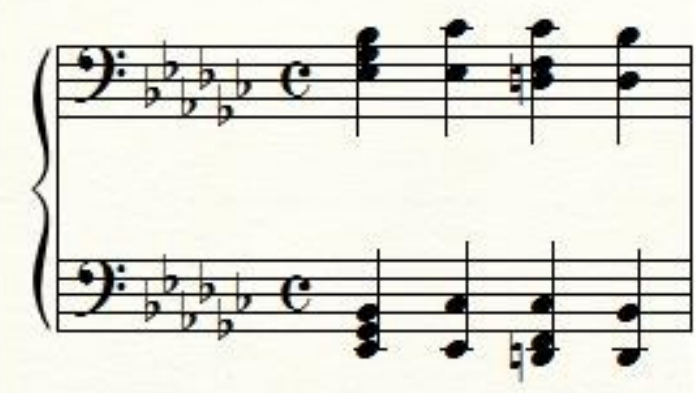

Example 2.10: Practice in block chords to study hand/wrist position in relation to white and black keys ${ }^{47}$

Utilizing block chords is also a helpful way to practice the half bar gestures by grouping the harmonic changes in the following way:

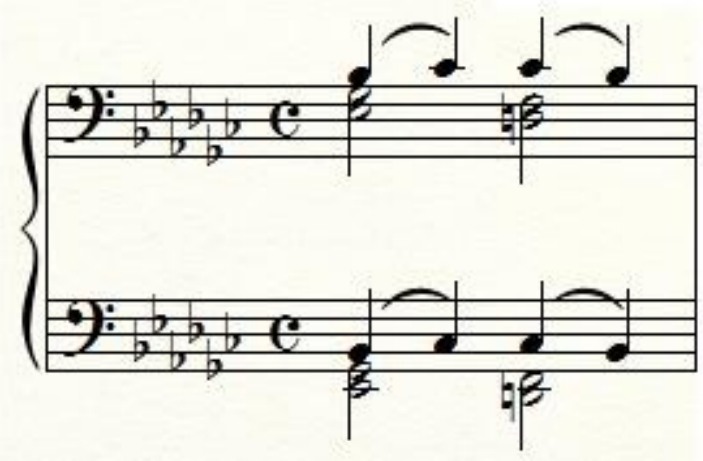

Example 2.11: Holding the common tones ${ }^{48}$

\footnotetext{
${ }^{46}$ The raised position of the black keys fits the natural curvature of the hand and fingers. Positioning the hand with the first and fifth fingers on $\mathrm{E}$ and $\mathrm{B}$ with the remaining fingers on the three black keys in between is the most natural position at the keyboard.

${ }^{47}$ Bailie, 94.

${ }^{48}$ Bailie, 95.
} 
Practice holding the common tones while slurring the upper notes that move. Do this with the down-up motion as shown in Example 2.9 to practice the half-bar gesture. Eleanor Bailie also suggests practicing in the following rhythmic patterns to gain stability and evenness:

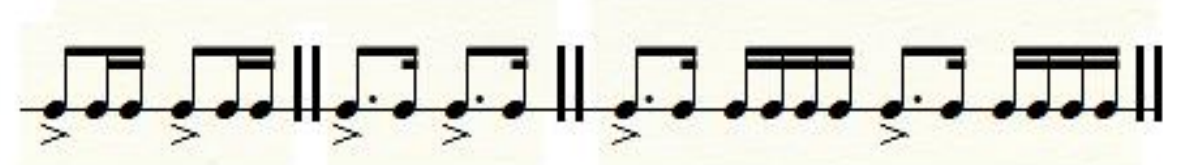

Example 2.12: Rhythmic patterns to practice for stability and evenness ${ }^{49}$

A final suggestion for attaining evenness and control is to play with the arm weight completely rather than superficially in the keys. It is easy, especially in fast playing, to simply "wiggle the fingers" above the keys without fully depressing the key or releasing the weight of the arm. While this may allow for fast performance, it is likely that the fingers will spin out of control, perhaps even becoming twisted and tangled with one another. This approach would also seem to be going against Chopin's own suggestion for this piece, which he marked pesante [heavy]. In fact, his general style of playing, and what he taught his students, was to play fully into the keys, so that "the fingers should sink, immerse themselves somehow in the depths of the piano... the fingers reluctant to leave the keys."50

A secondary technical challenge for this piece is dynamic control and scope. There is no starting dynamic to the piece. The only dynamic indicated is in measure 11 , marked fortissimo. The hairpin directives would seem to indicate that the dynamic contour of the entire piece is a

\footnotetext{
${ }^{49}$ Bailie, 95.

${ }^{50}$ Adam Czartkowski and Zofia Jeżewska, Fryderyk Chopin (Warsaw: PIW, 1970), 374, quoted in Jean-Jacques Eigeldinger, Chopin, Pianist and Teacher: As seen by His Pupils, ed. Roy Howat, trans. Naomi Shohet, Krysia Osostowicz and Roy Howat (New York: Cambridge University Press, 1986), 31. This information is from Chopin's student Princess Marcelina Czartoryska, reported to her pupil Cecylia Dzialyńska, who published it in an article reproduced in the book by Czartkowski and Jeżewska which was quoted by Eigeldinger.
} 
long range crescendo to this point, maintained (though varied) for approximately four bars, followed by a diminuendo to the end. It is important to make decisions about dynamic arrival points. It is easy to arrive at fortissimo too quickly, resulting in a bombardment of loud sound rather than a gradual sweeping affect. It is recommended to begin the prelude at piano so as to allow room to grow throughout.

Of Prelude No. 21in B-flat major, Bailie says "This is an extraordinary idea - a sustained, nocturne-like treble melody with a ceaseless undertow of LH quavers opening out through each bar in swathes of constantly changing intervals, predominantly in contrary motion." ${ }^{51}$ It is this ceaseless left hand figuration which is most technically challenging in this prelude. Long passages of double notes are always awkward to navigate, even more so when the notes are not moving in the same direction.

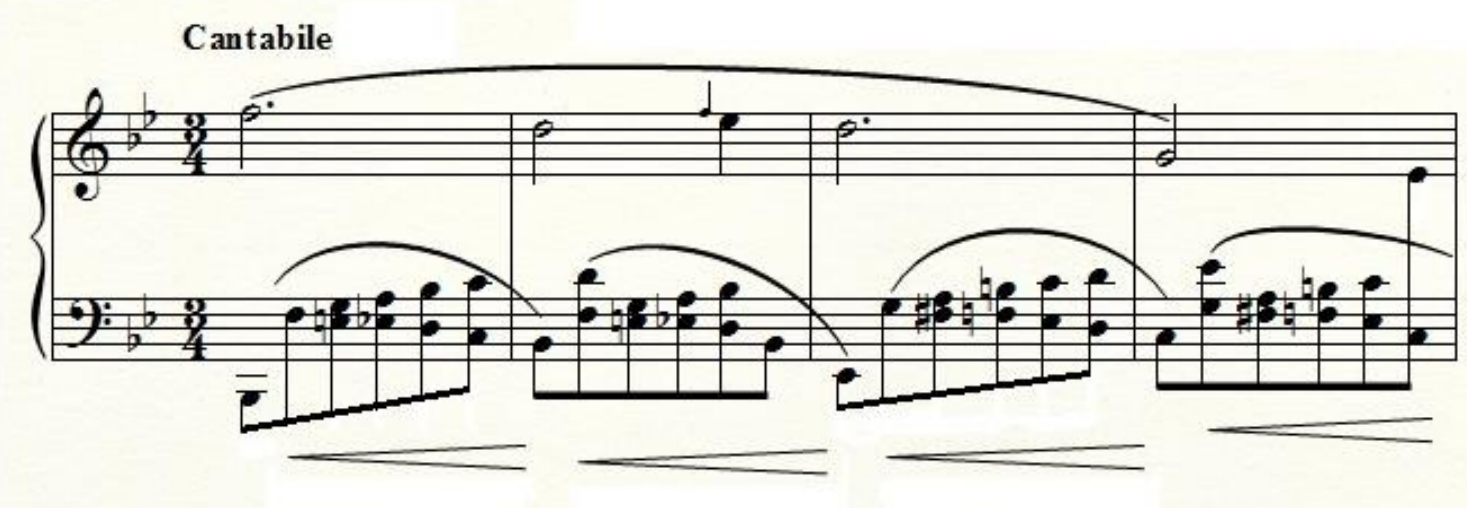

Example 2.13: Prelude No. 21, B-flat major, mm. 1-4

The most important consideration for successful navigation of double notes is fingering finding a good fingering and sticking to it. It is interesting to note that Chopin's approach to fingering was very innovative for his time.

\footnotetext{
${ }^{51}$ Bailie, 107.
} 
In the piano schools of Chopin's day fingering was prescribed according to strictly formulated rules. Chopin knew nothing of all this. His style of fingering evolved in tandem with the growth of his own playing skill. Contortion of any kind was anathema to him, and his fingering followed two main principles: a) the natural conformation of the hand in relation to the keyboard; and b) the appreciation of the natural characteristics of each finger in terms of strength, flexibility, and expressive potential... He sought to develop optimum suppleness, and then to dispose the fingering of a phrase in such a way as to 'fit' the expressive shape of the music. ${ }^{52}$

Following this line of thinking, it is advantageous to become familiar with the passage and what is required of the hand in navigating the keyboard, and discover a fingering which works for the hand as well as for the musical expression. ${ }^{53}$

Once a fingering has been established it is beneficial to practice the lower notes, as well as the upper notes alone, both with proper fingering. It may also be helpful to sing each line as it is played, or conversely to sing the opposite line, with the goal of smoothly connected forward motion. The momentum of the pattern begins on the second eighth note of each bar and proceeds to the downbeat of the following bar. This is indicated by the slur markings, and accentuated by the hairpin dynamic indications (see Example 2.14).

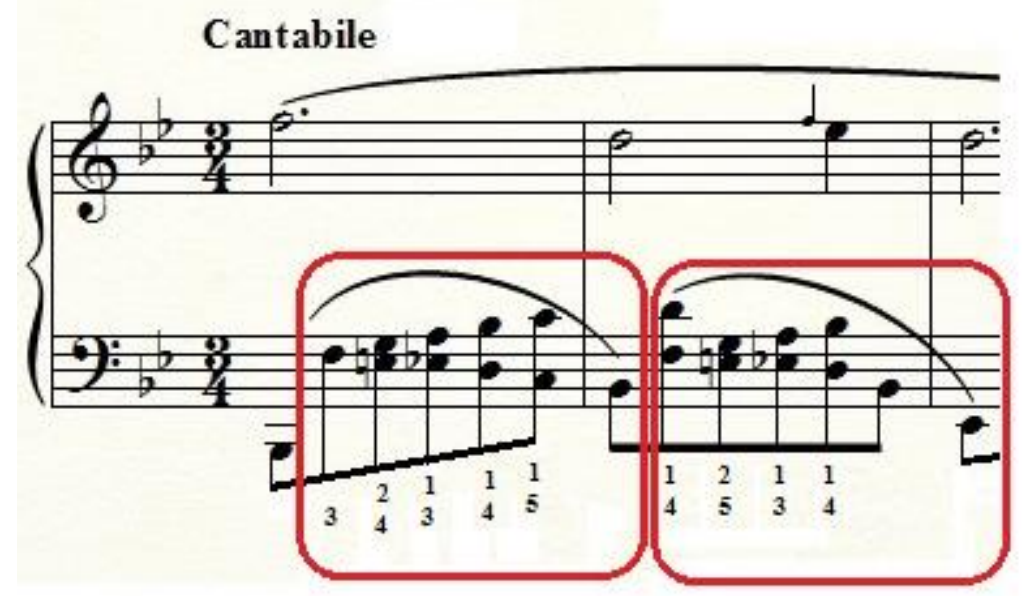

Example 2.14: Left hand pattern direction beginning on the second eighth note of the bar and proceeding to the downbeat of the following bar. ${ }^{54}$

\footnotetext{
${ }^{52}$ Bailie, 17.

${ }^{53}$ The fingering used by the author is shown in Example 2.14. Notice the free use of fingers 3, 4, and 5 on the bottom of the double note pattern. It is encouraged, however, that each individual experiment to find comfortable fingering.
} 
As the fingering of both the top and bottom notes becomes comfortable, practice the left hand alone as written at a slow tempo, gradually increasing in speed until the desired tempo is reached. Although the prelude is marked only cantabile without a tempo indication, it is recommended to take a slower, andante tempo to avoid a rushed feeling. When the right hand joins the left with double notes (mm. 14-16, mm. 33-45), apply the same steps to the right hand. It may be beneficial to practice the bottom notes only of both hands together, and then top notes only. The passage at mm. 33-38 is particularly difficult, as the right hand is responsible for projecting the melody note while also playing double notes (see Example 2.15). Again, applying comfortable and appropriate fingering will help, as well as singing the melodic line.

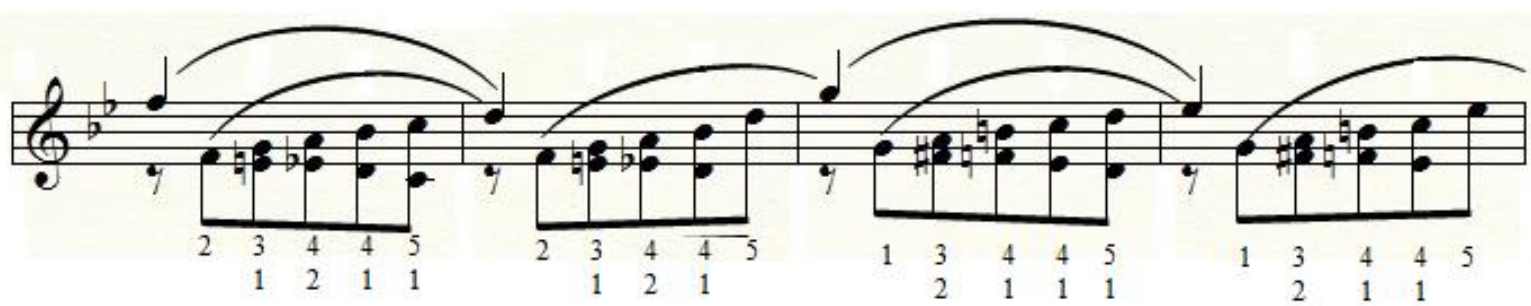

Example 2.15: Prelude No. 21, B-flat major, mm. 33-36 ${ }^{55}$

Prelude No. 21 in B-flat major is marked cantabile, indicating that the melody should have a singing quality. This style of playing, bel canto, is one of which Chopin was a great proponent.

The best way to attain naturalness in performance, in Chopin's view, was to listen frequently to Italian singers, among whom there were some very remarkable artists in Paris at the time. He always held up as an example to pianists their broad and simple

\footnotetext{
${ }^{54}$ Fingering provided is that which is used by the author.

${ }^{55}$ Fingering provided is that which is used by the author.
} 
style, the ease with which they used their voices and the remarkable sustaining powers which this ease gave them. 56

Indeed, it is reported that "to [his student] Madame Rubio he said: 'You must sing if you wish to play'; and he made her take lessons in singing." ${ }^{, 57}$ As noted before, this type of long, sustained melodic line can be difficult to play smoothly and connected as the tone decays on the piano. The best remedy is to sing the melody, and when not singing it aloud to hear it sung in the head. Bel canto playing also requires the full use of arm weight into the keys, a technique already discussed with the Prelude No. 14 in E-flat minor The use of arm weight will produce a full, resonant sound which has more sustaining potential than a forced or struck attack of a note.

Lastly, pedaling is also a technical challenge with this prelude. The natural instinct is to pedal with the melodic notes to lend maximum sustaining power and resonance to the long note values. However, with the ever changing harmonies of the left hand line, using full pedal for an entire measure, or even part of a measure, results in a blurred mess of sound. Conversely, no pedal at all makes it nearly impossible to perform the long legato lines indicated, especially in the left hand. Ultimately, the choice is again one of personal preference. Experiment with half pedal and flutter pedaling to find an affect that is pleasing.

All the techniques described here are reasonably managed by the intermediate student. As they encompass a wide range of skills, the study of these preludes will help to lay the technical foundation for later study of more difficult works by Chopin and other composers.

\footnotetext{
${ }^{56}$ Moritz Karasowski, Friedrich Chopin. Sein leben, seine Werke, und Briefe, vol. II (Dresden: Reis, 1877), 93, quoted in Jean-Jacques Eigeldinger, Chopin, Pianist and Teacher: As seen by His Pupils, 44.

${ }^{57}$ Frederick Niecks, Frederick Chopin as a Man and Musician, vol. II, $3^{\text {rd }}$ ed. (London: Novello, 1902), 187, quoted in Jean-Jacques Eigeldinger, Chopin, Pianist and Teacher: As seen by His Pupils, 45.
} 


\section{Chapter Three}

\section{Advanced ${ }^{58}$}

The Op. 28 preludes that require significant technical skill and are thus appropriated for advanced students meet the following criteria: Preludes in this group meet two criteria: 1) at most, only two major technical challenges are present at a time and 2) the tempo renders execution more difficult than the intermediate preludes. ${ }^{59}$ Also, the advanced preludes often require leaps and stretches which small hands might not be able to navigate. Consequently, they are more suitable for students with larger, fully grown hands.

A variety of technical challenges are found among this group. The $\mathrm{C}$ major prelude, No. 1 , requires voicing of three layers and is rhythmically complex. The voicing challenges found here may be approached in much the same manner as those of the Prelude No. 9 in E major discussed in the previous chapter. The G major prelude, No. 3, contains rapid left hand passagework which requires rhythmic coordination with the right hand. Prelude No. 10 in C\# minor has rapid right hand figuration interspersed with double notes. In the B major prelude, No. 11 , the eighth note motion in $6 / 8$ is constantly shifting in and out of hemiola. Interspersed throughout the perpetual motion eighth notes are double notes and ornaments, the execution of which requires appropriate wrist/arm motions. The A-flat major prelude, No. 17, also requires voicing, and features the technique of overlapping hands. In addition, it requires bel canto playing of the melody, in conjunction with the chordal voicing, as discussed in Chapter Two with the B-flat major prelude, No. 21. Prelude No. 22 in G minor showcases the melody in left hand octaves and requires complete independence of the hands. Finally, Prelude No. 23 in F

\footnotetext{
58 "Advanced" is used here to indicated degree of technical difficulty among Chopin's Preludes Op. 28 only.

${ }^{59}$ Refer to the Appendix, page 73, Table 1 for a list of Advanced Preludes.
} 
major has a melodic left hand under right hand passagework. The following discussion will focus on preludes 3, 10, 22 and 23.

Prelude No. 3 in G major, marked Vivace, is one of the most charming preludes in Op. 28, presenting a cheerful melodic line over a bubbling left hand accompaniment pattern. This is one prelude that can be performed at a variety of tempos with equal success. If a student is not up to performing at the break-neck tempo usually heard it is perfectly acceptable to play it at a more moderate tempo as long as the spirit is maintained. The left hand is the technical star of the piece, though equally difficult is coordinating the right hand with it.

The left hand sixteenth note pattern is relentless, spinning through the piece uninterrupted until the final two measures. Executing this whirl of sixteenth notes at a vivace tempo is complicated by itself, but adding to the challenge is the fact that it is to be played piano. This requires a great deal of control of both fingers and touch. Fortunately, the pattern is repetitive enough that careful practice of a few measures will make this prelude quite manageable.

The left hand pattern is presented in a two measure introduction before the right hand joins in:

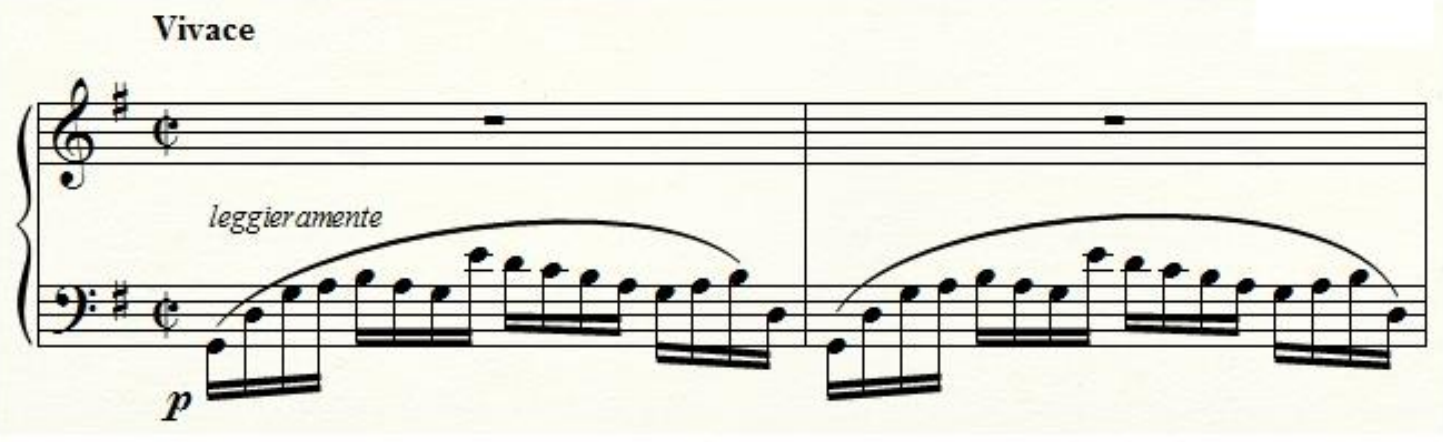

Example 3.1: Prelude No. 3, G major, mm. 1-2 
Eleanor Bailie suggests that mastering this pattern in its tonic presentation should be done before moving on to other passages. ${ }^{60}$ Since all of the left hand passagework is based upon this pattern, this makes good sense. Bailie also suggests practicing the pattern in different rhythms (see example 3.2).
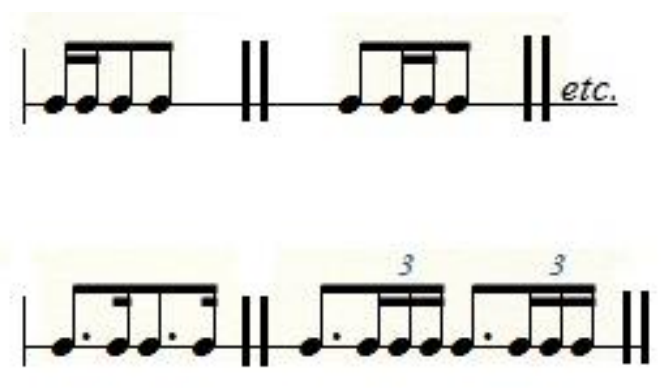

Example 3.2: Rhythms for practicing left hand of G major prelude ${ }^{61}$

She cautions:

Always be conscious of the need to lighten the sound, using the kind of finger articulation that is so clean that it sounds almost detached, until you begin to achieve that special aerated fleetness of sound that is at the same time not "wispy", like the scurrying feet of squirrels who know where they are going, and not the movement of a wafting cobweb. ${ }^{62}$

Thus, while the pattern does need to be soft and light there must still be substance and depth to the sound, achieved by releasing the weight of the arm and playing fully into the keys. ${ }^{63}$ This is in keeping with Chopin's principles of technique. His student Princess Marcelina Czartoryska reported that Chopin felt that "the fingers should be free [déliés], running over the keys without the slightest effort - but not superficially "tickling" the keyboard, except in the most delicate passages." 64

\footnotetext{
${ }^{60}$ Eleanor Bailie, Chopin: A Graded Practical Guide, (London: Kahn and Averill, 1998), 74.

${ }^{61}$ Bailie, 74.

${ }^{62}$ Bailie, 74.

${ }^{63}$ This approach is also considered in the Chapter Two discussion of Prelude No. 14 in E-flat minor.

${ }^{64}$ Adam Czartkowski and Zofia Jeżewska, Fryderyk Chopin (Warsaw: PIW, 1970), 374, quoted in Jean-Jacques Eigeldinger, Chopin, Pianist and Teacher: As seen by His Pupils, ed. Roy Howat, trans. Naomi Shohet, Krysia Osostowicz and Roy Howat (New York: Cambridge University Press, 1986), 30.
} 
An understanding of the contour of the pattern, and how that translates into wrist motion, is essential for the successful smooth execution over the course of the prelude. The goal of the following exercises is not to make each finger sound equal, but to create a sense of line and musical gesture. Chopin contended that each finger possesses differing capabilities, therefore different sound potentials, and said "no one will notice the inequality of sound in a very fast scale, as long as the notes are played in equal time - the goal isn't to learn to play everything with equal sound." ${ }^{65}$ He also understood that "evenness... depend[s] not merely on equal strengthening of all fingers... and on entire freedom of the thumb... but above all on a constant sideways movement of the hands... continuous and even-flowing rather than in steps."66

Principally, the wrist will lead the hand through this pattern, and the sideways motion prescribed by Chopin above is crucial. It may again be helpful to divide the pattern into gestures associated with wrist motion. A natural place to begin a gesture is where the contour of the line turns around (see Example 3.3).

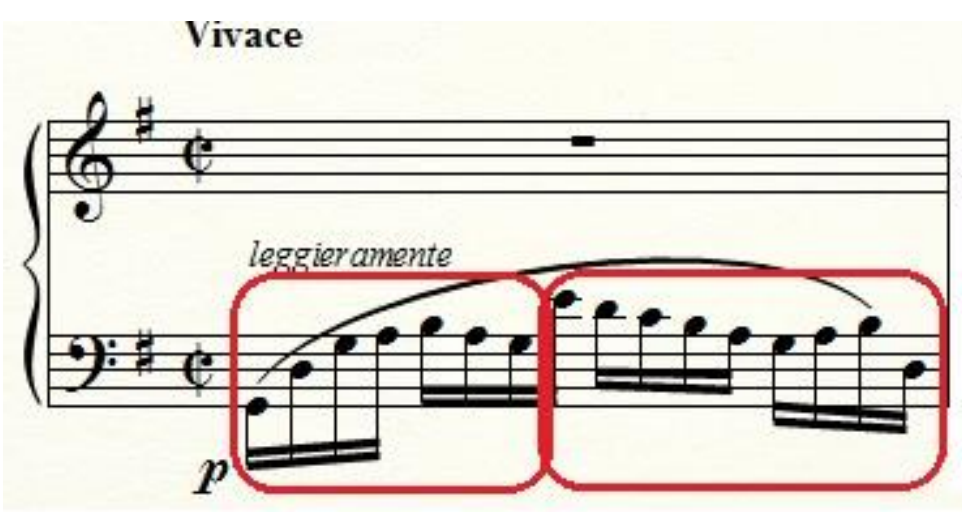

Example 3.3: Division of left hand pattern into gestures

\footnotetext{
${ }^{65}$ Frederic Chopin, "Sketch for a Method" (Project de Méthode), in Chopin, Pianist and Teacher: As Seen by his Pupils, Jean-Jacques Eigeldinger (New York: Cambridge University Press, 1986), 195.

${ }^{66}$ Carl Mikuli, Vorwart to Fr. Chopin's Pianoforte-Werke, ed. by Carl Mikuli (Leipzig: Kistner, 1880), 3, quoted in Jean-Jacques Eigeldinger, Chopin, Pianist and Teacher: As seen by His Pupils, 37.
} 
Here, the line changes direction once in the middle of the pattern and once to turn around and repeat the pattern. This division naturally breaks the pattern into two wrist motions, with another motion required to repeat. It also has the benefit of creating a natural pulse in two, lending fluidity to the line. The two motions within the pattern are left-right motions, on a horizontal plane (see Example 3.4). First, the wrist will travel right with a slight return to the left at the end. Then, returning to a neutral position on the $\mathrm{E}$ at the top of the pattern, the wrist moving left with a slight return to the right at the end.

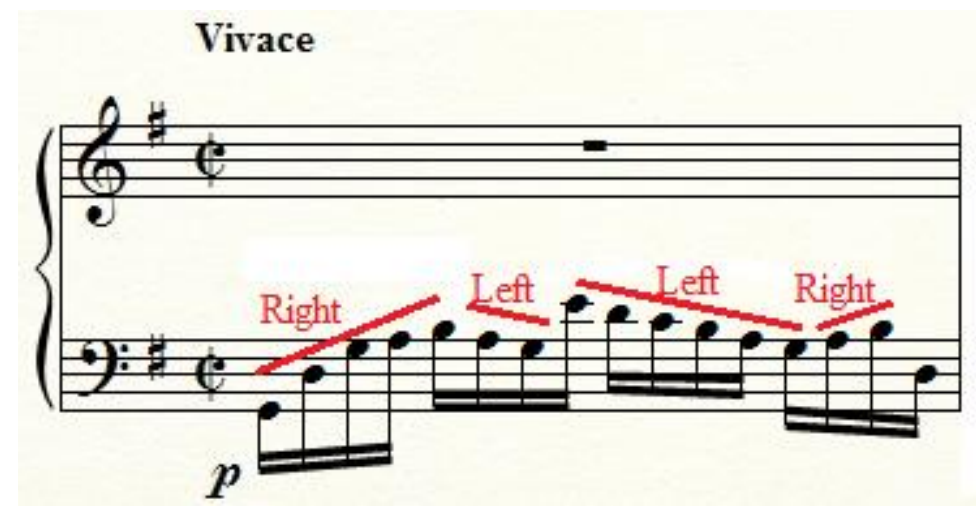

Example 3.4: Left-right wrist motion of left hand pattern

Once this feels natural, it becomes necessary to navigate the turn-around and repetition of the pattern. To turn around at the bottom and repeat requires a combination down-up and leftright motion (see Example 3.5). This combination is perhaps the most important motion for smooth execution of the repeating pattern. As the wrist travels down and left from $\mathrm{D}$ to $\mathrm{G}$, it should feel like it is pushing off the G, like a springboard, back up to the next D with an up/right motion. This is where the propulsion of the pattern happens, and the momentum of the left hand is essential to the right hand. 


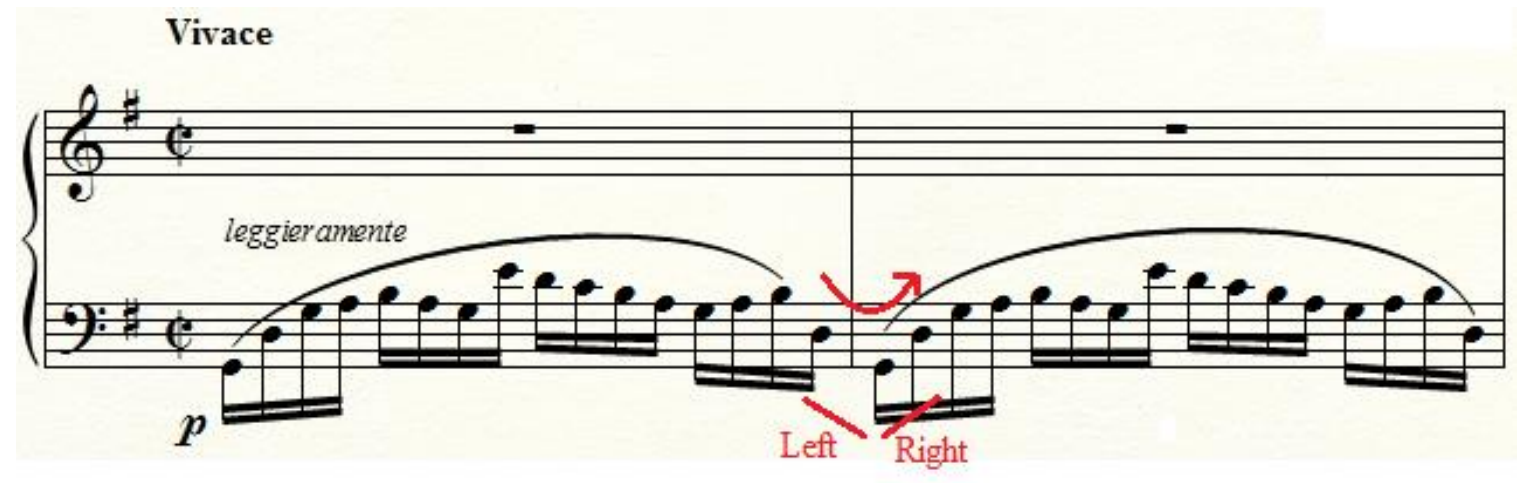

Example 3.5: Combination left-right, up-down wrist motion to turn around and repeat left hand pattern

The pattern is presented mostly in the tonic (mm. 1-6, mm. 12-17, mm. 26-31) with brief forays in the dominant (m. 8, mm. 10-11 and m. 25), and the subdominant (mm. 18-23). Measure 24 is a slightly modified version of the pattern in the dominant. All of these are basically the same pattern simply transposed, so all of the suggestions detailed for the tonic version apply to each adaptation.

The melodic line present in the treble in long notes requires the same bel canto approach as the Prelude No. 21 in B-flat major. However, the Prelude No. 3 in G major has the added challenge of inserting sixteenth note upbeats into the melody, almost like grace notes, but which must be rhythmically accurate, and absolutely synchronized with the undulating left hand passagework (see Example 3.6).

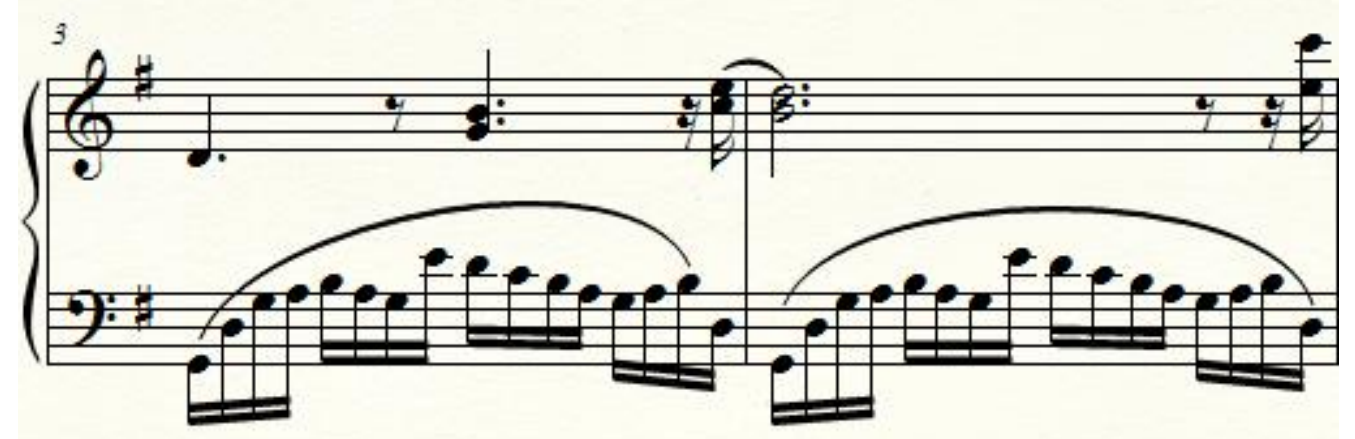

Example 3.6: Prelude No. 3, G major, mm. 3-4, right hand entrance 
It will be helpful to think of the right hand as emerging from the left hand passagework. As discussed above, the left hand provides a two measure introduction before the right hand joins in measure three. However, one should instead:

Feel that the [left hand] is not so much providing a two-bar introduction, as setting a wheel in motion onto which the [right hand] will land, as with a little spring, on the first beat of b. 3. Then feel that the [right hand] is 'riding' the ceaseless switchbacking arcs of the [left hand] ${ }^{67}$

This includes feeling the pulse in two, or even one pulse per bar, as with the left hand.

The sixteenth notes are the most difficult to coordinate. Bailie suggests very slow practice, making sure the hands come together absolutely in sync, and then gradually increasing the tempo. ${ }^{68}$ It is also helpful to isolate the sixteenth note and the succeeding note (see Example 3.7). Practice this gesture up to tempo.

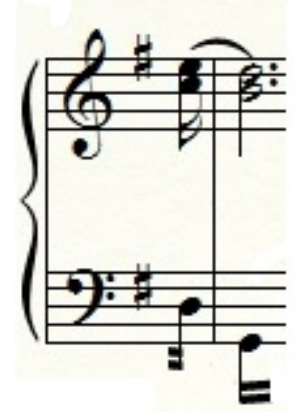

Example 3.7: Isolation of right hand sixteenth note gesture

Then, one note at a time, add notes working backwards (see Example 3.8).

${ }^{67}$ Bailie, 75 .

${ }^{68}$ Bailie, 75 . 

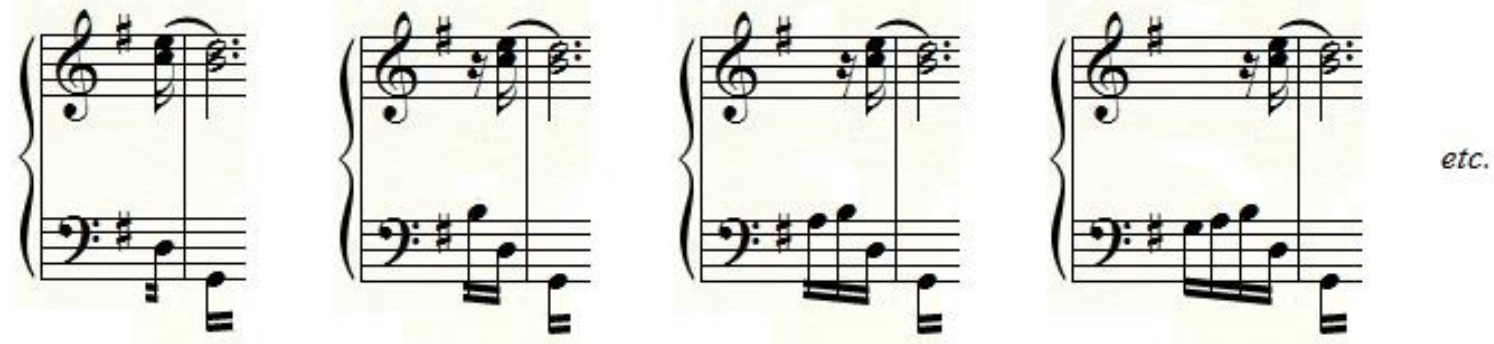

Example 3.8: To practice coordination, add one note at a time working backwards

This treatment will ensure that the sixteenth note entrance of the right hand is solidly in time, as well as making sure that the left hand is prepared to enter without hesitation. It may also be helpful to stop directly on the sixteenth note, assessing whether the hands were perfectly together.

In measures 28-31 the right hand joins the left with the sixteenth note pattern. The coordination required here is very similar to that discussed with Prelude No. 14 in E-flat minor in Chapter Two, and the same methods of practice can be applied. It is also important to use the same wrist motions, detailed above, that the left hand is using.

Prelude No. 10 in C\# minor is a fleeting flight of fancy that is over nearly as soon as it's begun. Its eighteen measures, played allegro molto, require precise and sensitive coordination. Most of the technical challenge lies within the twisting right hand passagework. There are four sections of passagework, each followed by a contrasting chordal section. Three of the four (one, two and four) are the same, while the third uses a slightly different intervallic pattern. However, all four require the same technique.

The right hand pattern is comprised of sixteenth notes in groups of five, grouped three and two, cascading down the keyboard. The pattern is predominantly in single notes, however a double note is added on each beat (see Example 3.9). 


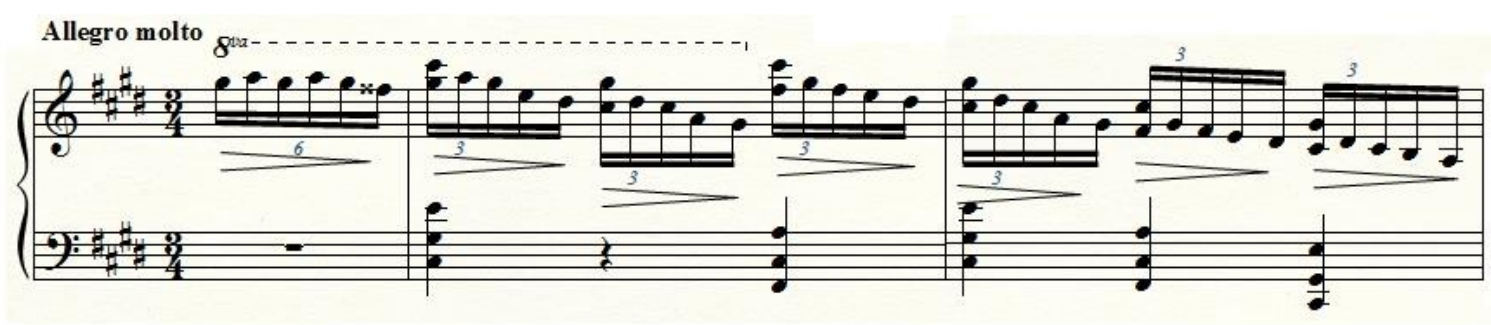

Example 3.9: Prelude No. 10, C\# minor, mm. 1-2

Using the suggestions outlined in the previous discussion of the Prelude No. 3 in G major, the patterns should be practiced first without the upper notes (see Example 3.10) ${ }^{69}$

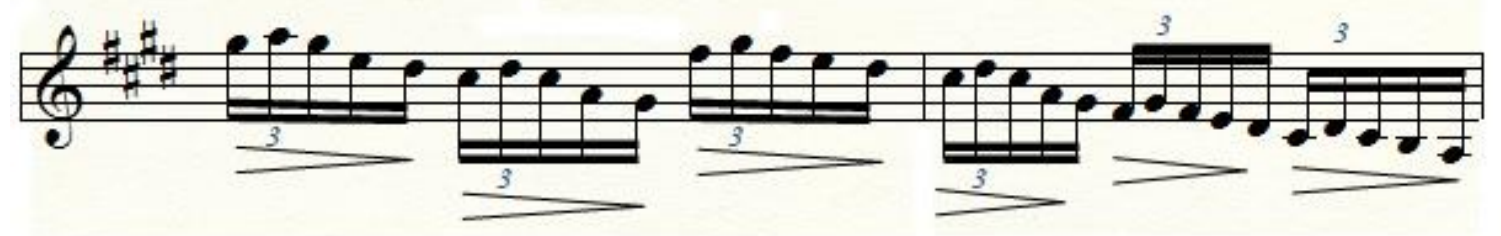

Example 3.10: Practice the bottom notes only

Each beat should be played with a slight downward motion, the remaining four notes lightly executed on the upward rebound, so that all five notes of the beat are played within one gesture. This grouping not only facilitates ease and relaxation, but also naturally follows the dynamic contour prescribed by the hairpin decrescendos.

When the upper note is added, be careful not to hold onto the note; it should be played with a short, light stroke so as to avoid giving a heavy feeling to the entire pattern. When the upper note is added one should give a slight push towards the outer note of the fourths and fifths in combination with the downward motion used for each beat. This will result in an overall circular motion of the hand and wrist, the impetus of the push creating momentum for the

${ }^{69}$ Bailie, 87. 
descending spiral of notes. ${ }^{70}$ It is also important to play with the hand inward on the keyboard (not on the edges of the white keys) so that the black keys are all well within reach, eliminating the need for any inward/outward motion which would interrupt the flow and ease of the pattern.

The left hand is very important to the stability of the prelude, acting as the conductor in providing the rhythmic pulse. As the tempo is increased, one should strive for a tempo in which one "can fit the [right hand] comfortably in with the [left hand] chords, and no faster, always feeling that the flying [right hand] is fitting in with the perfectly timed [left hand] chords, and not the other way around."

The Prelude No. 22 in G minor is a "furious tirade of LH octaves," and makes a superb technical study even if a virtuosic tempo is never reached (see Example 3.11 ). ${ }^{72}$ Bailie suggests practicing the left hand alone, slowly, being sure to play in precise time. ${ }^{73}$ To perform the octaves up to tempo, without a harsh or forced sound, one must use the weight of the arm, being sure that there is no tension in the hand, wrist, elbow, or shoulder.

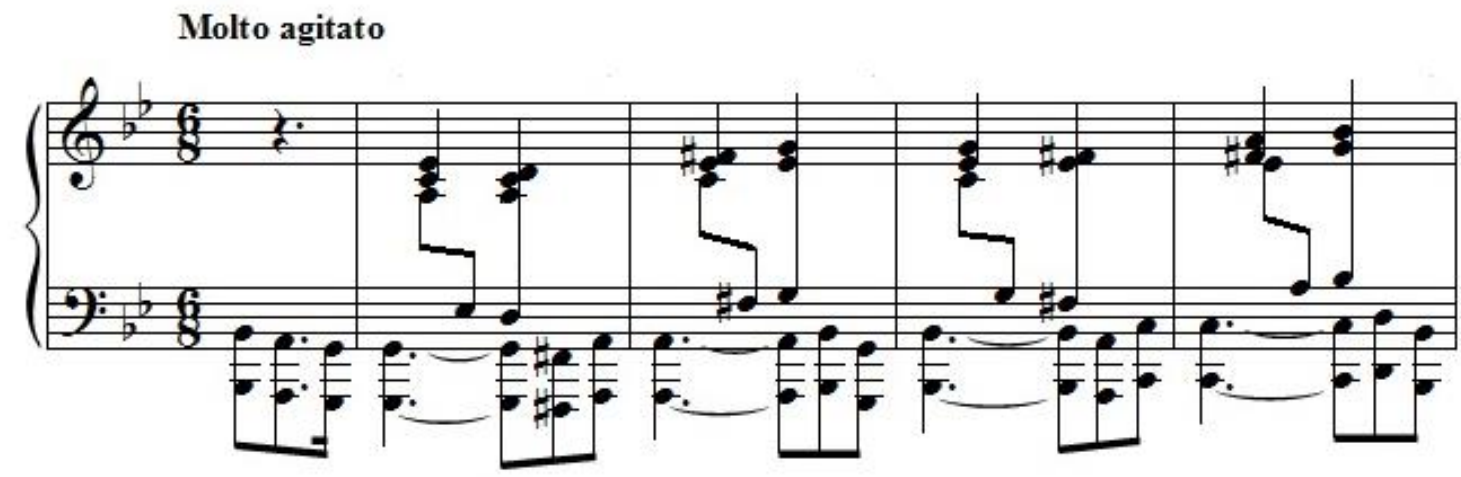

Example 3.11: Prelude No. 22, G minor, mm. 1-4

\footnotetext{
${ }^{70}$ Bailie, 87.

${ }^{71}$ Bailie, 87.

${ }^{72}$ Bailie, 109 .

${ }^{73}$ Bailie, 109.
} 
Use arm weight without tension to practice this, playing first the top note of the octaves with the thumb, then the bottom note of the octaves with the fifth finger. Do so slowly, checking with each note for relaxation and release from the shoulder down through the fingers. The goal is to produce a full, resonant tone. To achieve a resonant forte, Chopin advises to "caress the key, never bash it!" 74 As both the thumb and fifth finger become accustomed to the feeling of this release, practice the entire octave, again, slowly. Make sure to release any tension across the palm of the hand that may result from attempting to hold the thumb and fifth finger in position for the successive octaves.

Equally necessary to the success of the left hand octaves is phrase structure. Built into phrase structure is a natural tension and release which can be mirrored with physical release of tension. In the case of Prelude No. 22 in G minor, Chopin's phrase markings for the left hand are invaluable as indications of the physical approach that should be taken with the line (see Example 3.12).

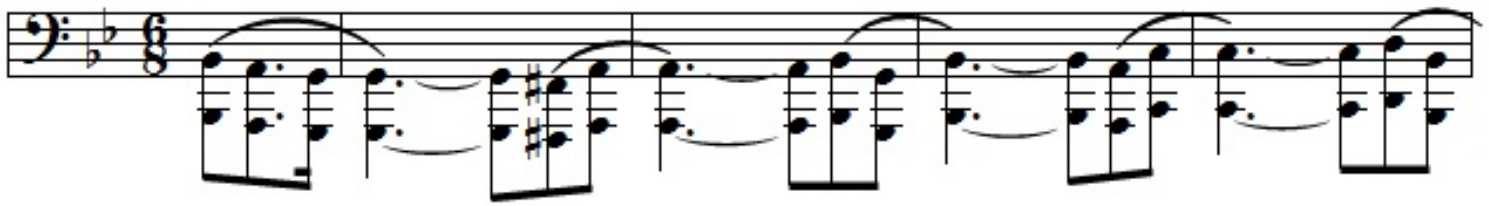

Example 3.12: Left hand phrase markings

The direction of the phrase should push towards the end of the slur, and then release, starting over with each new slur marking. In this example, the slur ends on a long note, ideal for the release of all physical tension. The two eighth notes preceding the downbeat long notes should be played as an upbeat figure. Beginning in measure 16 there are no slur markings indicated until

\footnotetext{
${ }^{74}$ Constantin Piron, L'Art du piano, (Paris: Arthème Fayard, 1949), 115, quoted in quoted in Jean-Jacques Eigeldinger, Chopin, Pianist and Teacher: As seen by His Pupils, 31. This quote of Chopin's came from his student Georges Mathias, passed on to Piron who published it in L'Art du piano.
} 
the return of the opening material in measure 34. A downward rush of octaves is presented multiple times (see Example 3.13).

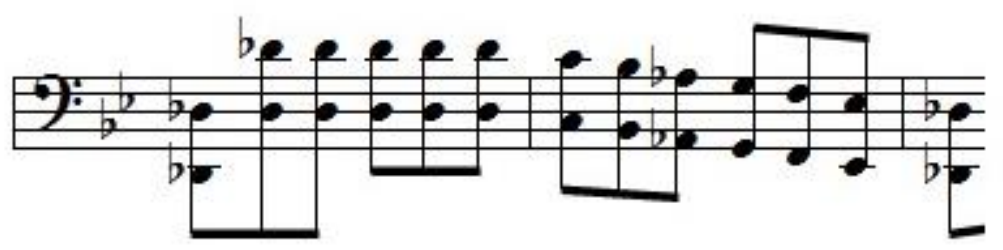

Example 3.13: Prelude No. 22, G minor, mm. 17-18, left hand descending octaves

These descending octaves should be played with the momentum of the arm weight being thrown to the left, while the wrist executes a quick motion as if dribbling a ball, rising as little as possible from the keyboard. This is the same principle of repeated notes and octaves of which Chopin said, “don't leave the key, but simply let the finger be softly pushed back up by the key itself." 75

As the entire prelude is indicated to be played at varying degrees of forte, it is important to plan out a long-range dynamic contour and not begin too loudly. Additionally, one should not rely on force to achieve a louder dynamic; striking the keys harder will only produce a harsh, less resonant sound. Instead, rely on full release of arm weight and playing fully into the keys to produce the desired dynamic range.

The right hand is completely different from, though complimentary to, the left hand and requires complete hand independence. The movement required for the right hand punctuations

\footnotetext{
75 Anonymous, Conseils aux jeunes pianists, (Paris: Fischbachre, 1904), 38, quoted in quoted in Jean-Jacques Eigeldinger, Chopin, Pianist and Teacher: As seen by His Pupils, 41. This advice was published in an anonymous booklet of indications given during lessons by Madame Charles Picquet, the neice of Auguste Franchomme, a cellist-composer and friend of Chopin. Picquet gathered many elements of the Chopin tradition, particularly through Franchomme, including the passage referenced here.
} 
throughout is a down-up motion, encompassing the three and two note gestures (see Example 3.14).

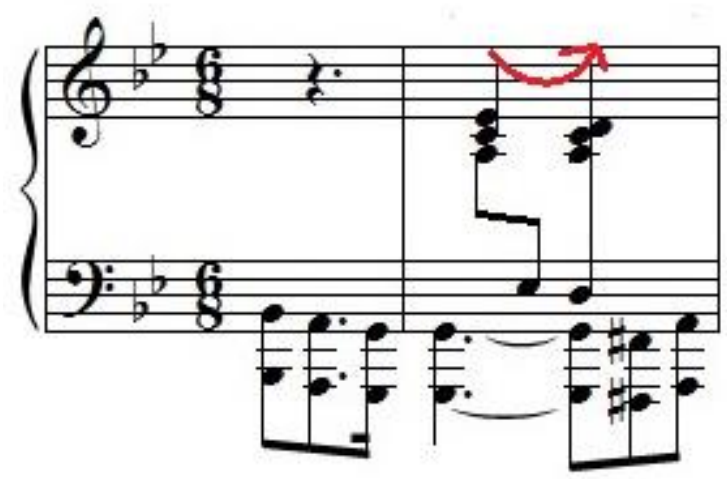

Example 3.14: Right hand down-up motion

At the beginning of the prelude this is not a problem, as the right hand gestures are executed during held notes in the left hand line. However, beginning in measure 13, as the left hand line becomes more active the necessity of hand independence is more pronounced. The movements of the hands must be coordinated. This is most easily done by isolating instances where the hands must execute opposing gestures. For instance, in measure 13:

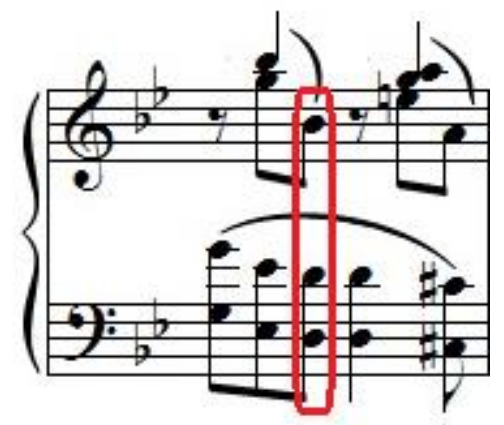

Example 3.15: Prelude No. 22, G minor, m. 13, right hand finishing a gesture while the left hand continues

In this example, on the third eighth note, the right hand is releasing a gesture while the left hand must continue the melodic line without a full release. Practice by stopping on the third eighth 
note, being sure the left hand remains on the keys, free of tension, while the right hand comes up. It is helpful in the beginning to exaggerate the upward motion. Eventually the right hand, while releasing upward, will remain close to the keys for its next entrance.

While many of the advanced preludes contain similar technical requirements to the intermediate preludes, they are at a higher level of difficulty. The advanced preludes can provide students with the opportunity to hone advanced technical skills through short, vignette-like pieces that are not time consuming and are a lot of fun to play. 


\section{Chapter Four \\ Very Advanced Preludes ${ }^{76}$}

The Op. 28 preludes that require the most advanced technique and are thus appropriated for very advanced students meet at least one of the following criteria: 1) multiple technical challenges are present or 2) one or more technical challenges are presented at a tempo which renders execution very difficult. ${ }^{77}$ These preludes require considerable technical skill, and are all suitable as technical studies for students with fully grown hands.

A variety of technical challenges are found within this group of preludes. Prelude in D major, No. 5, marked allegro molto, presents leaps, and double notes which must be voiced appropriately and are constantly changing direction. This prelude requires much study and thought to be executed with clean technique and musical clarity. Prelude No. 8 in F\# minor is a whirlwind of right hand figuration and cross-rhythms. The presto G\# minor prelude, No. 12, contains left hand leaps and octaves while the right hand contends with repeated notes and double notes. The B-flat minor prelude, No. 16, marked presto con fuoco, presents sweeping and chromatic right hand figuration in sixteenth notes that must be coordinated with left hand leaps. Prelude No. 18 in F minor is distinctly unique. Mimicking an opera recitative there is a dialogue between declamatory and punctuating passages. The presentation of passagework in both hands simultaneously requires extreme control of hand coordination. ${ }^{78}$ The E-flat major prelude, No. 19 , is a study in perpetual motion. The constant triplets of this prelude are made even more difficult by the leaps and stretches interspersed throughout the figuration and the vivace tempo indication. Finally, Prelude No. 24 in D minor is a perfect culmination to the set with a dramatic

\footnotetext{
76 "Very Advanced" is used here to indicated degree of technical difficulty among Chopin's Preludes Op. 28 only. ${ }^{77}$ Refer to Appendix, page 73, Table 1 for a list of Very Advanced Preludes.

${ }^{78}$ The hand coordination required for Prelude No. 18 in F minor is similar to, though more advanced than, the technique detailed in the Chapter Two discussion of the E-flat minor Prelude, No. 14. The practice techniques given in Chapter Two, pages 12-17, are also appropriate for use with the F minor Prelude, No. 18.
} 
presentation of several technical elements. These include: left hand figuration with stretches, rapid scales and arpeggios in the right hand, and double thirds. The following discussion will focus on Preludes 8, 12, 19 and 24.

Prelude No. 8 in F\# minor is “one of the most glorious of all Chopin's short pieces... It is a virtuosic piece... [and] it must shimmer and surge, the 'little' notes flying clearly and freely..."79 The "little notes" referenced by Bailie are shown in Example 4.1 below. At the tempo of molto agitato the right hand presents a melodic line in the thumb while the rest of the hand is responsible for this swirling figuration. Against this flurry of notes a triplet motif is posed in the left hand, a cross-rhythm on the first half of each beat. This pattern is repeated without break or repose over the course of two and a half pages, ${ }^{80}$ and the "tumultuous onward movement from first note to last requires considerable technical stamina and endurance of spirit." 81

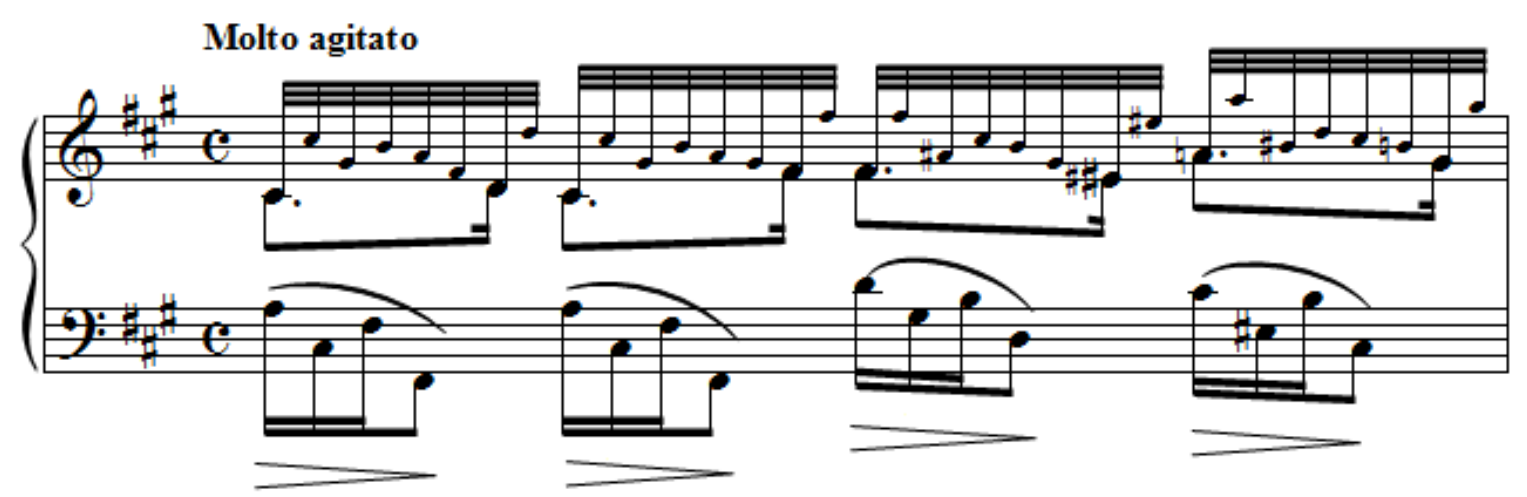

Example 4.1: Prelude No. 8, F\# minor, m. 1

First, the left hand should be practiced alone. Each group is marked with a slight decrescendo, implying an emphasis, or leaning, on the first note of the group which brings out a counter-melody in the left hand thumb. The whole figure should be treated as "an overall slurred

\footnotetext{
${ }^{79}$ Eleanor Bailie, Chopin: A Graded Practical Guide, (London: Kahn and Averill, 1998$), 82$.

${ }^{80}$ The Henle edition of the Preludes is referenced here.

${ }^{81}$ Bailie, 82.
} 
effect down to the lower quaver, ${ }^{, 82}$ and executed in one physical gesture. The wrist should work in a combination of down/up and left/right motions. The wrist will move down and to the left to execute the pattern, then slightly up and right to come back to position to execute the successive note group. The combination of motions becomes an outward circular pattern in the context of performance (see Example 4.2).

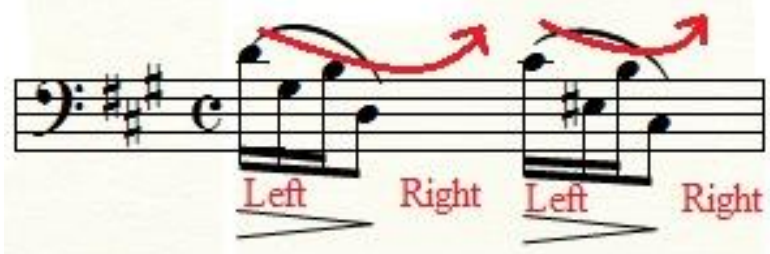

Example 4.2: Combination down-up and left write wrist motion

The right hand figuration may appear daunting, but there are several different ways to practice the patterns to attain stability and accuracy. First, group the notes into chords on each half beat (see Example 4.3). Cognitively, this creates logical groups of material to deal with rather than an unintelligible strand of individual notes. Physically, this allows the hand to settle into familiar positions and learn the general shape of the pattern. Aurally, this solidifies the harmonies created and allows the ear to absorb and remember them.

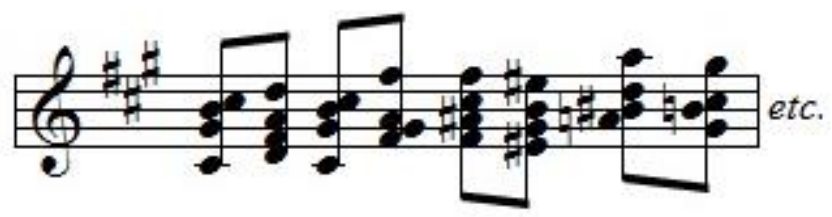

Example 4.3: Right hand pattern in block chords ${ }^{83}$

Once chordal practice feels comfortable and a suitable level of familiarity with a passage has been attained, practice the pattern as written, playing the thumb mezzo piano and the rest

\footnotetext{
${ }^{82}$ Bailie, 82 .

${ }^{83}$ Bailie, 82 .
} 
pianissimo. This exercise will help achieve the proper balance of the hand, the weight of which should be on the thumb. A good check for this is to play and hold the thumb then wave the rest of the hand, releasing any accumulated tension. Bailie suggests practicing thus:

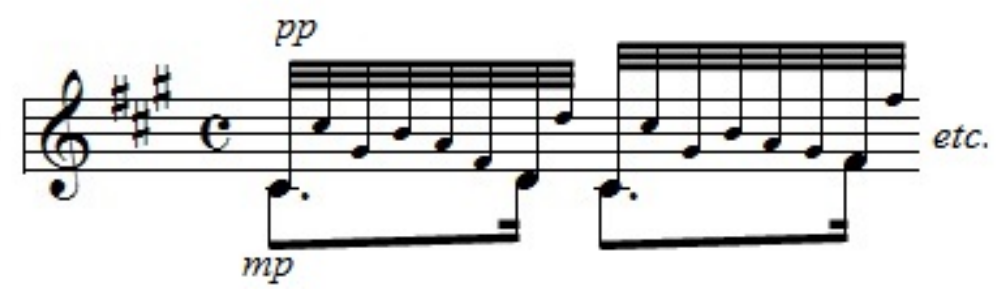

Example 4.4: Practice thumb $m p$ and the little notes $p p^{84}$

She also recommends practicing in the following rhythmic patterns:

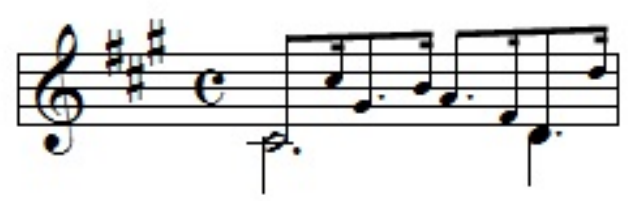

and

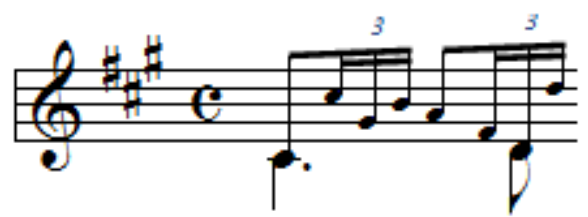

Example 4.5: Rhythmic patterns for practicing ${ }^{85}$

It may also be advantageous to practice stopping on each sixteenth note of the melody (see

Example 4.6).

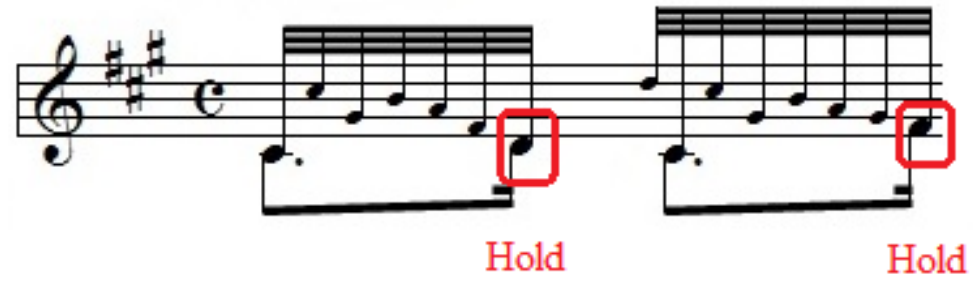

Example 4.6: Pause on the sixteenth note of the melodic line

${ }^{84}$ Bailie, 82 .

${ }^{85}$ Bailie, 82. 
The overall motion of each beat should be a combination of down/up and right/left, the mirror opposite of the left hand (see page 43, Example 4.2 for the discussion of the left hand/wrist motion).. ${ }^{86}$ The natural tendency when bringing out the melody will be to play each melody note in a downward striking motion to lend volume to line. Stopping on the sixteenth note in the thumb will help to make sure that this is being played up instead of down. This treatment makes it possible to bring out the melody while guarding against the build-up of tension in the hand.

When putting the hands together, it is important to have a firm sense of the rhythmic pulse, both at the quarter note and eighth note subdivisions. First, practice the right hand thumb with the left hand figure in strict time (see Example 4.7). The lowest note of the left hand pattern falls precisely on the second half of the beat. It is important to give the sixteenth note of the right hand its full value; it should feel like a duple hemiola after the triplet of the left hand.

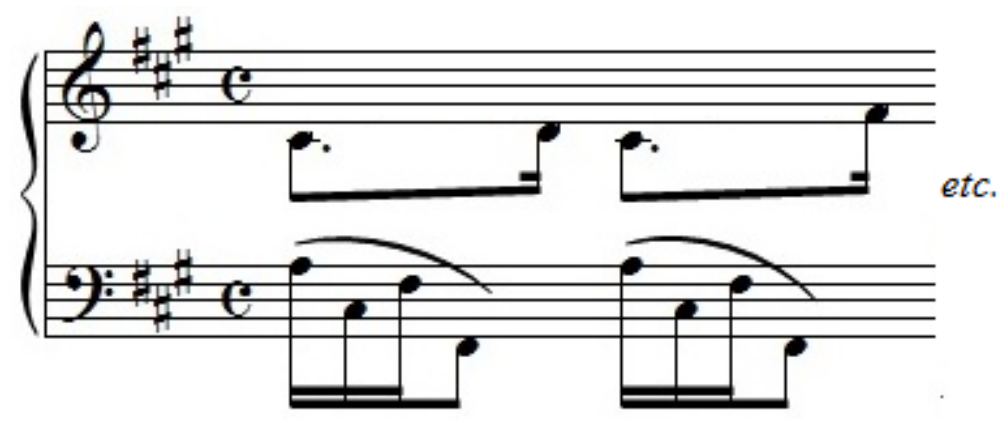

Example 4.7: How to practice right hand thumb and left hand together in strict time ${ }^{87}$

When adding the rest of the right hand notes, it is helpful to know which note of the right hand figuration aligns with the bass note on the second half of the beat (see example 4.8).

\footnotetext{
${ }^{86}$ The hands should both be making outward circular motions, coming back towards one another in a downward motion at the beginning of each figure.

${ }^{87}$ Bailie, 83 .
} 
Making sure that these notes sound together is essential to the successful execution of the crossrhythm. Practice by stopping on the second half of each beat to be sure of the proper alignment of notes.

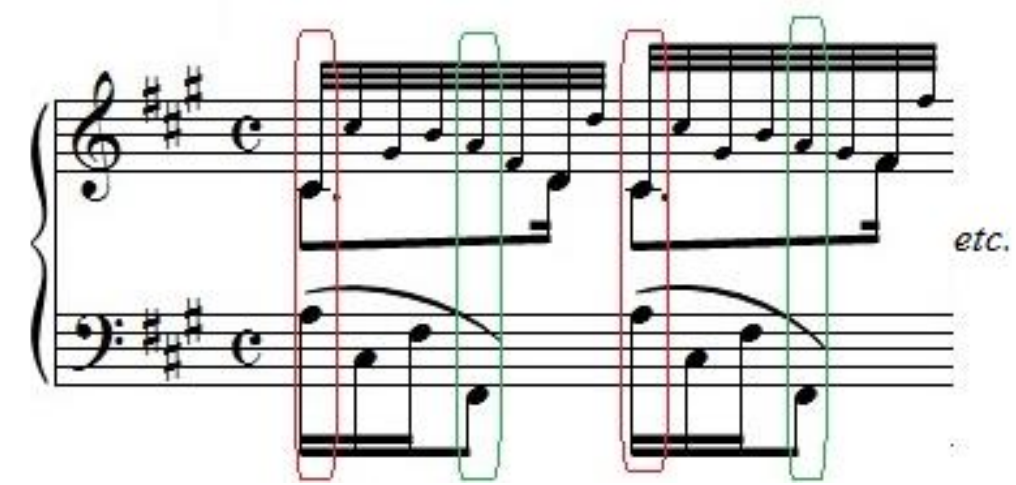

Example 4.8: Notes which are played together between the right and left hands

Bailie recommends practicing very slow, gradually increasing in tempo as the figure becomes comfortable. ${ }^{88}$ However, it may be easier to feel the cross-rhythms and proper arm/wrist motions by practicing small amounts of material at performance tempo, then gradually increasing the amount of material performed in succession. ${ }^{89}$ Having a good aural sense of the cross-rhythm is also useful; listen for the second $32^{\text {nd }}$ note of the right hand pattern to be played before the second note of the left hand sixteenth note triplet - the rest of the notes in the pattern should clearly fall into place after this. Memorization will also make execution of this prelude easier.

Prelude No. 12 in G\# minor is as technically challenging as any of the etudes Chopin composed. Bailie says:

It is a fearsome piece, both in its technical demands, and in its vicious hectoring spirit. Nevertheless, as in the case of some of the most virtuosic of the Studies, it is one from

\footnotetext{
${ }^{88}$ Bailie, 83.

${ }^{89}$ For instance, one might begin by practicing eight quarter notes individually at performance tempo. Then, practice the same material in four groups of two beats length, then two groups of four beats length, finally putting an entire eight beats (two measures) together at performance tempo before moving on to another section.
} 
which the competent sub-virtuoso player can profit, at least from the study of just a few bars. $^{90}$

Each hand by itself requires significant technical mastery. For most of the piece the left hand propels the right hand forward with an insistent leaping octave pattern, while the right hand contends with repeated and double notes (see Example 4.9).

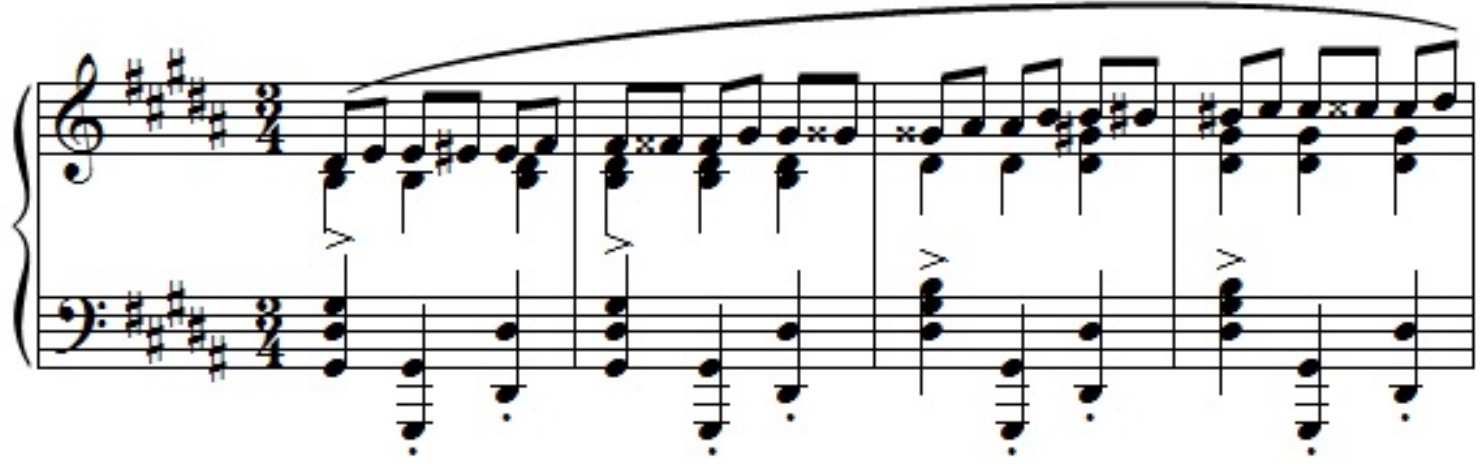

Example 4.9: Prelude No. 12, G\# minor, mm. 1-4

First, the left hand should be practiced alone. The combination of octaves, leaps, and chords can be quite daunting. Start by practicing the thumb alone with the rest of the hand in a loose fist, allowing the hand to be relaxed while getting acquainted with the distances of the leaps. When it is comfortable, add the remaining notes.

Using the appropriate arm and wrist gestures is essential to executing the left hand properly. First, as in the opening, group the beats across the bar, from beat 2 to the downbeat of the following bar in a single gesture (see Example 4.10).

\footnotetext{
${ }^{90}$ Bailie, 89.
} 


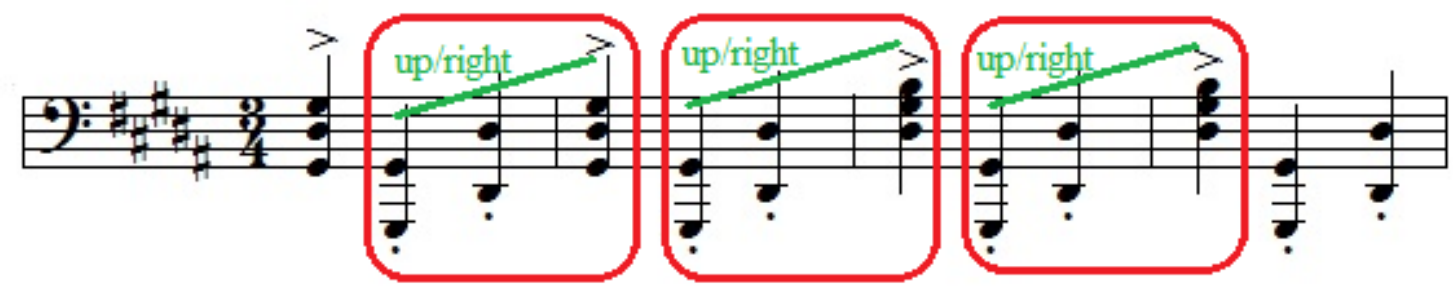

Example 4.10: Group left hand from beat two to following downbeat; perform with a single gesture

This grouping allows for a single upward (to the right) arm gesture, as opposed to two gestures in a bar (down then up) if each measure was grouped independently (see Example 4.11).

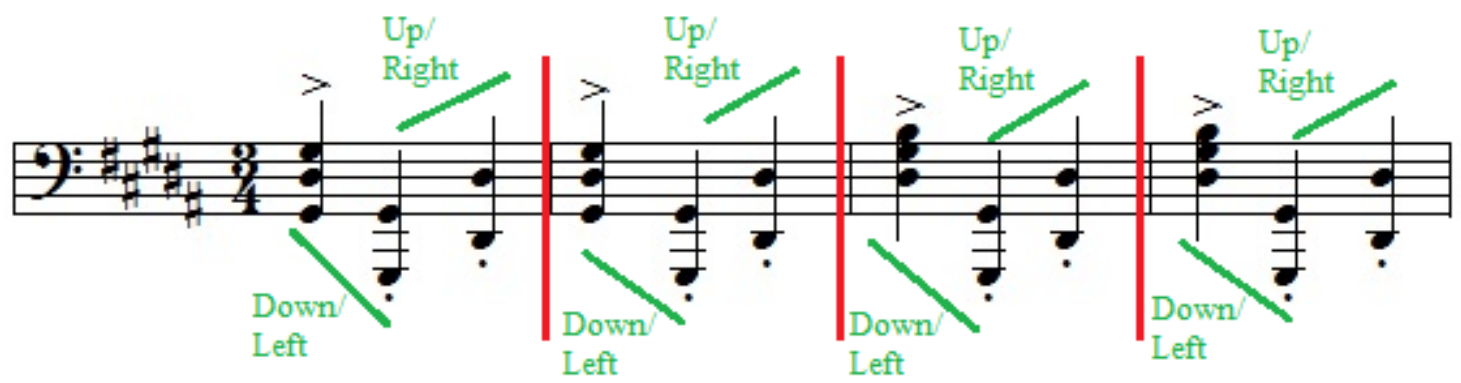

Example 4.11: Grouping by the measure resulting in two separate motions

Grouping across the bar is indicated in the score by Chopin's articulation markings. The second and third beats are staccato, leading to the downbeat which is accented (see Example 4.10).

Second, as in mm. 5-6, the middle of the hand should be used as a pivot to laterally move the wrist in a left-to-right motion (see Example 4.12).

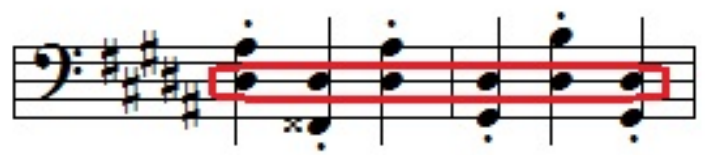

Example 4.12: Chopin Prelude No. 12, G\# minor, mm. 5-6 left hand

Use the middle of the hand as a pivot, in this instance on D 
Keeping to hand and wrist on a lateral plane will accommodate economy of motion, making it possible to play this type of passage with more ease and speed than if the hand is allowed to jump vertically.

The technique required of the right hand is completely different than that of the left hand; complete hand independence is necessary. The right hand pattern is fairly consistent throughout. Bailie suggests that the eighth notes should be treated as slurred couplets (see Example 4.13). ${ }^{91}$

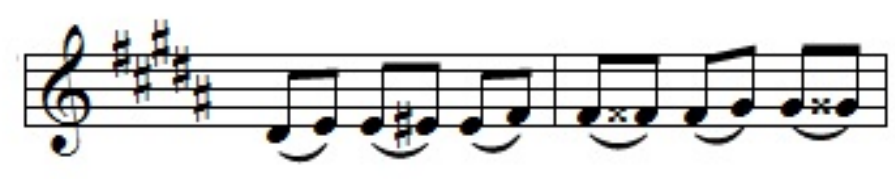

Example 4.13: Treatment of eighth notes as two-note slurs ${ }^{92}$

However, Chopin's markings do not indicate this. In fact, there is only a single slur marked over the first seven measures. While Bailie does acknowledge this, and tries to modify her two-note slur approach to accommodate the lengthy slur, her approach is not endorsed here. The two-note slur requires a down-up wrist motion, which wastes both time and energy in the presto passages, only serving to fatigue the performer over the course of the piece. Bailie argues that the slight release of tension with the up motion is essential to remaining relaxed; ${ }^{93}$ however, an alternative method is suggested.

The key to the right hand passage is to allow the weight of the hand to be on the thumb, leaving the rest of the hand (which is dealing with the faster and repeated notes) free to move lightly. Also, in direct contrast to Bailie's approach, it is suggested that the eighth notes be grouped according to repeated pair (see Example 4.14).

\footnotetext{
${ }^{91}$ Bailie, 89. Some editions have two-note slurs marked by the editor. It is suggested that an Urtext edition such as the Henle edition is used to avoid confusion.

92 Bailie, 89.

${ }^{93}$ Bailie, 89-90.
} 


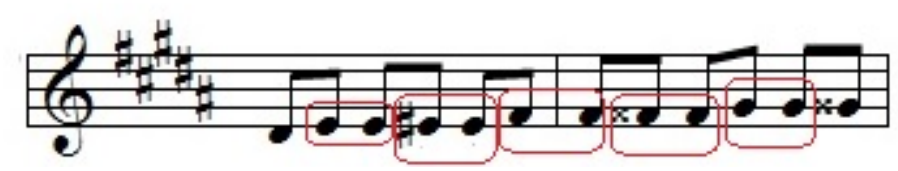

Example 4.14: Group repeated eighth notes together across the beat

Practice the upper notes alone first, in the following manner:

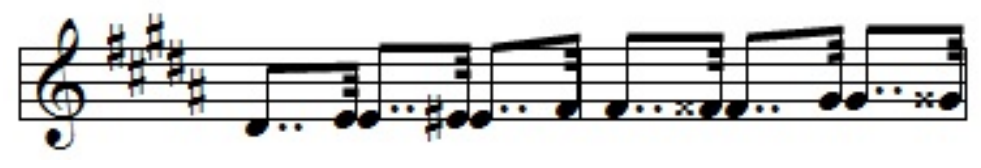

Example 4.15: Rhythmic pattern for practice of eighth notes

While the exact rhythm notated here is not the goal, the grouping of repeated notes in a shortlong fashion is. The repeated notes should be played together as quickly as possible, pausing on the second note to release any accumulated tension. Keep the hand as close to the keys as possible, eliminating any unnecessary down-up movement. Once the exercise is comfortable, add the lower notes, being sure to balance the weight of the hand on the thumb. Play the upper notes in the same rhythmic exercise as before, using firm but light keystrokes. When playing as written, use the repeated notes to drive the line forward, creating one long slur as indicated. The combination of proper balance of hand weight, economy of motion, and built in tension release on each beat will allow for tension-free performance of the right hand passage. When putting the hands together, allow the left hand to propel the right hand forward.

Prelude No. 19 in E-flat major is a "seraphic but highly exacting piece... [having] the happy spirit of many of the Studies, as well as that pursuit of a single technical pattern common 
to most of Ops. 10 and 25." 94 As with G\# minor, No. 12, this prelude is appropriate for less advanced students to study under tempo, or even just a few bars, to get a feel for the technique.

The entire piece is comprised of eighth note triplets in perpetual motion, marked vivace in tempo. The most difficult aspect of the pattern is that wide leaps are required by both hands at a very quick tempo (see example 4.16).

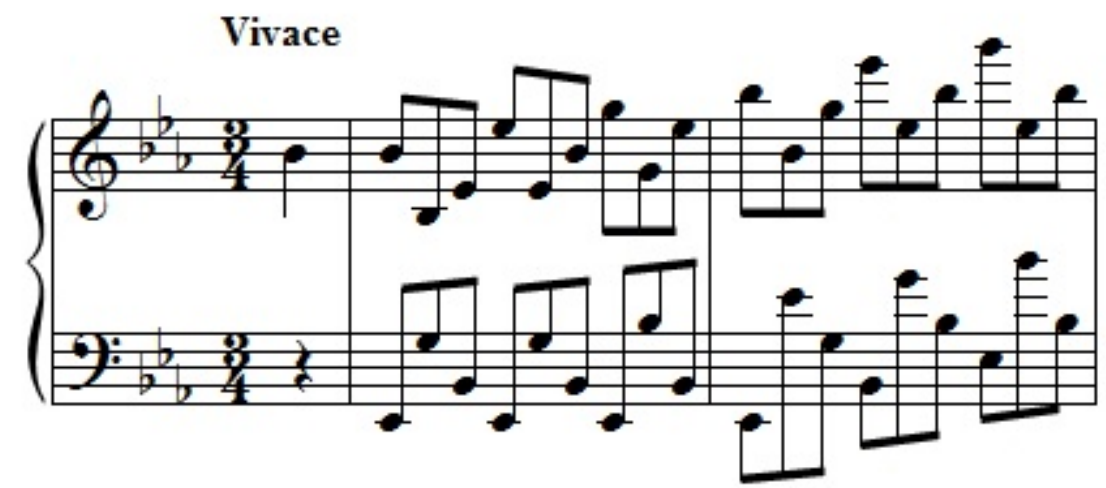

Example 4.16: Prelude No. 19, E-flat Major, mm. 1-2

Fundamental to the success of this prelude is a mastery of the physical movement required by the technique. It is very advantageous to memorize a few bars at a time and then focus on the physical approach to performing them while looking at the hands.

The approach to technique for each hand will be the same. The notes should be grouped from the second eighth note to the following downbeat (see Example 4.17).

\footnotetext{
${ }^{94}$ Bailie, 104.
} 


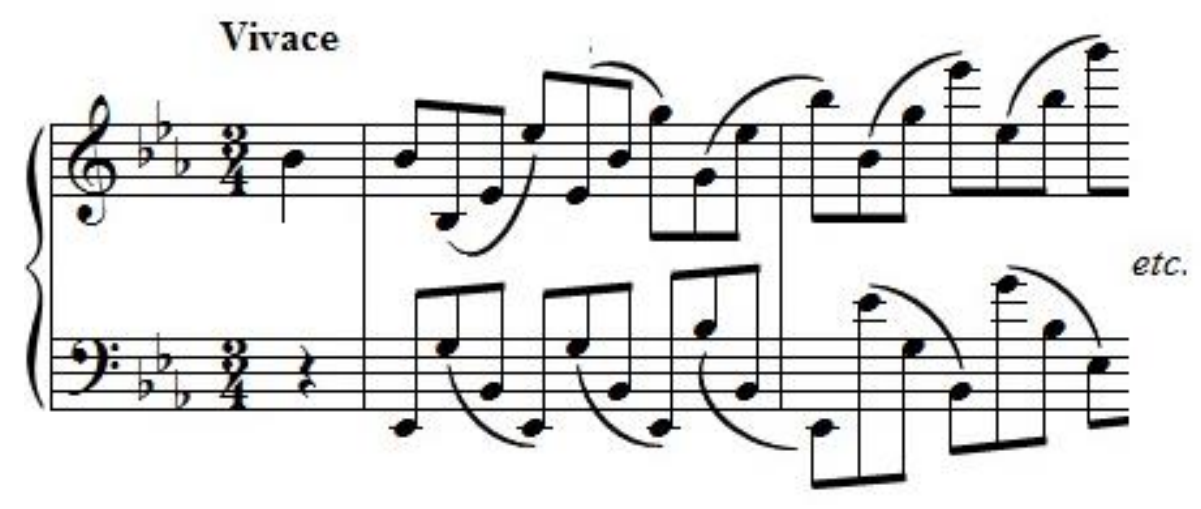

Example 4.17: Group eighth note triplets across the beat

This grouping allows for one physical gesture for the group; the left hand is a combination of down/left for the wrist, the right hand is a combination of down/right. Also, this allows the performer to let go before the leap between note groupings and reset the hand/wrist for the next gesture. It is important to let go before executing the leap; to hold on will cause tension and potentially an injury. Practice the groups in different rhythmic patterns. The most beneficial will be to play the first two notes quickly, pausing on the third. Then let go and reset before starting the next group (see Example 4.18).

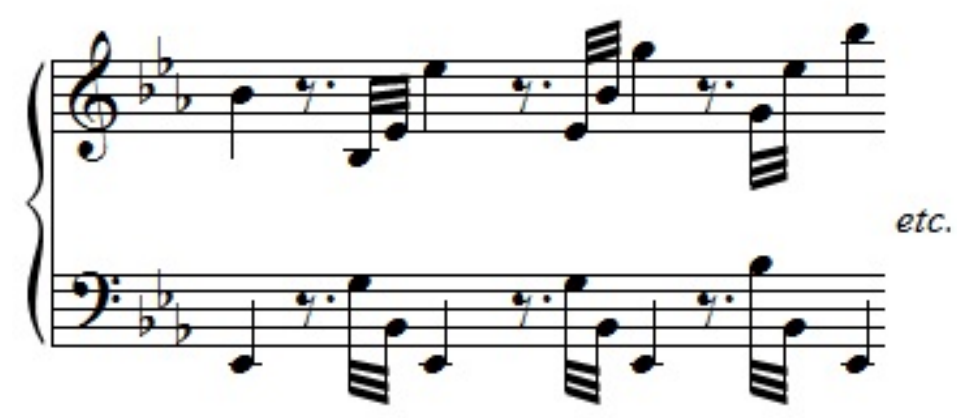

Example 4.18: Rhythmic practice for eighth note triplet groups

Bailie suggests that the right hand should be grouped thus: ${ }^{95}$

\footnotetext{
${ }^{95}$ Bailie, 104.
} 


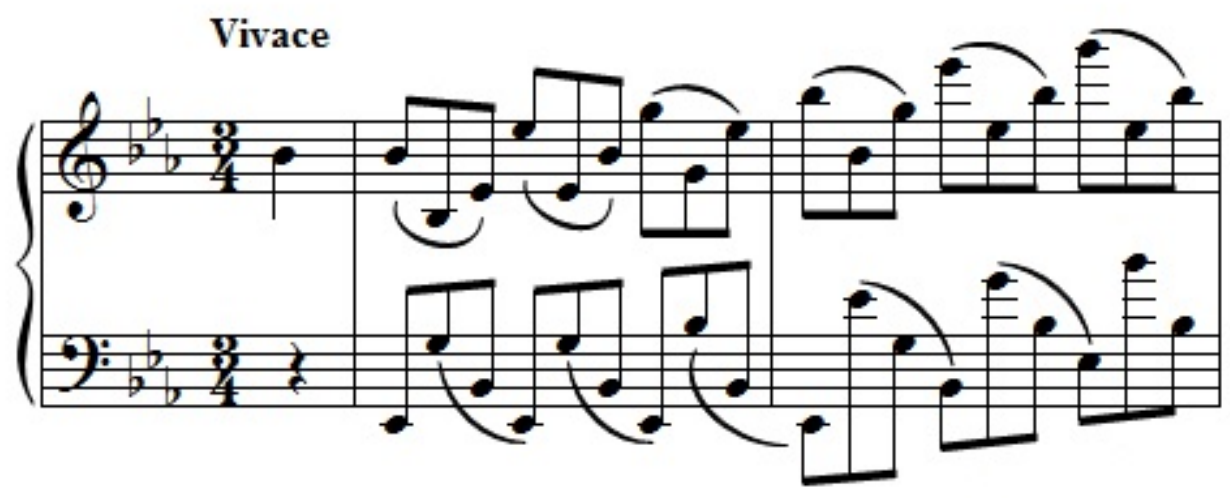

Example 4.19: Eleanor Bailie's suggestion for note grouping

This approach is not endorsed here, as the right hand requires changing the motion of the wrist/hand in the middle of the group, thus making execution inherently slower as well as creating tension. The right hand grouping is also not in sync with that of the left hand, causing coordination issues between the hands (see page 51-52, Example 4.17 and the corresponding discussion for grouping recommended by the author).

When practicing, be sure to keep the hands as close to the keyboard as possible, moving on a horizontal plane rather than vertically. The wrists perform shallow outward circular arcs from one gesture to the next. When the hands are played together the wrists will move first away from each other, then back in to reset for the next group. Care should be taken not to land heavily on the second eighth note (the beginning of the gesture) or the momentum of the hand/wrist will be interrupted. It is better to land lightly and then build through the gesture to the highest/lowest notes of the group.

One final suggestion to facilitate the technique of Prelude No. 19 in E-flat major is to consider the third eighth note of the beat, the second note when grouped as suggested above, as the pivot. Depending on the intervals and the performer's individual hand, the second or third finger is responsible for playing this note. Using it as a pivot for the hand/wrist is in keeping with 
what is considered to be Chopin's "particular physiological discovery: in covering distances on the keyboard, the central pivoting finger is not the third, but the index finger." ${ }^{\prime 96}$ From this idea he derived many innovative techniques, including simultaneous extensions in both hands, exemplified in this prelude.

The final prelude, No. 24 in D minor, has dramatic impact and is especially suited as the conclusion of the set. Marked Allegro appassionato, it is often played too fast, more of a Presto con fuoco. Better is the sense of an immense building power that comes with a steady and determined tempo. The prelude makes "enormous demands... upon the technique and stamina of the player. ${ }^{.97}$ Unlike the Etudes, this prelude has a number of technical demands, and is more in line with a concert show piece than a study.

The left hand presents a constant, relentlessly forceful pattern throughout, introduced in the first two measures, which covers the range of an octave plus a fifth (sometimes an octave plus a sixth) on the keyboard (see Example 4.20).

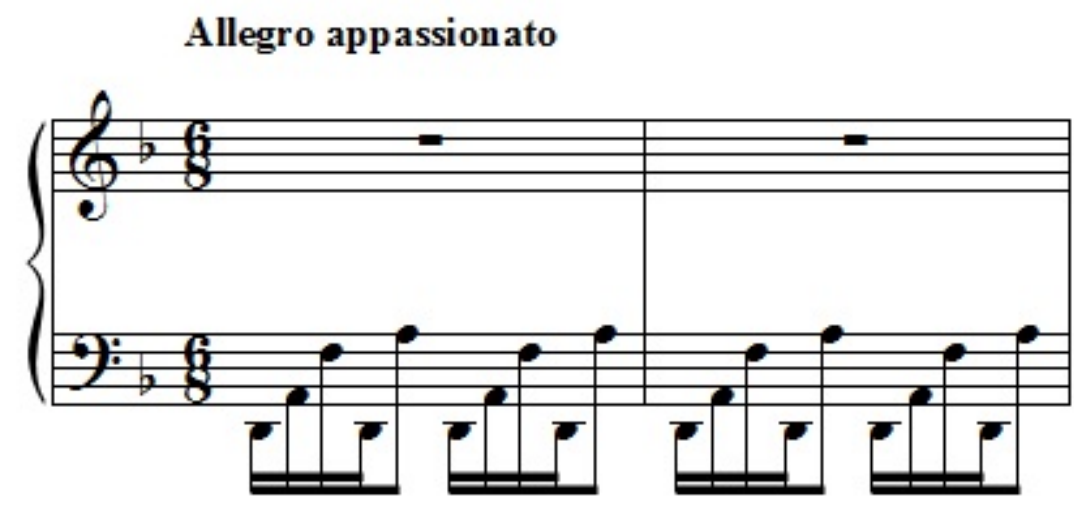

Example 4.20: Prelude No. 24, D minor, mm. 1-2

\footnotetext{
${ }^{96}$ Jean-Jacques Eigeldinger, Chopin, Pianist and Teacher: As seen by His Pupils, ed. Roy Howat, trans. Naomi Shohet, Krysia Osostowicz and Roy Howat (New York: Cambridge University Press, 1986), 18.

${ }^{97}$ Bailie, 113.
} 
As mentioned in the discussion of Prelude No. 19 in E-flat major, the index finger is an important pivot here. Pivoting around the index finger creates a reference for the distance of the leaps. It also helps in keeping the hand close to the keyboard and using as little motion as possible to execute the leaps. The pattern can be very tiring if one allows unnecessary movement of the hand, wrist, and arm. The main outline of the pattern is the movement from beat one to beat three, then beat four to beat six (see Example 4.21).

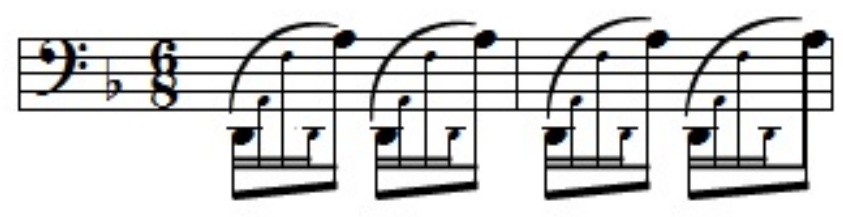

Example 4.21: Outline of left hand gesture Emphasizes beats one and three, then four and six

The notes in between these two are of somewhat lesser importance. In executing the pattern it is helpful to push off the first beat, using it as a kind of springboard to propel the hand upward to beat three, playing the intervening notes as lightly as possible.

The right hand begins with a relatively simple, yet impassioned melodic line, moderately embellished. However, beginning in measure 14 there is a series of rapid scalar and arpeggiated passages in tuplet rhythms (see Example 4.22). ${ }^{98}$

\footnotetext{
${ }^{98}$ Tuplet refers to a "temporary increase or decrease in the number of notes subdividing a beat from what is standard for a given time signature. Tuplets are usually notated with a numeral or ratio that indicates the number of notes to be performed within the beat." "Tuplet," Oxford Music Online, accessed February 4, 2014, http://www.oxfordmusiconline.com.www.libproxy.wvu.edu/subscriber/article/grove/music/ 2233258?q=tuplet\&search=quick\&pos=1\&_start=1\#firsthit.
} 


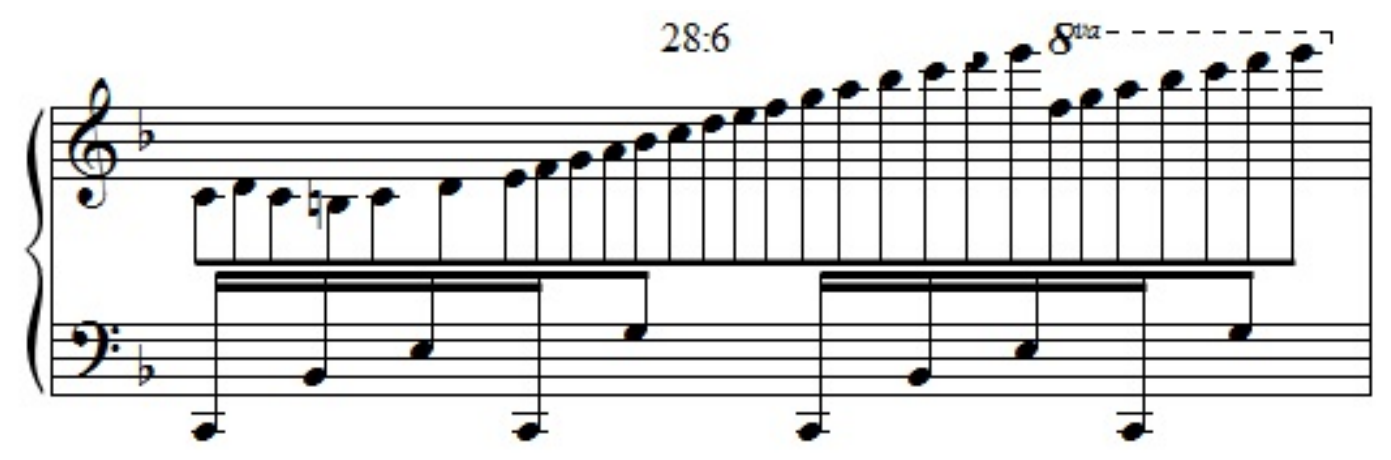

Example 4.22: Prelude No. 24, D minor, m. 14 tuplet rhythm

Ideally, in these passages each hand would be completely independent from the other, each maintaining its own rhythmic pattern. In practice, this is not so easily done. When learning this prelude it is best to decide which notes of the right hand will correspond with notes of the left hand. The number of notes in each group will not be the same; however at a fast tempo this will not be overly noticeable. Practice the passage slowly to become comfortable with the coordination of the hands and then gradually increase the tempo up to performance speed.

Measures 55 and 56 present one of the most difficult piano techniques: fast chromatic thirds (see Example 4.23). 

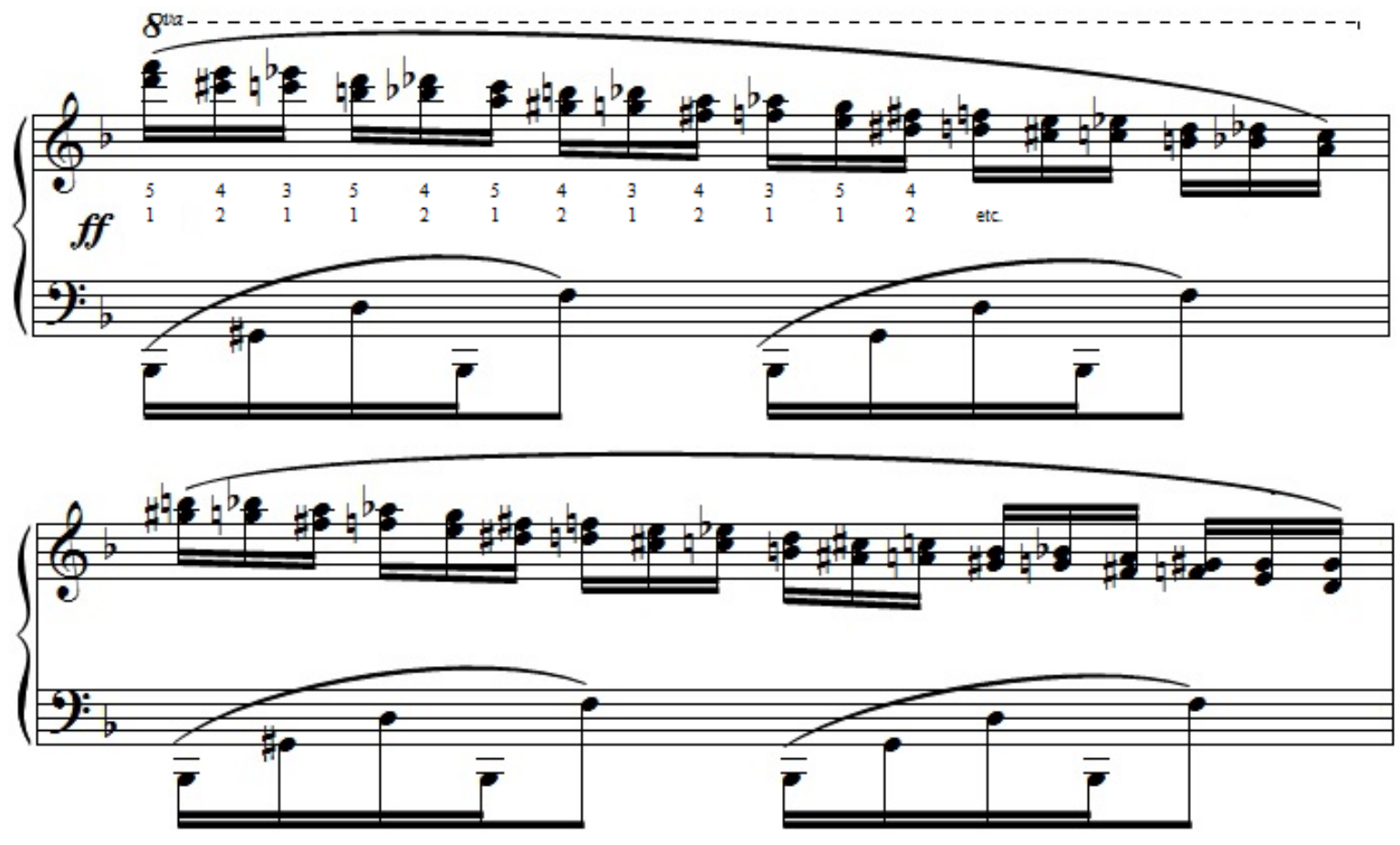

Example 4.23: Prelude No. 24, D minor, mm. 55-56 ${ }^{99}$

Successful execution of this passage is largely dependent upon using a comfortable fingering.

Chopin was highly innovative in his use of fingering, not hesitating to break with the Classical traditions in order to achieve "the most comfortable succession of fingers, best suited both to the form of the hand and to conveying the musical discourse." ${ }^{\prime 100}$ Among his many innovations concerning fingering, the one that is most relevant here is letting the third, fourth and fifth fingers cross over one another in chromatic passages. The top notes of the chromatic thirds will be played with these three fingers, the bottom notes with fingers one and two. Allowing the upper fingers to cross freely over (or under) one another will facilitate a smooth line, and enable faster playing.

\footnotetext{
${ }^{99}$ Fingering shown is that used by the author.

${ }^{100}$ Eigeldinger, 19.
} 
All the techniques described here will challenge even the most advanced of pianists.

Study of any preludes listed here as very advanced will enhance the technical skill of any student when care is taken to cultivate a proper physical approach to the piano, even if only studied in part and under tempo. 


\section{Chapter Five}

\section{Comparison of the Preludes Op. 28 with other Chopin Works}

Almost every aspect of Chopin's style is found among the Preludes, and a wide range of technical benefits can be gained from their study. Several of the Preludes can be appropriately utilized as introductory pieces to or substitute pieces for other commonly used teaching pieces in Chopin's oeuvre, such as the Nocturnes and Mazurkas. The following will be a discussion of the applicability of this idea, with particular emphasis on how the Preludes can be used to augment the study of the Etudes Opp. 10 and 25.

Chopin's Nocturnes are often used as teaching pieces. The Henle and Vienna Urtext editions both contain 21 nocturnes, spanning nine opus numbers plus one posthumous work. Composed between 1830 and $1847^{101}$, Chopin wrote in the genre throughout his career. The nocturnes contain some of Chopin's most "personal and innovative writing."102 The melodic bel canto style is highly pervasive throughout these pieces. Jim Samson writes:

He had of course borrowed the title, and to a large extent the manner also, from John Field and, like Field's, his nocturnes eschew any obvious virtuosity in favour of an expressive, reflective lyricism. The nocturnes are above all character pieces, exploring many nuances within a deliberately restricted affective range, most often nostalgic, languid, consolatory, the music of a sad smile. ${ }^{103}$

The technical challenges involved in convincingly performing a nocturne include flowing, accompanimental left hand patterns, and bel canto, singing right hand melodies which undergo constant transformation through different ranges and rhythmic configurations. Both of these elements are found among the Preludes.

Prelude No. 13 in F\# major is a good introductory piece in the style of a nocturne. intermediate in terms of technical difficulty among the Preludes it is easier than most of

\footnotetext{
${ }^{101}$ Jim Samson, The Music of Chopin (New York: Oxford University Press, 1994), 235-238.

102 Bailie, 299.

103 Samson, 81.
} 
Chopin's nocturnes. ${ }^{104}$ The ideas and techniques presented in the prelude are an excellent source to introduce both the musical and technical demands of the genre.

As stated above, nocturnes are generally composed in the bel canto style of melody and accompaniment. The left hand lines of Chopin's nocturnes are often smooth and flowing in a sort of repetitive pattern. Prelude No. 13 in F\# major presents an example of this (see Example 5.1).

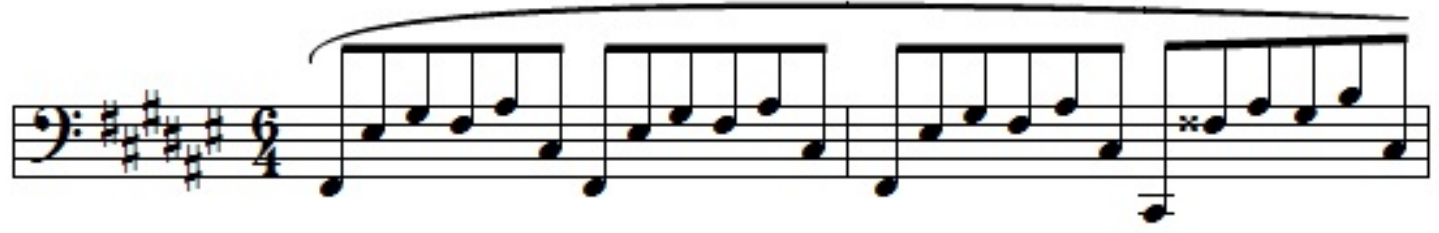

Example 5.1: Prelude No. 13, F\# major, mm. 1-2, left hand

The pattern presented in this prelude is relatively simple, teaching students the importance of proper fingering, lateral arm and wrist motions, and appropriate voicing of this type of left hand passagework against a melodic right hand line. These principles can then be applied to nocturnes with similar left hand passagework, such as Nocturne in B-flat minor, Op. 9 No. 1 and Nocturne in D-flat major, Op. 27 No. 2 (see Examples 5.2 and 5.3).

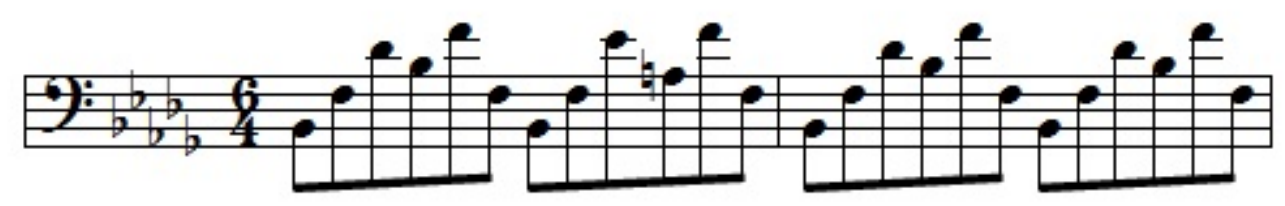

Example 5.2: Nocturne Op. 9 No. 1, B-flat minor, mm. 1-2, left hand

\footnotetext{
${ }^{104}$ Bailie, 299-384. The grading Bailie assigned to each nocturne ranges from Grade 6 to VA (Very Advanced) on her grading scale. See Preface, vi, for explanation of Bailie's grading scale. This is comparable to the Advanced and Very Advanced preludes. Bailie, 299-384.
}

Comparison of the Preludes Op. 28 with other Chopin Works - 59 


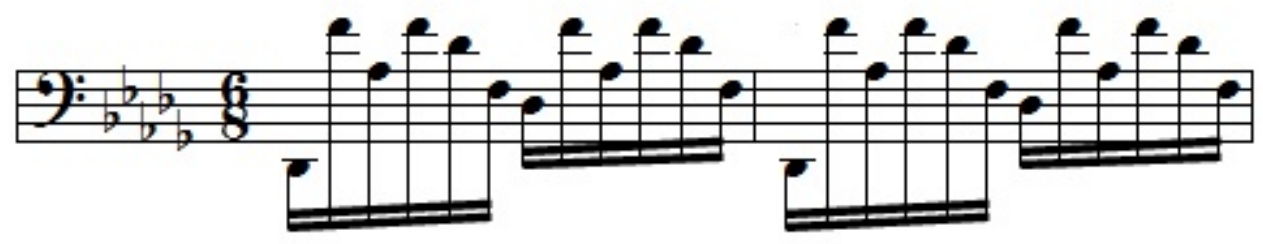

Example 5.3: Nocturne Op. 27 No. 1, D-flat major, mm. 1-2, left hand

Voicing is also a major technical demand of the nocturnes, and it is presented in several different ways in Prelude No. 13 in F\# major. The most obvious is the chordal voicing required throughout the opening of the prelude (see Example 5.4).

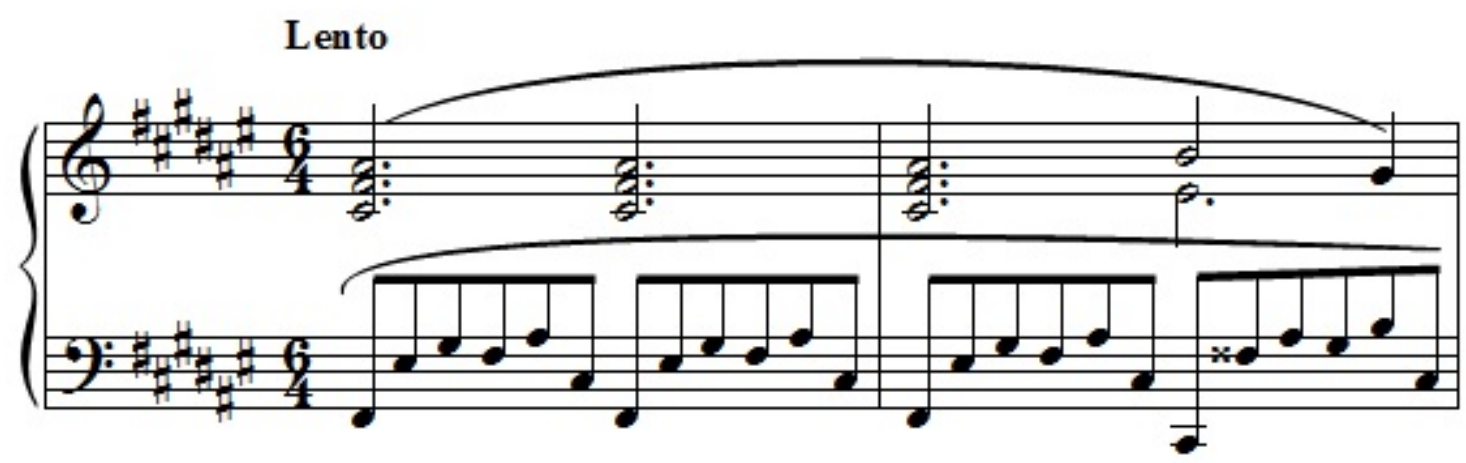

Example 5.4: Prelude No. 13, F\# major, chordal voicing of opening

This type of chordal voicing which must project a melodic line is found throughout various nocturnes, including Nocturne in G minor, Op. 15 No. 3 and Nocturne in C minor, Op. 48 No. 1 (see Examples 5.5 and 5.6).

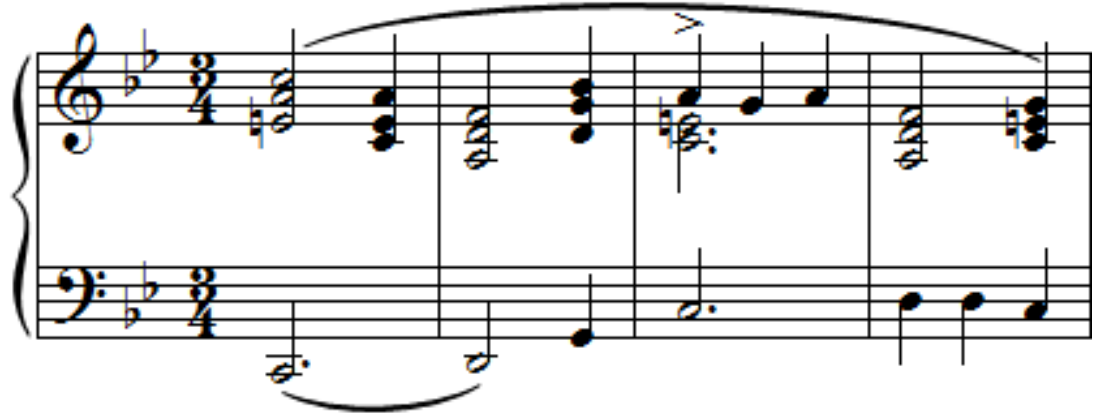

Example 5.5: Nocturne Op. 15 No. 3, G minor, mm. 89-92, chordal voicing mm. 89-92

Comparison of the Preludes Op. 28 with other Chopin Works - 60 


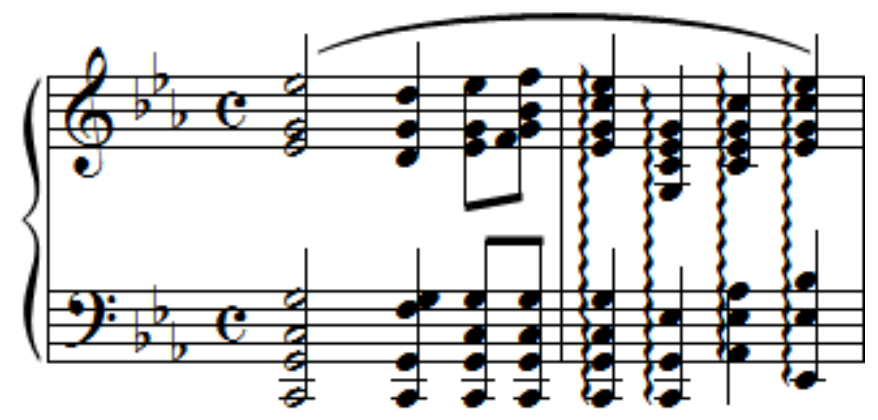

Example 5.6: Nocturne Op. 48 No. 1, C minor, mm. 30-31, chordal voicing

The voicing of melodic lines embedded within the texture of the piece is also presented in Prelude No. 13 in F\# major (see Example 5.7).

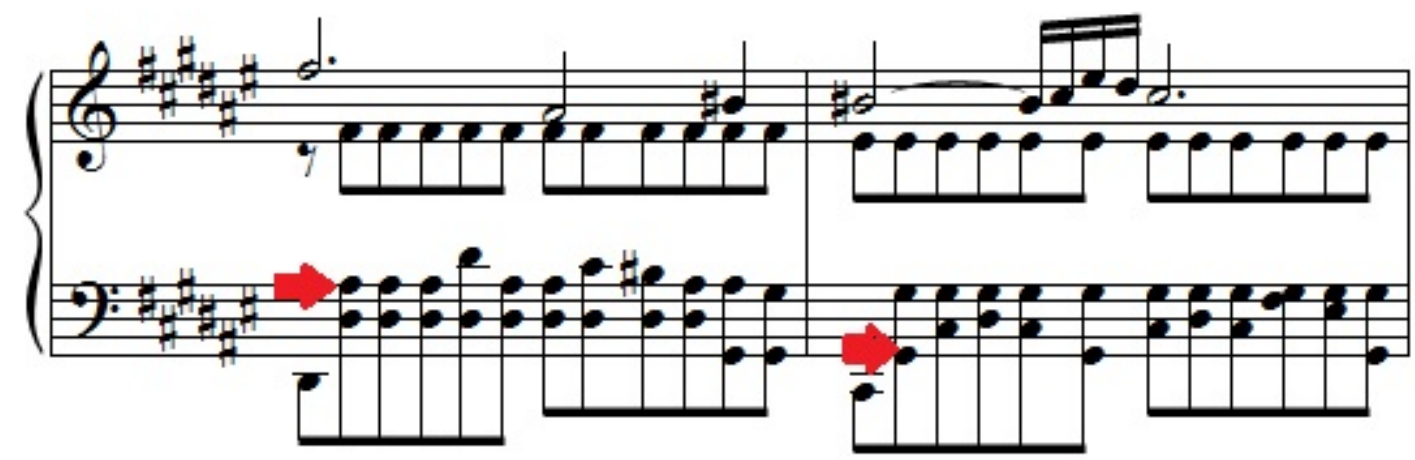

Example 5.7: Prelude No. 13, F\# major, mm. 21-22, melodic lines embedded within texture

A similar passage is found in the Nocturne in D-flat major, Op. 27 No. 2 (see Example 5.8).

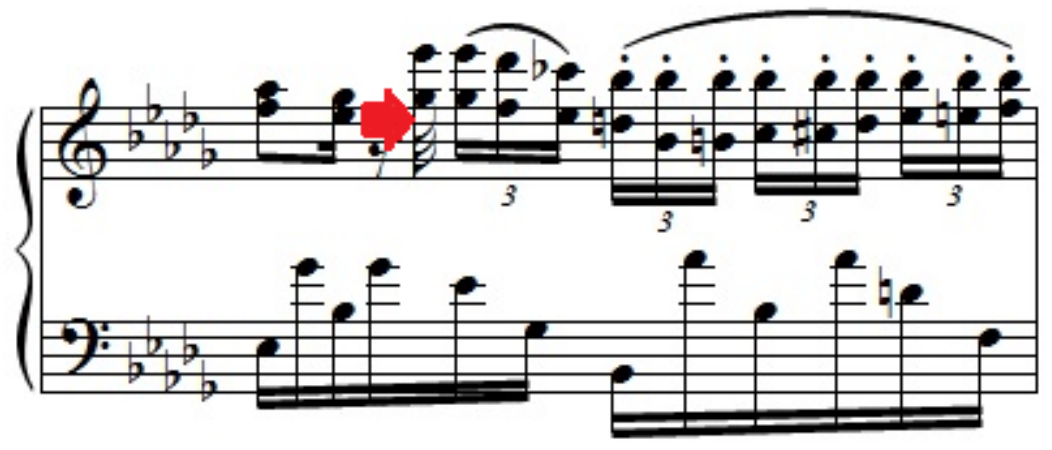

Example 5.8: Nocturne Op. 27 No. 1, D-flat major, m.15, melodic line embedded within texture 
Lastly, Prelude No. 13 in F\# major is a clear example of the formal structure seen in several of the nocturnes. Generally, the form presented is $\mathrm{ABA}^{1}$. The prelude distinctly represents this pattern: Section A - mm. 1-20, Section B - mm. 21-28, Section A ${ }^{1}-m m$. 29-38. While this form is not always so clearly defined in the nocturnes, it is the common starting point for variation of their formal structure. Good examples can be seen in Nocturne in G minor, Op. 37 No. 1 and Nocturne in C minor, Op. 48 No. 1.

The bel canto right hand is required of all the Nocturnes. ${ }^{105}$ There are several examples throughout the Preludes of bel canto melodies at varying levels of difficulty. Prelude No. 21 in B-flat major is a good example of a prelude of intermediate difficulty which presents a singing right hand melody. Other examples include Preludes No. 15 in D-flat major, No. 17 in A-flat major, and No. 24 in D minor. Each of these preludes requires bel canto right hand playing in different contexts; over different accompanimental patterns, various textures, and presenting diverse moods and characters. Any of these would be appropriate to introduce a singing style of playing which is then easily translated into the context of a nocturne.

Another genre of Chopin's pieces often used in the studio is the mazurka. As treated by Chopin, the mazurka is a stylized dance composed for musical enjoyment, not dancing. In them, Chopin "draws on his memories of the folk songs and dances he knew and loved in his boyhood. ${ }^{106}$ Fifty-seven in number, the mazurkas were composed from 1830-1849. ${ }^{107}$

Overall, the mazurkas require rhythmic vitality to convey the spirit of the dances and to avoid sounding contrived. While not directly related to the mazurkas, it may be beneficial to introduce students to some of the Preludes which require rhythmic drive, whether fast or slow, to bring life to the piece. Almost any of the Preludes could be used for this purpose. However,

\footnotetext{
${ }^{105}$ For a discussion of bel canto playing, please see Chapter 2, pages 19-20. s

${ }^{106}$ Bailie, 119.

${ }^{107}$ Samson, 235-238.
} 
some of the more appropriate ones include: Preludes No. 1 in C major, No. 3 in G major, No. 5 in D major, No. 6 in B minor, No. 9 in E major, No. 10 in C\# minor, No. 22 in G minor, No. 24 in $\mathrm{D}$ minor.

Prelude No. 7 in A major provides a rudimentary introduction into some of the characteristics of Chopin's mazurkas. Like the Preludes, the mazurkas present a wide range of technical difficulty, the easiest of which are slightly more challenging than Prelude No. 7 in A major. ${ }^{108}$ Three mazurkas are given Grade 4-5 by Bailie: Op. 7 No. 5 in C major, Op. Posth. 68 No. 3 in F major, and Op. Posth. 68 No. 4 in F minor. It would be appropriate to use this prelude to introduce these easier mazurkas then work up to more challenging mazurkas as the student's technique grows.

Prelude No. 7 in A major introduces a left hand pattern that is found among several of the mazurkas (see Examples 5.9, 5.10, and 5.11).

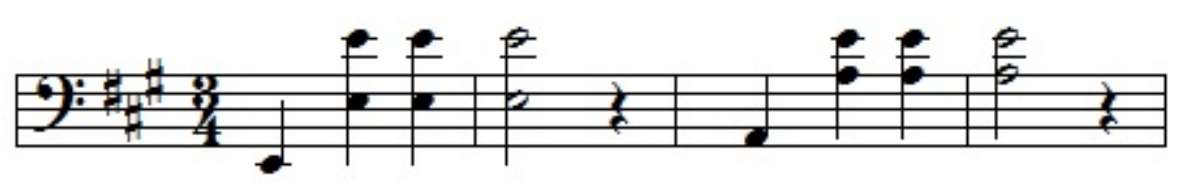

Example 5.9: Prelude No. 7, A major, mm. 1-4, left hand dance pattern

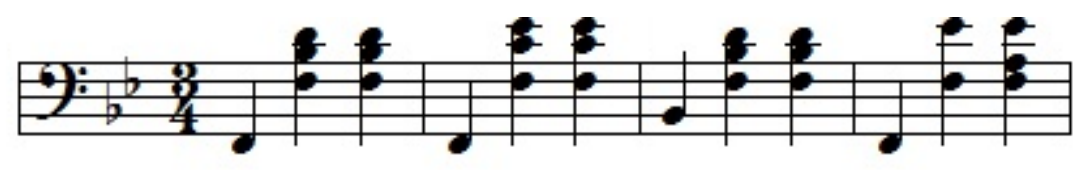

Example 5.10: Mazurka Op. 7 No. 1, B-flat major, mm. 4-7, left hand pattern

\footnotetext{
${ }^{108}$ Bailie 124-215. Bailie's grading of the Mazurkas ranges from 4-5 (3 mazurkas) to 8+. None are graded VA. The three which are graded 4-5 are slightly more challenging than Prelude No. 7 in A major. Those graded 6 through 8+ would be comparable to the Intermediate and Advanced Preludes. Bailie 124-215.
} 


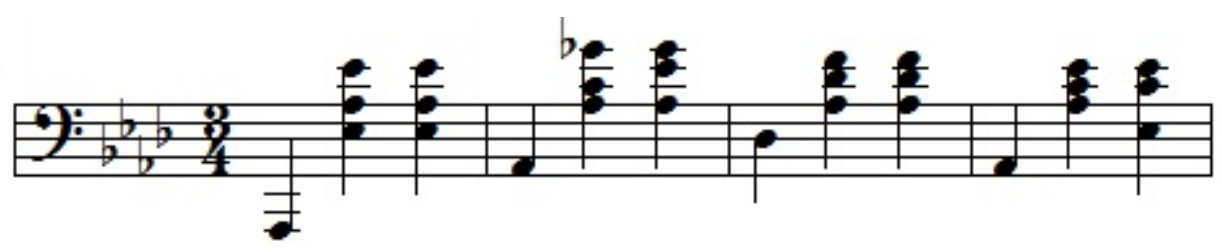

Example 5.11: Mazurka Op. 59 No. 2, A-flat major, mm. 1-4, left hand pattern

This is also a pattern which is found among Chopin's waltzes.

Prelude No. 7 in A major also introduces the dotted rhythm that is characteristic of many of the mazurkas (see Example 5.12).

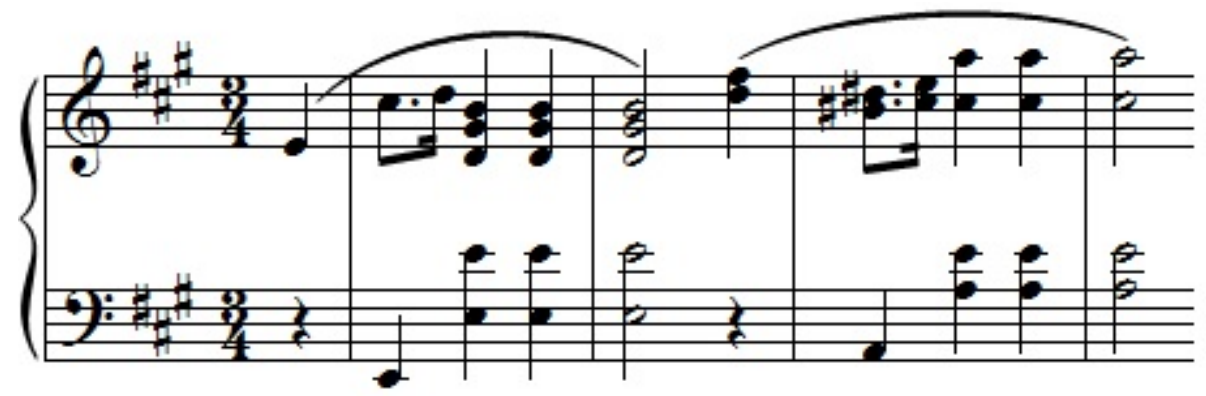

Example 5.12: Prelude No. 7, A major, mm. 1-4, dotted rhythm characteristic of mazurkas

This dotted rhythm is juxtaposed with the eighth note triplet, also characteristic of the mazurka, in Op. 7 No. 5 (see Example 5.13).

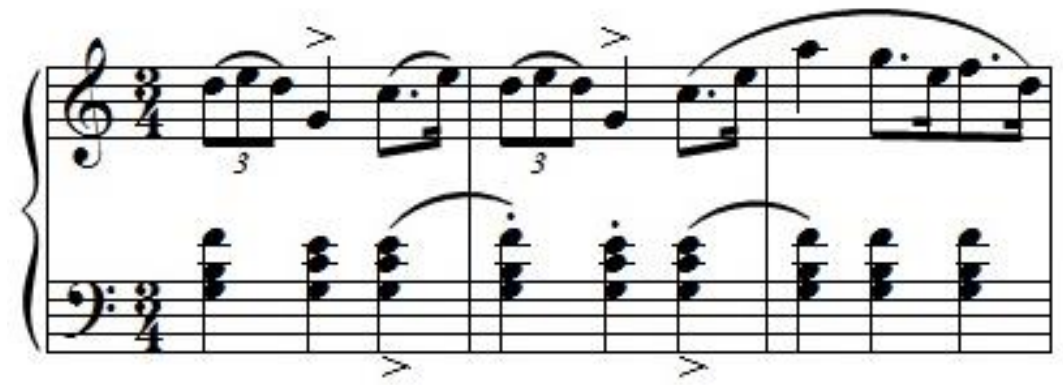

Example 5.13: Mazurka Op. 7 No. 5, C major, mm. 5-8 
We also see the dotted rhythm in some of the more difficult mazurkas, but notated slightly differently (see Example 5.14).

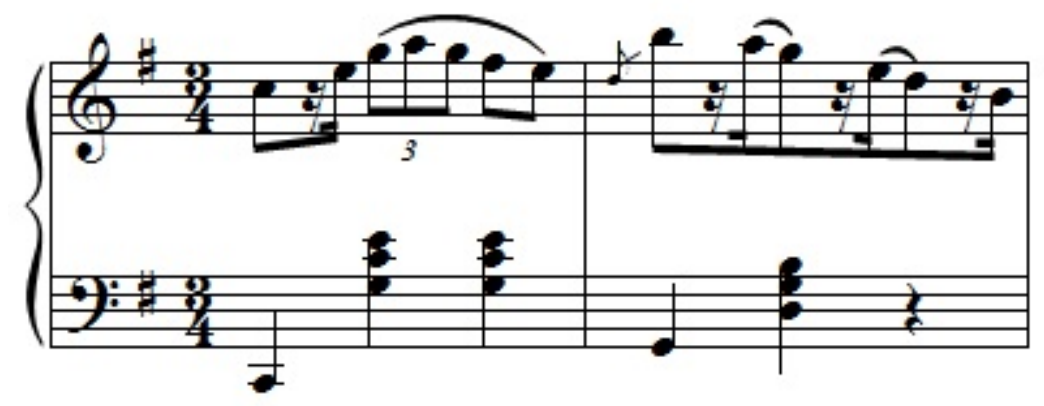

Example 5.14: Mazurka Op. 67 No. 1, G major, mm. 15-16

Shown above, the dotted rhythm was often presented with a rest in place of the dot, indicating that the hand should let go and re-attack on the sixteenth note. This execution is "essential to the 'spring' of a quick movement." ${ }^{109}$ Example 5.14 also shows the triplet figure, along with the left hand pattern introduced in Prelude No. 7 in A major. It is easy to see the progression from the prelude, through the easier mazurkas, and on to the more technically challenging mazurkas.

Perhaps most pertinent to the discussion of technique are the Etudes Opp. 10 and 25. Each opus contains twelve etudes, each of which is a musical work of art. However, they are also technical studies, and are a "practical demonstration of Chopin's inborn understanding of the human physique in relation to the keyboard, in particular of the natural individual characteristics of each finger." 110 The etudes are all very technically demanding. ${ }^{111}$

While the nocturnes and mazurkas, though many in number, present similar style and technical characteristics throughout the genre, the etudes are as varied as the preludes of Op. 28.

\footnotetext{
109 Bailie, 122.

110 Bailie, 385 .

${ }^{111}$ Bailie, 388-453. Bailie grades all of the etudes Grade 8 and above, with most being VA (Very Advanced). These are comparable to the Very Advanced Preludes.
}

Comparison of the Preludes Op. 28 with other Chopin Works - 65 
Consequently, the comparison between the preludes and etudes must be on a more individual basis than with the genre as a whole. ${ }^{112}$ Some of the preludes work well to introduce techniques found in certain etudes, while others are sufficiently demanding to warrant substituting them in place of etudes requiring similar technical skills. The following discussion will highlight two introductory preludes and two alternate preludes.

Prelude No. 3 in G major can be used to introduce the techniques required for Etude Op. 10 No. 12 (see Examples 5.15 and 5.16).
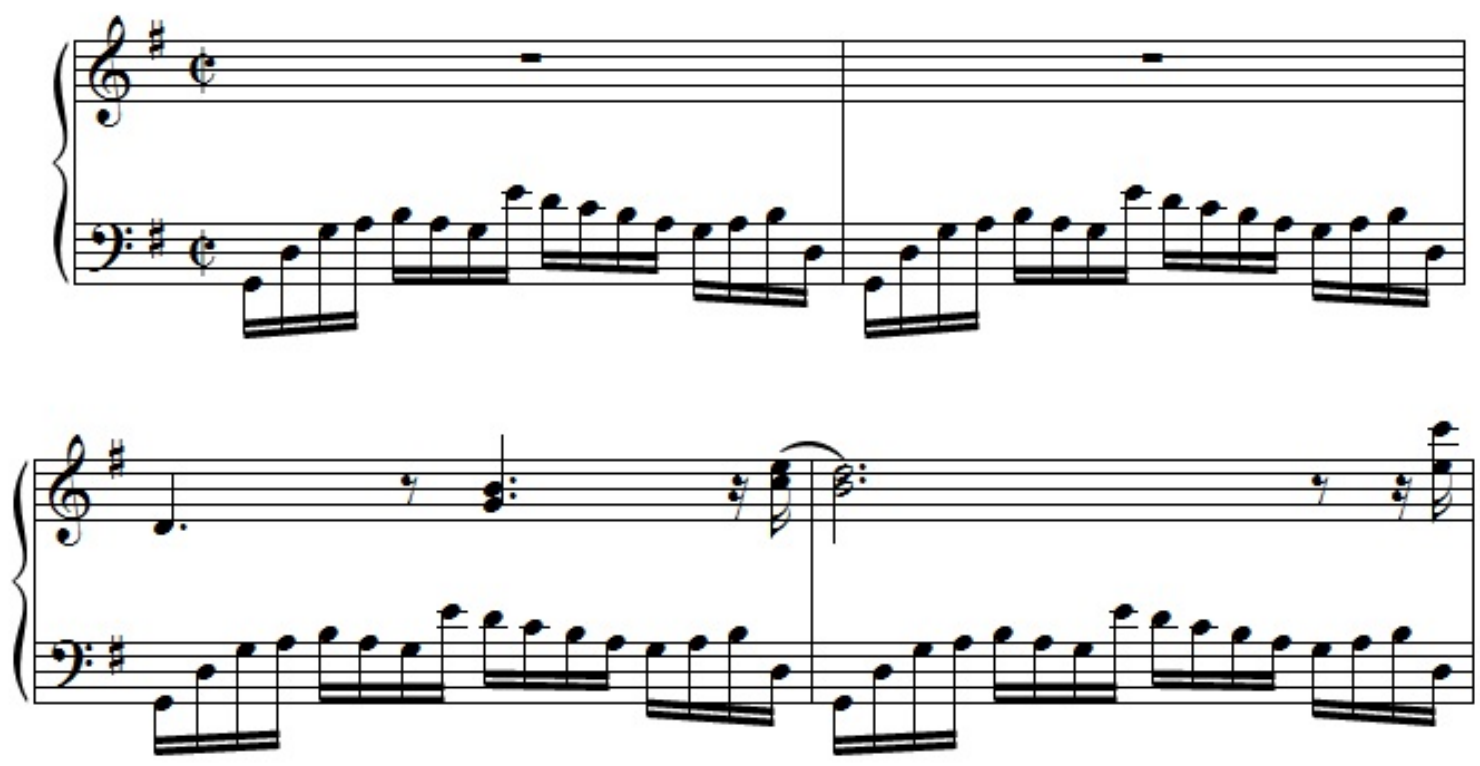

Example 5.15: Prelude No. 3, G major, mm. 1-4

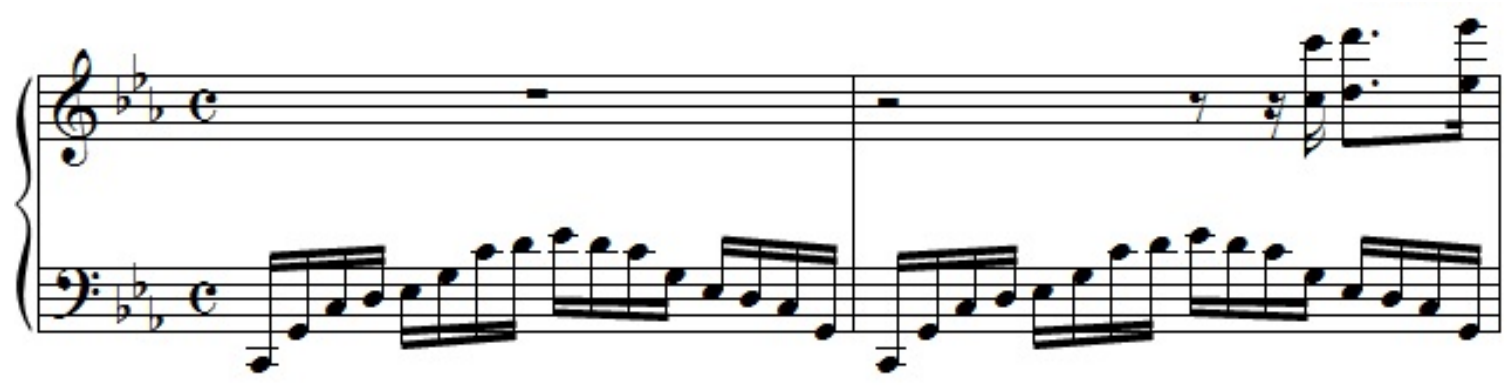

Example 5.16: Etude Op. 10 No. 12, C minor, mm. 9-10

\footnotetext{
${ }^{112}$ Refer to the Appendix, page 76, Table 4 for a list preludes which may be used to introduce or substitute for the etudes.
} 
Often nicknamed the "Revolutionary Etude", Op. 10 No. 12 is a study for the left hand. While the pattern is more difficult and less repetitive than that of the $\mathrm{G}$ major prelude, it requires the same technique discussed in Chapter Three. This etude also contains elements of rhythmic coordination with the right hand (see Example 5.16) and hand coordination (see Example 5.17), both of which are presented in the third prelude. ${ }^{113}$

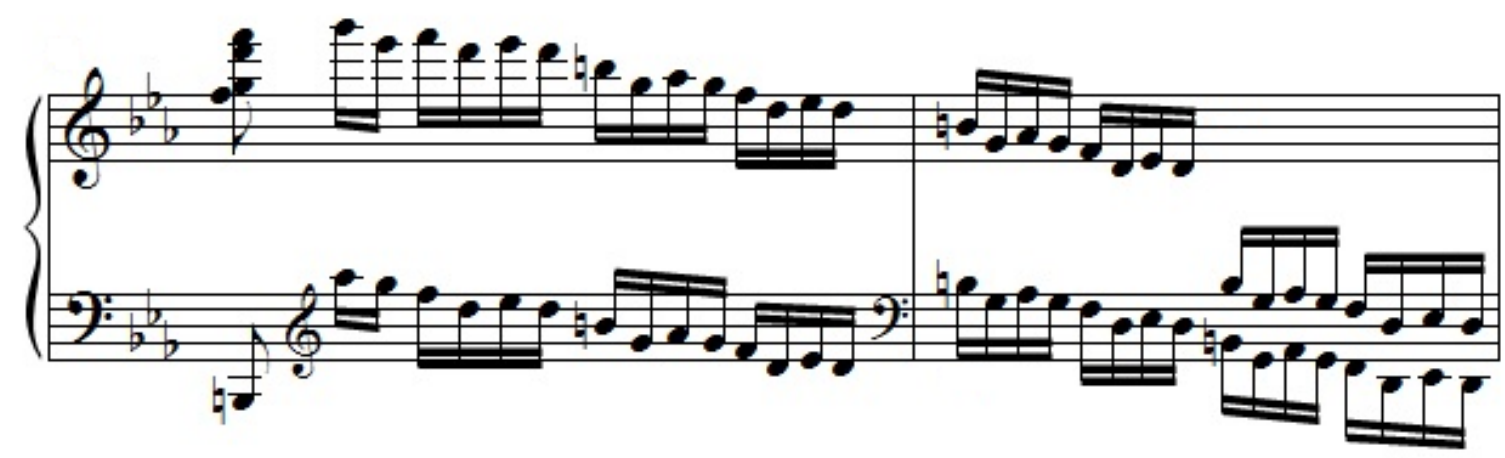

Example 5.17: Etude Op. 10 No. 12, C minor, mm. 5-6

Study of Prelude No. 3 in G major will lay the technical foundation for subsequent study of Etude Op. 10 No. 12.

Etude Op. 25 No. 12 is a study in hand coordination, reminiscent of the texture and technique found in Prelude No. 14 in E-flat minor (see Examples 5.18 and 5.19).

${ }^{113}$ See Chapter Three, pages 22-28, for the full discussion of the technique of Prelude No. 3 in G major. Comparison of the Preludes Op. 28 with other Chopin Works - 67 


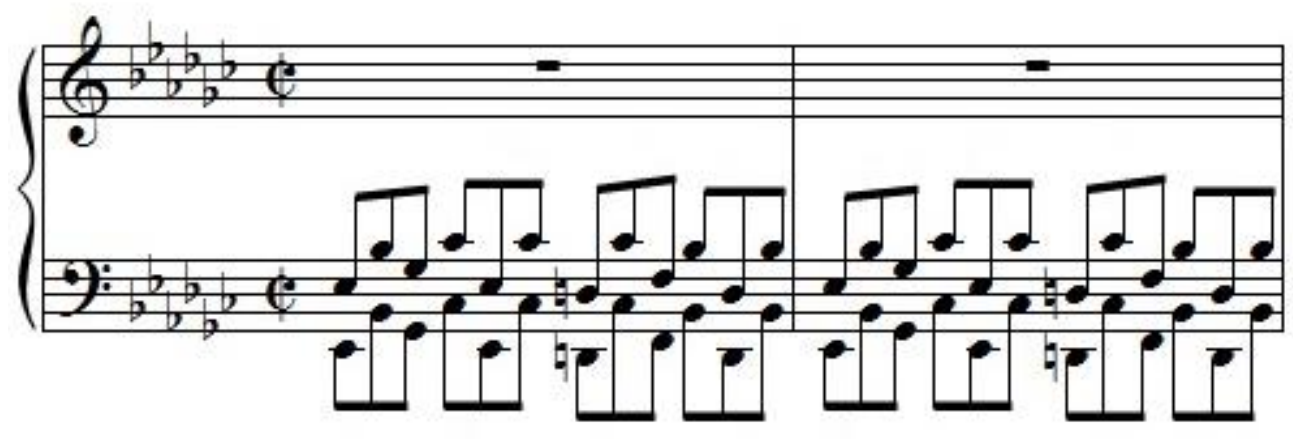

Example 5.18: Prelude No. 14, E-flat minor, mm. 1-2

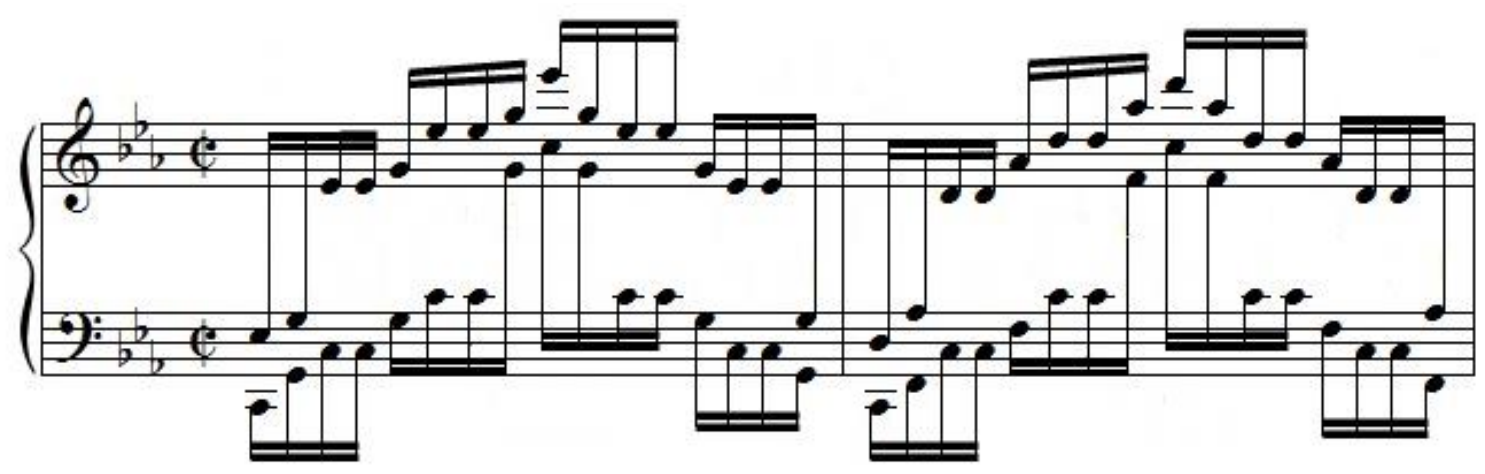

Example 5.19: Etude Op. 25 No. 12, C minor, mm. 1-2

In this case, the etude is much more difficult than the prelude. While Prelude No. 14 in E-flat minor presented material at the octave, the intervals presented in the perpetual sixteenths of Op. 25 No. 12 are constantly changing. To add to the challenges, some notes are double-stemmed to indicate melodic emphasis on weak portions of the beat.

Since there is such a large gap in difficulty between the two pieces, it is not suggested that Prelude No. 14 immediately introduce this etude. However, studying the prelude will lay the groundwork for the technique required by the etude at a later time. The practice suggestions in Chapter Two for the technical challenges presented by Prelude No. 14 in E-flat minor can be applied when studying Op. 25 No. 12 with equal success. ${ }^{114}$

\footnotetext{
${ }^{114}$ See Chapter Two, pages 12-17, for the full discussion of the technique of Prelude No. 14 in E-flat minor.
} 
The technical skills required in Prelude No. 12 in G\# minor are comparable to those needed for Etude Op. 10 No. 2 (see Examples 5.20 and 5.21).

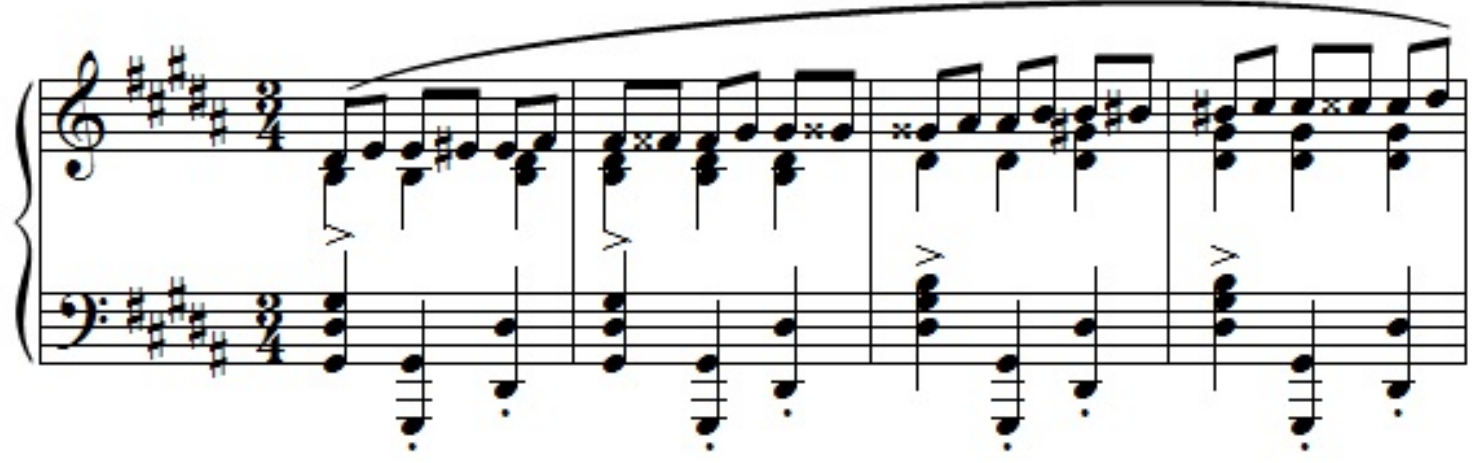

Example 5.20: Prelude No. 12, G\# minor, mm. 1-4

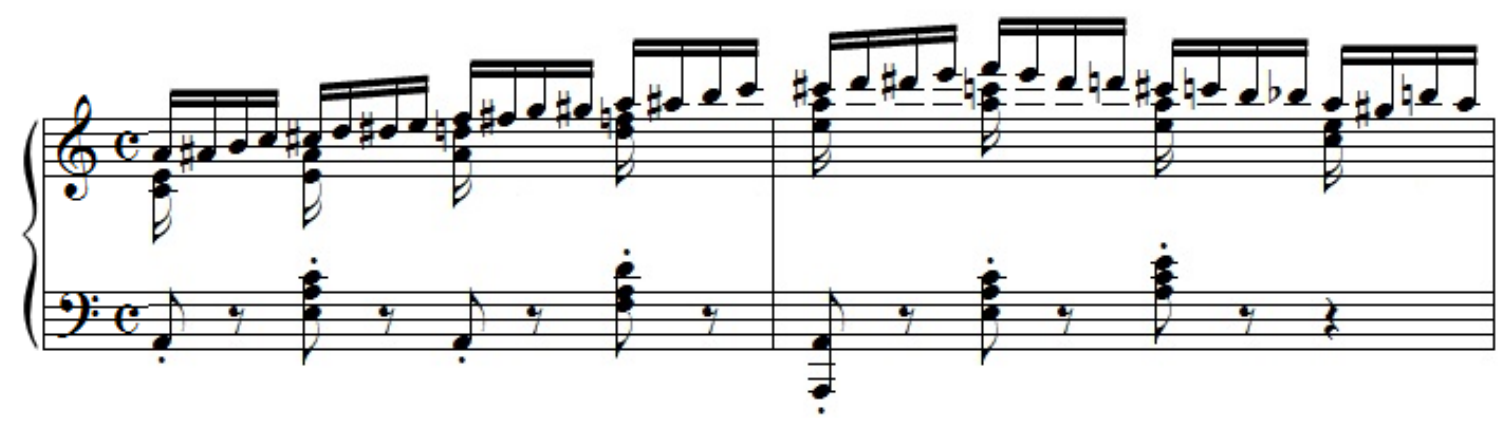

Example 5.21: Etude Op. 10 No. 2, A minor, mm. 1-2

Unlike the prelude, the right hand of Etude Op. 10 No. 2 does not contain repeated notes, and is made up of sixteenth notes as opposed to eighth notes. However, the physical approach is the same. To successfully navigate the figuration the weight of the hand must be balanced on the thumb and second finger, allowing the third, fourth and fifth fingers the freedom to lightly execute the rapid sixteenths. ${ }^{115}$ This etude is a prime example of Chopin's innovative approach to fingering, allowing the third, fourth and fifth fingers to cross freely over one another in

${ }^{115}$ See Chapter Four, pages 40-44, for the full discussion of the technique of Prelude No. 12 in G\# minor. 
chromatic passages. ${ }^{116}$ Also, like the prelude, it is important to be economical with up/down wrist motions, moving as laterally across the keyboard as much as possible to avoid fatigue.

The left hand of Etude Op. 10 No. 2 also poses similar challenges to those found in Prelude No. 12 in G\# minor. While the etude does not present a succession of octaves, it does require leaps of the hand. Properly grouping the left hand beats in patterns that require single gestures, as detailed in the Chapter Four discussion of Prelude No. 12 in G\# minor, will facilitate ease in the execution of these leaps. Being of equal difficulty and containing similar technical challenges, Prelude No. 12 and Etude Op. 10 No. 2 can be used almost interchangeably as technical studies.

Finally, Etude Op. 10 No. 9 is strikingly similar in texture and technique to Prelude No. 24 in D minor (see Examples 5.22 and 5.23).

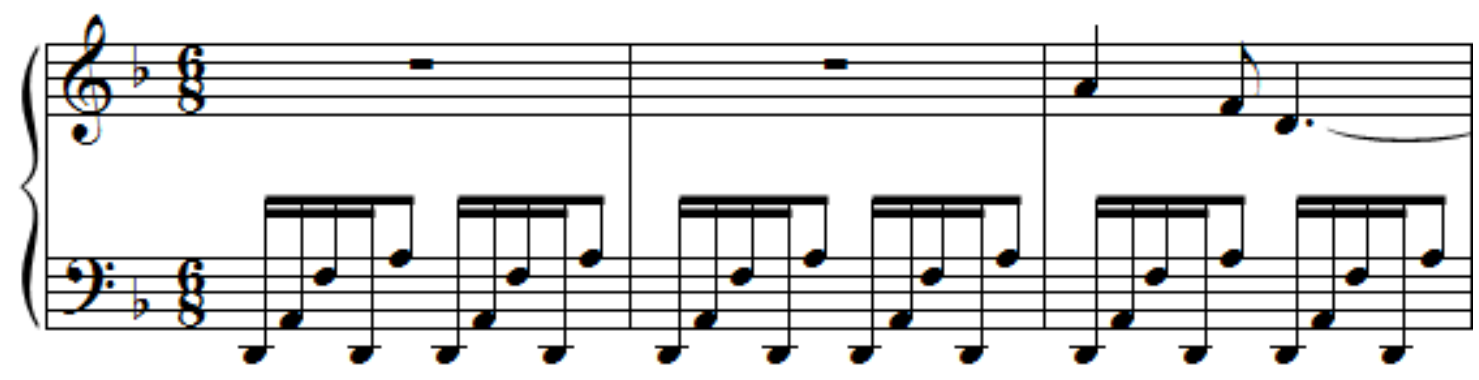

Example 5.22: Prelude No. 24, D minor, mm. 1-3

\footnotetext{
${ }^{116}$ Jean-Jacques Eigeldinger, Chopin, Pianist and Teacher: As seen by His Pupils, ed. Roy Howat, trans. Naomi Shohet, Krysia Osostowicz and Roy Howat (New York: Cambridge University Press, 1986), 19. This fingering innovation was also discussed in Chapter Four, page 50.
} 


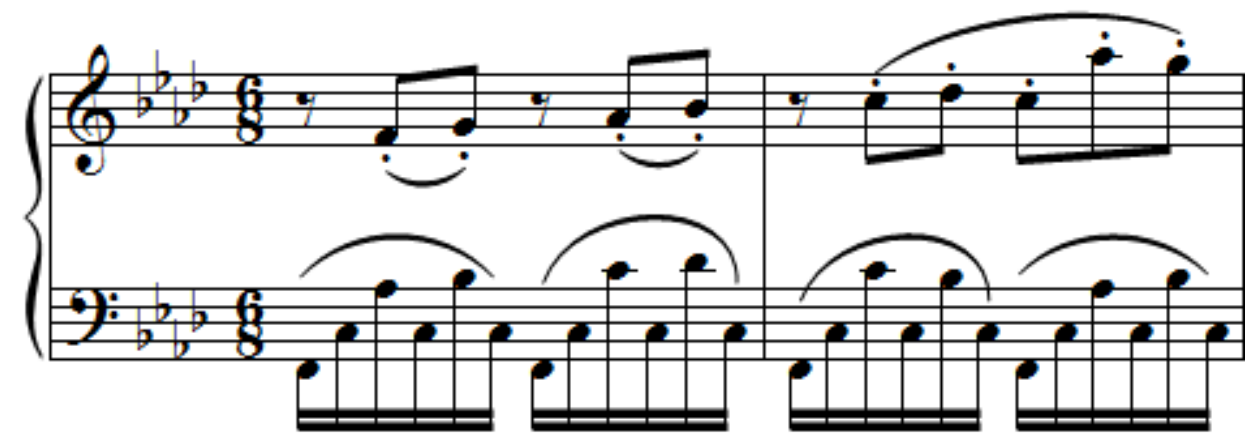

Example 5.23: Etude Op. 10 No. 9, F minor, mm. 1-2

The left hand patterns are very alike with only minor differences. While the pattern shown in the prelude is fairly repetitive, that in the etude is constantly changing. Also, where the prelude presents a five note gesture the etude presents a six note gesture. However, the physical approach to play the gesture in each is the same. Using the middle of the hand (most likely the index finger, depending on the size of hand) as a pivot, the hand moves laterally across the keys to cover the wide range. ${ }^{117}$

Whereas the left hand is slightly more intricate in Etude Op. 10 No. 9 than in Prelude No. 24 in D minor, the right hand is decidedly less taxing. Absent the rapid scales, arpeggios, and chromatic thirds of the prelude, the right hand of Op. 10 No. 9 presents a fairly simple melodic line in single notes or octaves with a portato articulation. When all elements are considered, Prelude No. 24 in D minor is perhaps more technically difficult than Etude Op. 10 No. 9, a fact which supports the idea of using the prelude as a substitute for the etude. ${ }^{118}$ In this particular instance, it may even be appropriate to use the etude to introduce the prelude.

Overall, the Etudes are highly demanding and require a high level of endurance in performance. In order to achieve such endurance, a careful physical approach to the keyboard is

\footnotetext{
${ }^{117}$ See Chapter Four, pages 47-50, for the full discussion of the technique of Prelude No. 24 in D minor.

${ }^{118}$ Bailie, 113, 405. Bailie grades Prelude No. 24 in D minor as VA (Very Advanced) while Etude Op. 10 No. 9 is Grade 8+.
} 
required. Constant attention must be paid to the release of accumulated tension in the hand, wrist, arm, and shoulder. Practice techniques to facilitate ease of execution and therefore endurance can be found in the discussion of the very advanced Preludes in Chapter Four. Cultivating the proper physical approach to the piano in less demanding repertoire of the Preludes, as discussed in Chapters Two, Three and Four, will pave the way to tension-free execution of even the most demanding etude.

The wide variety of styles and techniques found in the preludes of Op. 28 make it an ideal set from which to study almost every aspect of Chopin's compositional style. As such, many of the preludes can be used to introduce concepts of Chopin's style to students and build their technique to tackle some of the more difficult repertoire. Some of the preludes are of such advanced difficulty as to be appropriate substitutes for certain of the etudes. 


\section{Chapter Six}

\section{Conclusion}

While Chopin's Preludes Op. 28 occupy a unique place in piano literature as the first of their kind to be considered character pieces, the Preludes also hold a unique place in Chopin's oeuvre. Opus 28 is the only set in Chopin's output which so completely represents the variety of technique found among his works and the numerous characteristics of his compositional style. Encompassing a wide range of technical difficulty, the Preludes are perfect to use to teach and reinforce technical skills.

Piano teachers have many responsibilities to our students' musical education; one of those responsibilities is to cultivate their technique at the piano. However, it is often the case that this aspect of learning piano is one of the least appealing to our students. The study of technique need not be confined to the realm of scales, etudes, and other technical exercises. Many students are easily bored by such drills which quickly become a mindless necessity in their daily routine, if not an entirely neglected part. Relegating the study of technique to such exercises also separates distances skill from music-making in students' minds; the two become separate entities.

With the goal of both engaging students and creating a correlation between technique and repertoire, it is necessary to teach and reinforce technical skills through the study of appropriate repertoire. While there are many examples of technique-building repertoire, the preludes of Chopin's Op. 28 work particularly well as technical exercises. Short pieces which require one or two technical skills are most suited for the task. Drawing the parallel between the practice of technical exercises and the practice of repertoire equips students to define and navigate technical 
challenges in other repertoire. It also makes the practice of technique more enjoyable and therefore more likely to be accomplished.

While a variety of techniques are required to perform any given piece, in the Preludes often one or two technical skills are most prominently on display, making for a suitable technical study. Using the tables found in the Appendix of this document it is possible to find a prelude that is appropriate for both the study of a specific technical skill and suitable difficulty level. Several of the Preludes can be appropriately utilized as introductory pieces to or substitute pieces for other commonly used teaching pieces composed by Chopin.

The study of any of Chopin's Preludes Op. 28 will enhance the technical skill of the student. These short pieces are sure to engage students while emphasizing the correlation between technique and musicality. Many passages which seem difficult can be executed with surprising ease when attempted in the manner that Chopin would have played them. As only a select few of the Preludes routinely show up in method books and collections, our working knowledge of the set is generally limited to those few. However, the entire set is a wealth of musical material at a variety of different levels that is particularly well suited to teaching. It can be a preferred source for technique building repertoire that is musically engaging and satisfying. There is a prelude for almost any student. These wonderful miniature pieces of music will capture student's interest, demanding musicality while also fostering technical achievement. 


\section{Bibliography}

\section{Works Cited:}

Bailie, Eleanor. Chopin: A Graded Practical Guide. London: Kahn \& Averill, 1998.

Brown, Maurice J. E. "The Chronology of Chopin's Preludes." The Musical Times 98, no. 1374 (August 1957): 423-4.

Chopin, Frederic. "Sketch for a Method" (Project de Méthode)." In Chopin, Pianist and Teacher: As Seen by his Pupils, by Jean-Jacques Eigeldinger. New York: Cambridge University Press, 1986.

Eigeldinger, Jean-Jacques. Chopin, Pianist and Teacher: As seen by His Pupils. Edited by Roy Howat. Translated by Naomi Shohet, Krysia Osostowicz and Roy Howat. New York: Cambridge University Press, 1986.

—_. "Twenty-Four Preludes Op. 28: Genre, Structure and Significance.” In Chopin Studies, edited by Jim Samson, 167-193. New York: Cambridge University Press, 1988.

Higgins, Thomas. Historical Background to Preludes, Op. 28: An Authoritative Score, Historical Background, Analysis, Views and Comments, by Frederic Chopin. New York: W.W. Norton, 1973.

Higgins, Thomas, ed. Views and Comments to Preludes, Op. 28: An Authoritative score, Historical Background, Analysis, Views and Comments, by Frederic Chopin. New York: WW. Norton, 1973.

Kallberg, Jeffrey. "'Small 'Forms': In Defense of the Prelude." In The Cambridge Companion to Chopin, edited by Jim Samson, 124-144. New York: Cambridge University Press, 1992.

Kresky, Jeffrey. A Reader's Guide to the Chopin Preludes. Westport, CN: Greenwood Press, 1994.

Samson, Jim. The Music of Chopin. New York: Oxford University Press, 1994

True, Nelita. "An Introduction to Chopin: Teaching the Easier Preludes." IRMT Journal, no. 41 (June 1995): 10-12.

Walker, Alan, ed. The Chopin Companion: Profiles of the Man and the Musician. New York: W. W. Norton \& Company, Inc., 1966. 


\section{Additional Resources:}

This section contains additional sources which address Chopin's Preludes. While this section is by no means exhaustive and contains only sources written in English, it is a good sampling of the available literature on the Preludes.

Agawu, V. Kofi. "Concepts of Closure and Chopin's Opus 28." Music Theory Spectrum 9 (Spring 1987): 1-17.

Boelcke, Andreas, "Chopin's 24 Preludes, Opus 28: A Cycle Unified by Motion Between the Fifth and Sixth Scale Degrees.” DMA diss., University of Cincinnati, 2008.

Burkhart, Charles. “The Two Curious Moments in Chopin's E-flat Major Prelude.” In Structure and meaning in tonal music: Festschrift in honor of Carl Schachter, edited by L. Poundie Burstein and David Gagné, 5-18. Hillsdale, NY:

Pendragon Press, 2006.

Cinnamon, Howard. "New Observations on Voice Leading, Hemiola, and their Roles in Tonal and Rhythmic Structures in Chopin's Prelude in B Minor, Op. 28, no. 6." Intégral: The Journal of Applied Musical Thought 6 (1992): 66-106.

Hansen, Martin. "The Pedal Indications in Chopin's Preludes: A Performer's Look at the Autograph." In Chopin in Performance: History, Theory, Practice, edited by Artur Szklener, Kinga Tarka, Wojciech Bońkowski, and John Comber, translated by John Comber, 121-139. Warsaw: Narodowy Instytut Fryderyka Chopina (2004).

Hood, Alison. "Tonal and Rhythmic Hidden Repetition in Chopin's Prelude, Op. 28 no. 14." In Chopin in Paris: The 1830s, edited by Artur Szklener, Magdalena Chylińska and John Comber, translated by John Comber, 203-213. Poland: Narodowy Instytut Fryderyka Chopina Warszawa, 2006.

Hoyt, Reed J.. "Chopin's Prelude in A Minor Revisited: The Issue of Tonality." In Theory Only 8, no. 6 (April 1985): 7-16.

Kang, Yunjoo. "The Chopin Preludes Opus 28: An Eclectic Analysis with Performance Guide." DA diss., New York University, 1994.

Kielian-Gilbert, Marianne. "Motive Transfer in Chopin's A-minor Prelude.” In Theory Only 9, no. 1 (March 1986): 21-32.

Kirk, Kenneth Patrick. "The Golden Ratio in Chopin's Preludes, Opus 28." Doctoral Diss., University of Cincinnati, 1987.

Kramer, Lawrence. "Romantic Meaning in Chopin's Prelude in A Minor." 19th-Century Music 9, no. 2 (Fall 1985): 145-55. 
Kurucz, Tímea. "The Conception of the Musical Form of Fryderyk Chopin's Preludes Op. 28." Translated by Zsuzsa Borbély Bartalis. Studia Universitatis Babeş-Bolyai: Musica 55, no. 1 (2010): 59-106.

Lee, Yangkyung. "Non-Harmonic Tones as Aesthetic Elements in Chopin's Preludes, Op. 28." DMA diss., University of Cincinnati, 2002.

Leikin, Anatole. "Chopin's Preludes Op. 28 and Lamartine's Les Préludes." In Sonic Transformations of Literary Texts: From Program Music to Musical Ekphrasis, edited by Singlind Bruhn, 13-43. Hillsdale, NY: Pendragon Press, 2008.

—. "Chopin's A-Minor Prelude and its Symbolic Language." International Journal of Musicology 6 (1997): 149-62.

Lopinski, Janet Marie. "The Preludes Opus 28 by Fryderyk Chopin with an Emphasis on Polish Sources.” DMA diss., University of Cincinnati, 1990.

Oren, Benjamin. "Connections between Bach and Chopin." Music in Time (Spring 2003): 7-46.

Park, Hana. "A Performer's Analysis of Twenty-Four Preludes, Op. 28, Prelude in C-Sharp Minor, Op. 45, and Prelude in A-Flat Major, WoO, by Frédéric François Chopin." DMA diss., Southwestern Baptist Theological Seminary, 2003.

Rink, John and Jim Samson, eds. Chopin Studies 2. New York: Cambridge University Press, 1994.

Rink, John S.. "The Line of Argument in Chopin's E-Minor Prelude." Early Music 29, no. 3 (August 2001): 434-44.

Rothstein, William. "Like Falling Off a Log: Rubato in Chopin's Prelude in A-Flat Major (Op. 28, no. 17)." Music Theory Online 11, no. 1 (March 2005).

Schwarz, David. "Stucturalism, Post-Structuralism, and a Classical Musical Text: A New Look at Chopin's 'Preludes', Opus 28." DMA diss. University of Texas, Austin, 1987.

Schachter, Carl. "Chopin's Prelude in D Major, Op. 28, No. 5: Analysis and Performance” Journal of Music Theory Pedagogy 8 (1994): 27-45.

Wright, Theresa. "Formal Principles in Chopin's Preludes Op. 28." MM thesis, University of London, Goldsmiths College, 1989. 


\section{Appendix A}

Table 1: Technical Difficulty Levels of Chopin's 24 Preludes Op. 28

\begin{tabular}{|c|l|}
\hline Difficulty & \\
\hline Easy** & $\# 4-$ E minor \\
& $\# 6-$ B minor \\
& $\# 7-$ A major* \\
& $\# 20-$ C minor* \\
\hline Intermediate** & $\# 2-$ A minor* \\
& $\# 9-$ E major* \\
& $\# 13-$ F\# major \\
& $\# 14-$ Eb minor \\
& $\# 15-$ Db major \\
& $\# 21-$ Bb major \\
\hline \multirow{3}{*}{ Advanced** } & $\# 1-$ C major \\
& $\# 3-$ G major \\
& $\# 10-$ C\# minor \\
& $\# 11-$ B major \\
& $\# 17-$ Ab major \\
& $\# 22-$ G minor \\
& $\# 23-$ F major \\
\hline \multirow{3}{*}{ Very Advanced** } & $\# 5-$ D major \\
& $\# 8-$ F\# minor \\
& $\# 12-$ G\# minor \\
& $\# 16-$ Bb minor \\
& $\# 18-$ F minor \\
& $\# 19-$ Eb major \\
& $\# 24-$ D minor \\
\hline
\end{tabular}

* Represents a piece most suitable for students with fully grown hands, or those with larger hands, as the prelude contains stretches not easily executed by smaller hands.

** These categories are representative of the Preludes in relation to each other, not as compared with other repertoire. It is advisable that none of the Preludes be attempted until a later intermediate level (Grade 4-5) has been achieved.

*** This is a grading of technical difficulty only, not musical difficulty. Each prelude presents significant musical challenges, and they are all appropriate for the most advanced students. 
Appendix B

Table 2: Primary Technical Challenges of Chopin's 24 Preludes Op. 28

\begin{tabular}{|l|l|}
\hline \multicolumn{1}{|c|}{ Prelude } & \multicolumn{1}{c|}{ Primary Technical Challenges } \\
\hline $1-$ C major & Voicing, Rhythm \\
\hline $2-$ A minor & Left hand stretches/fingering \\
\hline $3-$ G major & Rapid left hand, hand coordination \\
\hline $4-$ E minor & Tone and tempo control \\
\hline $5-$ D major & Voicing, leaps, double notes \\
\hline 6- B minor & Melodic left hand \\
\hline $7-$ A major & Rhythm, Voicing \\
\hline $8-$ F\# minor & Cross-rhythms, right hand figuration \\
\hline $9-$ E major & Voicing, left hand trills \\
\hline $10-$ C\# minor & Right hand figuration, double notes \\
\hline $11-$ B major & Rhythm, voicing, inner grace notes \\
\hline $12-$ G\# minor & Double notes, left hand leaps \\
\hline $13-$ F\# major & Voicing, left hand passagework \\
\hline $14-$ E-flat minor & Hand coordination \\
\hline $15-$ D-flat major & Left hand stretches, A-flat pedal note, tone control \\
\hline $16-$ B-flat minor & Fast and chromatic right hand, left hand leaps \\
\hline $17-$ A-flat major & Overlapping hands, voicing \\
\hline $18-$ F minor & Hand coordination, leaps \\
\hline $19-$ E-flat major & Leaps, presto tempo \\
\hline $20-$ C minor & Voicing \\
\hline $21-$ B-flat major & Double notes, fingering \\
\hline $22-$ G minor & Left hand melody in octaves, hand independence \\
\hline $23-$ F major & Left hand melody, left hand trills, right hand figuration \\
\hline $24-$ D minor & $\begin{array}{l}\text { Left hand figuration/stretches, rapid scales/arpeggios, double } \\
\text { thirds }\end{array}$ \\
\hline
\end{tabular}


Appendix C

Table 3: Preludes Requiring Specific Skills at Various Technique Levels

\begin{tabular}{|c|c|c|c|c|c|c|}
\hline & $\begin{array}{l}\text { Moderately } \\
\text { Easy }\end{array}$ & Moderate & $\begin{array}{c}\text { Moderately } \\
\text { Advanced }\end{array}$ & Advanced \\
\hline \multicolumn{3}{|c|}{ Skill } & \multicolumn{4}{|c|}{ Preludes Requiring Specific Skill } \\
\hline \multirow{3}{*}{\multicolumn{2}{|c|}{$\begin{array}{l}\text { Wrist Motion/ } \\
\text { Transfer of Arm } \\
\text { Weight }\end{array}$}} & Right & 6 & 9 & $10,22,23$ & 12,16 \\
\hline & & Left & & $2,13,14$ & 1,3 & 24 \\
\hline & & Both & $4,7,20$ & 15,21 & 11,17 & $5,8,18,19$ \\
\hline \multicolumn{3}{|c|}{ Voicing } & 20 & $2,9,13,15$ & $1,11,17$ & $5,8,12,19$ \\
\hline \multicolumn{3}{|c|}{ Passagework } & & 13,14 & $3,10,23$ & $\begin{array}{l}5,8,16,18, \\
19,24\end{array}$ \\
\hline \multicolumn{3}{|c|}{ Hand Coordination } & & 14 & 3 & $5,18,19$ \\
\hline \multicolumn{3}{|c|}{ Rhythm } & 4,7 & 9, & $1,10,11$ & $8,18,24$ \\
\hline \multicolumn{3}{|l|}{ Octaves } & & & 22 & $12,16,24$ \\
\hline \multirow[t]{3}{*}{ Stretches } & \multicolumn{2}{|c|}{ Right } & & 13 & $3,11,23$ & \\
\hline & \multicolumn{2}{|c|}{ Left } & & $2,15,21$ & 10,17 & 8,24 \\
\hline & \multicolumn{2}{|c|}{ Both } & & & & 5,19 \\
\hline \multirow[t]{3}{*}{ Leaps } & \multicolumn{2}{|c|}{ Right } & & 13 & & \\
\hline & \multicolumn{2}{|c|}{ Left } & & 21 & 17,22 & 12,16 \\
\hline & \multicolumn{2}{|c|}{ Both } & & & & 18,19 \\
\hline \multicolumn{3}{|l|}{ Fingering } & & $2,14,21$ & 10,23 & $\begin{array}{l}5,8,12,16, \\
18\end{array}$ \\
\hline \multicolumn{3}{|c|}{ Double Notes } & & 21 & 10,11 & $5,12,24$ \\
\hline \multicolumn{3}{|c|}{ Overlapping Hands } & & & 17 & \\
\hline \multicolumn{3}{|c|}{ Repeated Notes } & & & & 12 \\
\hline \multicolumn{3}{|c|}{ Inner Grace Notes } & & & 11 & 12 \\
\hline \multicolumn{3}{|c|}{ Pedaling } & & $2,13,14$ & $\begin{array}{l}1,3,10,11, \\
23\end{array}$ & $\begin{array}{l}5,8,16,18, \\
19,24\end{array}$ \\
\hline \multicolumn{3}{|c|}{ Melodic Left Hand } & 6 & 13 & 23 & \\
\hline \multicolumn{3}{|c|}{ Tone Control } & $4,6,7,20$ & $2,9,13,15$ & $\begin{array}{l}11,17,22, \\
23\end{array}$ & $18,19,24$ \\
\hline \multicolumn{3}{|c|}{ Left Hand Trills } & & 9 & 23 & \\
\hline
\end{tabular}




\section{Appendix D}

\section{Table 4: Preludes which can Introduce or Substitute for Etudes}

\begin{tabular}{|l|l|}
\hline \multicolumn{1}{|c|}{ Etude } & \multicolumn{1}{|c|}{ Prelude } \\
\hline Op. 10 No. 2 & No 12, G\# minor* \\
\hline Op. 10 No. 3 & No. 17, A-flat major \\
\hline Op. 10 No. 5 & No. 19, E-flat major* \\
\hline Op. 10 No. 6 & No. 13, F\# major \\
\hline Op. 10 No. 7 & No. 21, B-flat major \\
\hline Op. 10 No. 8 & No. 23, F major \\
\hline Op. 10 No. 9 & No. 24, D minor* \\
\hline Op. 10 No. 12 & No. 3, G major \\
\hline Op. 25 No. 1 & No. 8, F\# minor* \\
\hline Op. 25 No. 7 & No. 6, B minor \\
\hline Op. 25 No. 11 & No. 16, B-flat minor* \\
\hline Op. 25 No. 12 & No. 14, E-flat minor \\
\hline
\end{tabular}

*Indicates a prelude which can be a substitute for the specified etude. All others can be used as introductory or stepping-stone pieces to build technique for the corresponding etudes. 